\title{
Insertion of genes and operons into the Escherichia coli genome through targeted recombination
}

\author{
Dennis Coss \\ West Virginia University
}

Follow this and additional works at: https://researchrepository.wvu.edu/etd

\section{Recommended Citation}

Coss, Dennis, "Insertion of genes and operons into the Escherichia coli genome through targeted recombination" (2004). Graduate Theses, Dissertations, and Problem Reports. 4130.

https://researchrepository.wvu.edu/etd/4130

This Dissertation is protected by copyright and/or related rights. It has been brought to you by the The Research Repository @ WVU with permission from the rights-holder(s). You are free to use this Dissertation in any way that is permitted by the copyright and related rights legislation that applies to your use. For other uses you must obtain permission from the rights-holder(s) directly, unless additional rights are indicated by a Creative Commons license in the record and/ or on the work itself. This Dissertation has been accepted for inclusion in WVU Graduate Theses, Dissertations, and Problem Reports collection by an authorized administrator of The Research Repository @ WVU.

For more information, please contact researchrepository@mail.wvu.edu. 


\title{
Insertion of Genes and Operons into the Escherichia coli Genome through Targeted Recombination.
}

\author{
Dennis Coss \\ Dissertation submitted to the \\ College of Agriculture, Forestry and Consumer Sciences \\ at West Virginia University \\ for the degree of \\ Doctor of Philosophy \\ in \\ Genetics
Walter Kaczmarczyk, Ph.D., Chair Joginder Nath, Ph.D.
C. Larry Harris, Ph.D. Clifton Bishop, Ph.D. Jed Doelling, Ph.D.

Department of Genetics and Developmental Biology

Morgantown, West Virginia

2005 


\section{Abstract \\ Insertion of Genes and Operons into the Escherichia coli Genome through Targeted Recombination. \\ Dennis Coss}

A method whereby DNA sequences of varying size may be accurately inserted into pre-determined locations within the Escherichia coli genome was developed. Using a binary vector system that takes advantage of either the $E$. coli RecET enzyme tandem or bacteriophage lambda's Redaß recombinatory proteins, this method has the benefits of being both inducible and self-degrading, thereby offering a level of control to the experimenter as well as alleviating any problems that may be associated with leaving residual DNA in the bacterium. To demonstrate the usability of this system, two antibiotic resistance genes, as well as the pyrroloquinoline quinone (pqq) and gluconate dehydrogenase (gadh) operons were used as targeting molecules in three different strains of $E$. coli, with three distinct genomic targets. The location of the inserted sequences was confirmed through a primer-specific PCR detection assay. The combined expression of these operons demonstrates that $E$. coli can be made to produce 2-ketogluconate, an organic acid previously shown to dissolve insoluble rock phosphate, using glucose or gluconate as the sole source of carbon. Diversification of the substrates required for the production of 2-ketogluconate allows for the possibility of agricultural applications, while the recombinogenic targeting system offers a variety of possible uses in the modification of DNA molecules within the E. coli bacterium. 


\section{Table of Contents}

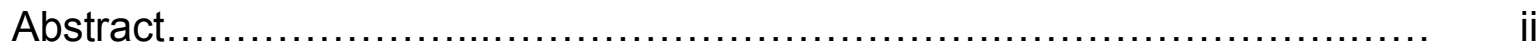

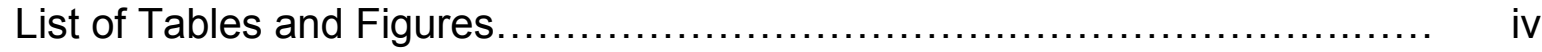

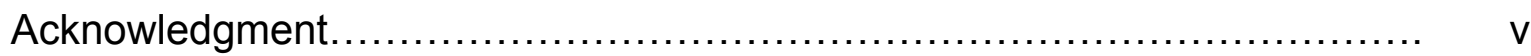

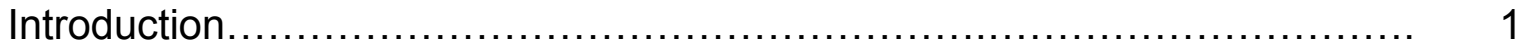

Literature Review............................................................... 8

Objectives.................................................................... 27

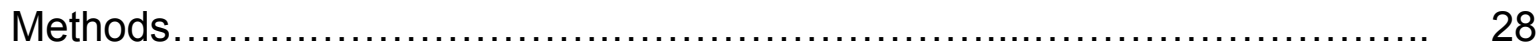

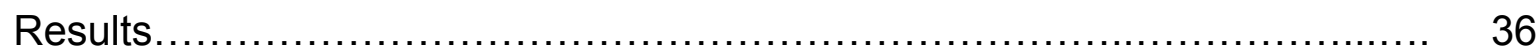

Discussion....................................................................... 52

Future Direction .................................................................... 64

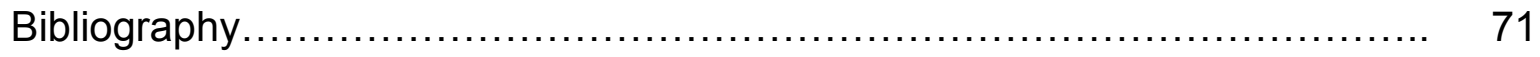

Appendix A. Gene and Promoter Sequence Data............................. 88

Appendix B. Escherichia coli Strains Employed............................... 94

Appendix C. PCR Primers.................................................. 96

Appendix D. Transformation and Recombination Efficiency Tables............ 99

Appendix E. Experimental Protocols........................................ 111 


\section{List of Figures and Tables}

Figure Title

1. Overall Experimental Concept....

2. Mechanism of Homologous Recombination by RecET or Redaß...

3. Degradative Pathways of D-Gluconic Acid.

4. Targeting Cassette Design.

5. Targeting Plasmid pACYC exo/l-Scel

6. Targeting Plasmid pBS-bet/gam with and without the gadh operon...

7. Targeting Plasmid pACYC-t-recE/I-Scel.

8. Targeting Plasmid $\mathrm{pBS}-\mathrm{recT/gam}$ with and without the gadh operon.

9. Detecting Recombination

10. PCR-Detected Inserts.
Page

3

5

21

26

37

38

39

40

41

$44-6$

\section{Table Title}

Page

1. Recombination efficiencies of $E$. coli strains using linear dsDNA.....

2. DCPIP/PMS Detection of Gluconate Dehydrogenase Activity...

36

3. GADH Activity in E. coli containing both pqq and gadh Operons and grown on M9 minimal media, plus glucose

Recombination and Transformation Efficiencies of $E$. coli when

Recombination and Transformation
order of gene expression is varied 


\section{Acknowledgement}

Getting a Ph.D. is no small undertaking. Persistence, hard work and dedication are the fundamental traits of any graduate student who seeks to achieve a doctoral degree, but these attributes in themselves are not enough to make it through. Friendship and guidance are paramount, and I feel that my work is living proof of this. For this reason I would be in remiss if I did not take a moment to say thanks to my fellow grad students in the genetics department, as well as those in the animal sciences programs with whom I shared many thoughts, frustrations and lab equipment. I would also like to thank each of my advisors: Dr. Nath, not only for his friendship, but also his guidance at each phase of my graduate career. Drs. Harris and Bishop for starting me down my chosen path and teaching me what it means to be a scientist, as well as equipping me with the basic tools to do so. I would also like to thank Dr. Doelling for filling in when I needed him; not to mention for breathing new life into the laboratory I called home for so long. Lastly, and certainly not least, I would like to thank Dr. Walter Kaczmarczyk who gave me the privilege of working in his lab and always provided me with a unique perspective on research and the larger picture of life. If I were to only receive half of the wisdom he had imparted to me I would still be a better man for it. 


\section{Introduction}

The focus of the research described within has two primary focus areas: the isolation and expression of bacterial genes that result in mineral phosphate solubilization and the targeted recombination of DNA fragments within the Escherichia coli genome. The paragraphs below briefly describe the rationale and justification behind choosing these areas as topics of research.

Gene Targeting. Over the past few years a number of methods by which DNA is inserted or deleted from Escherichia coli in a precise and accurate manner have been investigated, many employing either the host genes recE and recT or the reda and red $\beta$ genes from bacteriophage lambda $(6,56,59,116)$. The benefit of using either of these protein tandems in E. coli is that they allow for the induction of recombination using only a small homology sequence (116). A component found to be lacking from all previous approaches has been the removal of residual genetic material required for their induction and implementation. Having pre-existing plasmids in the bacterium can interfere with downstream applications where additional use of plasmid DNA is required. To address this issue, a means by which to induce the degradation of this residual DNA has been developed. The approach employs two plasmid DNA vectors, one possessing a low copy origin of replication and the other a high copy origin (Figure 1). 
To the low copy plasmid (Figures 4 and 6 ) the following modifications had been made: insertion of the rare-cutting intron-homing endonuclease $I$-Scel, driven by the inducible arabinose promoter $\left(\mathrm{P}_{\mathrm{BAD}}\right)$, recognition sites for the I-Scel endonuclease, the araC gene whose protein represses $P_{B A D}$ expression in the absence of arabinose and either the $E$. coli recE or bacteriophage $\lambda$ reda endonuclease genes. To the high copy plasmid (Figures 5 and 7 ) the following modifications had been made: insertion of either the $E$. coli recT or bacteriophage $\lambda$ red $\beta$ annealing proteins, a targeting cassette which contains the modification of interest flanked by sequences bearing homology to a predetermined location on the E. coli chromosome (Figure 9), the bacteriophage $\lambda$ gam gene, plus recognition sequences for the rare-cutting intron-homing endonuclease I-Scel. Using a high copy vector as a carrier of the aforementioned sequences offers the benefit of having the annealing protein over-expressed, relative to the exonuclease carried on the low copy vector, which has been previously demonstrated to increase the efficiency with which recombination occurs (116). Additionally, having the targeting cassette replicated in high numbers increases the likelihood that a recombination event will occur.

The underlying mechanism is as follows. Various E. coli strains will be cotransformed with high and low copy vector tandems containing either E.coli recET or bacteriophage $\lambda$ reda $\beta$ genes. Upon entering the bacterium, gam expression will result in the inactivation of the RecBCD complex while RecET or Reda $\beta$ will be independently expressed at levels favorable for recombination. In 
order to generate the double-stranded DNA breaks required to stimulate recombination through either of these pathways, arabinose will be added to the growth media, thereby inducing expression of the I-Scel endonuclease which is driven by the $\mathrm{P}_{\mathrm{BAD}}$ promoter.
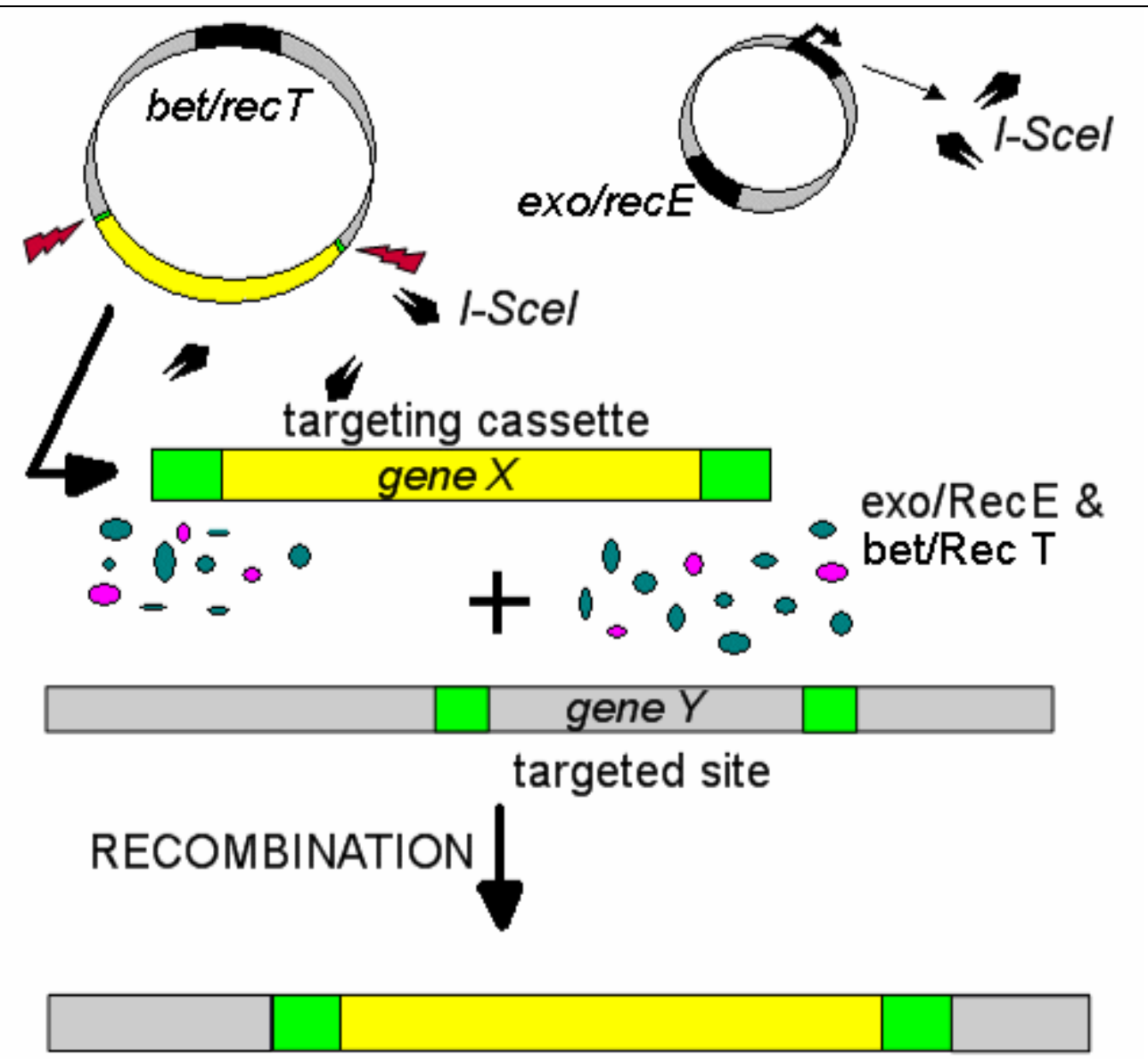

Figure 1. Overall Experimental Concept. After introduction of the binary vector system into E.coli, expression of the restriction-homing endonuclease, IScel, is induced. The result is formation of dsDNA breaks in both of the vectors at the I-Scel recognition sites, ultimately leading to their degradation. I-Scel sites are located on either end of the homology arms located at the termini of the gene to be inserted (gene X). Once the dsDNA breaks are induced at these sites RecE or Reda resects one strand of the dsDNA at the site of the break while $\operatorname{RecT}$ or Red $\beta$ binds to the remaining ssDNA. RecT or Red $\beta$ then pair to the homologous portions of the E.coli chromosome (homology arms A and B) and strand exchange is induced, resulting in the removal of gene $Y$ and simultaneous replacement by gene $X$.

I-Scel sites located on both plasmids will be cleaved resulting in the production of three linear dsDNA fragments: the linearized high-copy vector, the targeting 
cassette and the linearized low-copy vector. Once created, either RecE or Reda will bind to the 5' ends and degrade the terminal portion (Figure 2). As this occurs, either RecT or Red $\beta$ will bind to the corresponding ssDNA to prevent its degradation and search for a homologous sequence with which to recombine. The homology arms within the targeting cassette will direct recombination at the targeted location within the chromosome, while the remaining linearized plasmids will be degraded once RecBCD is again activated. This is achieved through locating an I-Scel site near the gam gene. Once cut, either RecE or Reda will resect the double-stranded break, effectively removing a portion of the gene and resulting in loss of expression. Since there is no gam gene in E. coli, this DNA fragment will not recombine with the chromosome. This same principal applies to the remaining, linearized plasmid. The end result is therefore the insertion of the targeting cassette at any pre-determined location on the $E$. coli chromosome, along with the degradation of the plasmid vectors used to induce this process. 

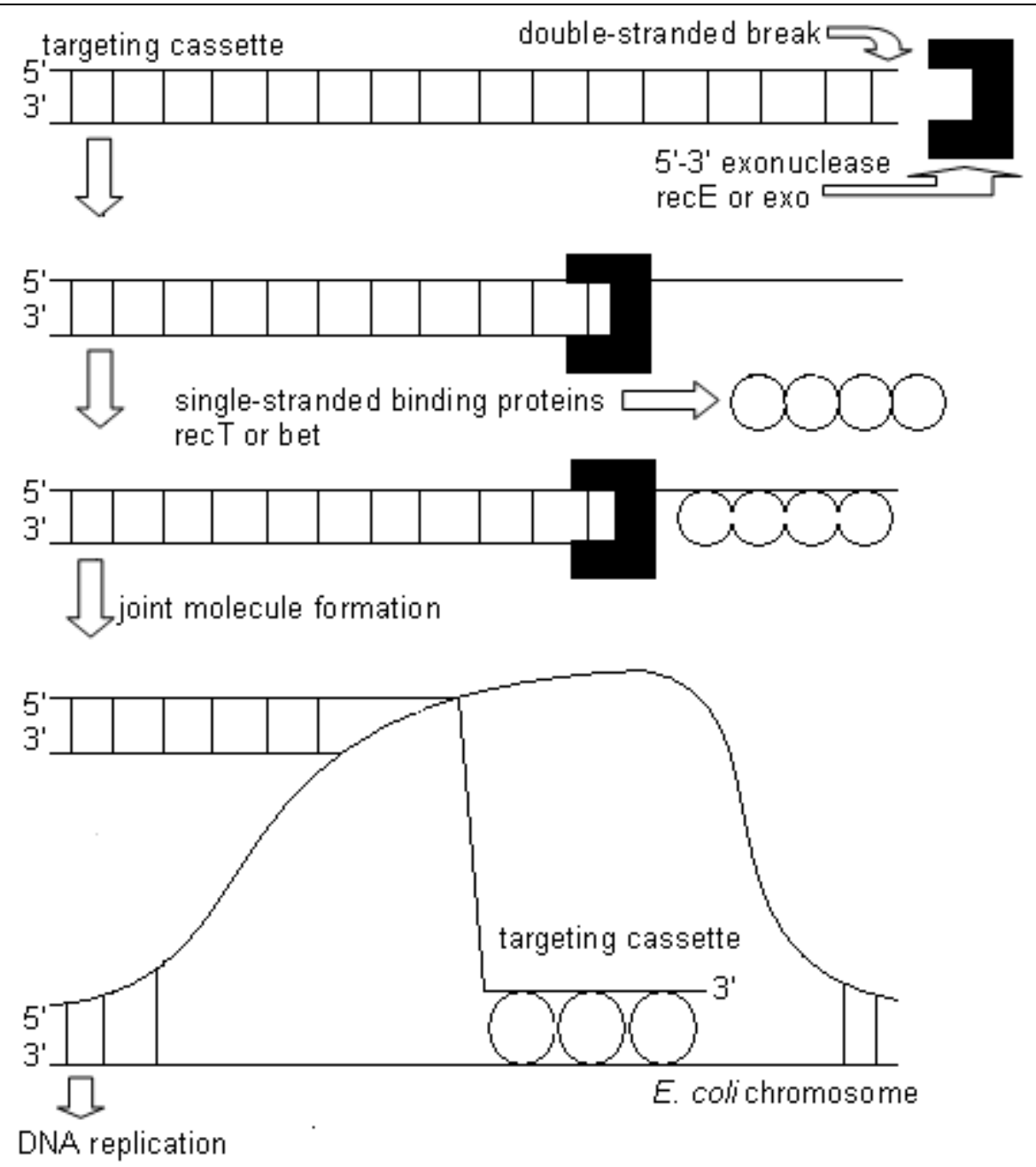

Figure 2. Mechanism of homologous recombination by RecET and Reda $\beta$. At the terminal end of a double-stranded DNA break either RecE or Reda (exo) will bind and resect one of the stranded in the $5^{\prime} \rightarrow 3^{\prime}$ direction, leaving a portion of single-stranded DNA. The portion is immediately bound by either RecT or $\operatorname{Red} \beta$ (bet) which protects it from degradation and also searches for a stretch of dsDNA with homologous sequences with which to bind. Once recognized, the double-stranded fragment is disrupted by the invading ssDNA. RecT or Redß then promote annealing of the strands, resulting in replacement of the original DNA fragment by the invading sequence. 
Mineral Phosphate Solubilization. In general, there are three ways by which the availability of soluble phosphate can be increased in soil:

1. Application of additional fertilizer, manure or other chemical treatments.

2. Genetically modify plant species.

3. Genetically modify rhizobacterial species.

Additional applications of fertilizer are commonly practiced but it is a nonrenewable resource, expensive (a major detractor in underdeveloped nations) and creates additional problems in terms of runoff into waterways $(31,95)$. Genetically modifying plant species is a viable alternative and was initially considered by our lab as the best means by which to solubilize phosphate. Other labs have successfully modified plant genomes by the introduction of the bacterial citrate synthase gene which facilitates the breakdown of phytate, a loose association of soil compounds that represents twenty to fifty percent of all available soil phosphate $(54,55,60,63)$. While this is a promising achievement, several issues remain before this approach can be applied on a large scale; the first of which being the localized expression of the inserted gene in the root system. This is particularly important for crops of economic significance due the possibility of altering a desirable phenotype. An additional problem, beyond the scope of biological science, is the unfavorable public perception of genetically modified crops. These problems would have to be addressed for each species of plant modified, in addition to the variance in efficacy. 
Genetically modifying rhizobacterial species circumvents many of these obstacles. Making genetic modifications to bacteria is far easier than with any multi-cellular organism and a single species could be possibly be used in conjunction with several plant varieties. For this reason we sought to modify bacteria to produce significant levels of the bio-acid 2-keto-D-gluconate (2KG) which has previously been demonstrated to induce the mineral phosphate solubilization (MPS) phenotype. 2KG is produced by the direct oxidation of gluconic acid, a six carbon sugar acid. To increase the availability of this substrate the genes required for the synthesis of the cofactor pqq, which is required for the activation of glucose dehydrogenase (GDH), were also transferred to the E. coli chromosome. Since GDH oxidizes glucose to form gluconic acid, the likelihood of $2 \mathrm{KG}$ production is increased. Also, the nature of the substrates dictates that its production will be highly localized to the rhizosphere, an area where soil sugar concentration is localized. 


\section{Literature Review}

\section{RecE and RecT physical properties:}

RecE is a $120 \mathrm{kDa}$ protein that acts as an ATP-independent DNA exonuclease and is sometimes referred to as ExoVIII $(49,58)$. RecE has an absolute requirement for $\mathrm{Mg}^{2+}$, with optimal activity at $20 \mathrm{mM}$. ExoVIII degrades doublestranded DNA in a $5^{\prime} \rightarrow 3^{\prime}$ direction, yielding both $5^{\prime}$ mononucleotides and singlestranded DNA $(33,48,49,58)$. It displays very little activity towards singlestranded DNA and none to circular double-stranded DNA in a supercoiled, nicked or gapped configuration $(19,48)$. ExoVIII has high processivity, degrading dsDNA on the order of 20,000 bases per binding event (39). Biochemically, ExoVIII resembles $\lambda$ exo (Red $\alpha)$, the product of the red $\alpha$ gene of bacteriophage $\lambda$. The recE gene is located in the cryptic Rac prophage which resides in the genomes of $E$. coli $\mathrm{K}-12$ strains (50).

RecT is a $33 \mathrm{kDa}$ protein that binds to single-stranded DNA and promotes renaturation to complementary ssDNA strands in an ATP-independent fashion when in the presence of $\operatorname{RecE}(23,40)$. The recT gene is also located in the Rac prophage and partially overlaps the 3 ' end of the recE gene by five nucleotides, although it is out of frame with respect to recE (23). Like RecE, the RecT protein is also very similar in function to a bacteriophage $\lambda$ gene. In case of RecT it is the $\operatorname{Red} \beta$ protein, which acts in concert with the Red $\alpha$ in the same manner as RecE/RecT. In fact, the RecE/RecT proteins can replace the $\operatorname{Red} \alpha / \operatorname{Red} \beta$ proteins in bacteriophage $\lambda(40,52,81)$. The reverse is also true, but they cannot 
interchange proteins, i.e., Red $\alpha$ cannot work in concert with RecT (81). This holds true for RecE and Red $\beta$. Interestingly, these $E$. coli proteins differ greatly in size and share no sequence homology with their $\lambda$ phage counterparts, although it has been observed that the first 587 amino acids of RecE are disposable (19).

The recE was discovered in 1970 by the Barbour lab as a gene that encoded an ATP-independent exonuclease (13). The protein was purified by two groups and found to have a molecular weight of $140 \mathrm{kDa}(49,58)$. Based on the size of the protein, the gene sequence was anticipated to be an open reading frame of approximately $4 \mathrm{~kb}$. The actual size of the recE gene is 2601 base pairs (23).

The gene was first cloned from an $s b c A^{+}$strain of $E$. coli as a part of a $7.6 \mathrm{~kb}$ HindIII insert using lambda phage as a vector (40). Recombinant phage carrying recE were selected for by the ability to form plaques on polA and lig hosts. Partial sequencing of recE was not done until 1989 when the Clark lab used derivatives of plasmids which he had previously isolated in 1985 (23). One particular plasmid carried the nucleotide sequences for the gene racC and the $\mathrm{N}$ terminal portion of the wild-type $r e c E$ gene. The portion of $r e c E$ in this plasmid carried a frameshift mutation that prevented synthesis of active RecE. They used the information from this plasmid to construct an additional series of plasmids that carried internal and external deletions which either fused the $\mathrm{N}$ terminal portion of the recE gene to the C-terminal portion of recE, or the $\mathrm{N}$ terminal of the immediately upstream racC gene to the C-terminal of the recE 
(23). This bears repeating because in addition to the sequence information they also discovered that roughly $70 \%$ of RecE (the first 587 amino acids) were not required to form an active enzyme $(15,57)$. The C-terminal portion of the gene was not published until 1993 (23).

In wild-type $E$. coli the primary means of recombination is provided by the RecBCD complex. Subsequently, in $\operatorname{rec} B$ recC mutant strains virtually all recombination is abolished. Still, background recombination does occur, which has lead to the suggestion that there is an alternate, albeit minor pathway of recombination that is independent of $\operatorname{RecB}$ and $\operatorname{RecC}$. It was found that recombination in these strains can be restored to near normal levels by an additional mutation in $s b c A$ locus, an indirect suppressor of the RecE and RecT

genes (13). Although mapped to the Rac prophage inserted into the chromosome of all E.coli $\mathrm{K} 12$ derivatives, the precise sequence of this DNA element, whether it is a regulatory sequence or gene, has not been determined.

\section{Key experiments involving RecE and RecT:}

1. Isolation of the RecE protein (Exo VIII). Based on the observations that $s b c A$ strains maintain increased levels of an ATP-independent DNase, and that $s b c A$ recBC cells are still able to perform the tasks carried out by RecBC (Exo V), the Clark lab devised a purification protocol in order to isolate the protein(s) responsible for the continued ability to correct UV-damaged DNA (58), as well as maintain a proficiency in recombination. Through ammonium sulfate precipitation and ion-exchange fractionation they were able to achieve a purity of roughly $50 \%$ 
and estimated the size of the protein by SDS-PAGE to be approximately 120 $\mathrm{kDa}$.

The size of the RecE protein had been a point of discussion for some time. The observed mass of Exo VIII by SDS-PAGE $(140 \mathrm{kDa})$ is too great for the corresponding sequence of the recE gene $(96.2 \mathrm{kDa})(19)$. The Clark lab pointed out a discrepancy between the size of the recE gene predicted by molecular mass estimates of Exo VIII proteins and the estimated location of a Tn10 insertion which appeared to eliminate Exo VIII activity (recE101::Tn10) (23). The Luisi-DeLuca lab subsequently showed that the insertion reduced but did not eliminate a protein whose mobility in SDS-PAGE was the same as that of wildtype Exo VIII (52). Through later sequencing attempts it was discovered that the estimated location of rec-101:: Tn10 is in recT (19). Using PCR, instead of Southern blotting (which had been used previously, the Clark lab found the exact location of the transposable element to be between bases 3499 and 3766 of recT (23). The Chu lab had proposed that the discrepancy was due to a series of five alternating, for the most part, alpha-helix and beta-sheet sheet motifs in the Exo VIII protein from amino acids 257 to 355 that was contained in an $\mathrm{N}$-terminal fragment copy of recE (recE939) (19). The observed mobility of this protein in SDS-PAGE was $86 \mathrm{kDa}$, while the expected mass was only $65 \mathrm{kDa}$. Nested deletions of this area yield proteins that migrate in accordance with sizes that can be predicted by from the size of the DNA fragment. Chou-Fasman analysis predicts this area of recE939 to be the densest region of beta-sheets in the protein and, on this basis, may be rendered resistant to SDS binding (19). The 
Chu lab believed this reduction in SDS binding to be the cause of the overestimation of size, as it would lead to a decrease in mobility on SDS-PAGE (23). They, therefore, believe the mass of Exo VIII to be closer to $120 \mathrm{kDa}$.

Based on the sequence data for $\operatorname{rec} E$ and $\operatorname{rec} T$, the Clark lab had speculated that the observed mass of $125.9 \mathrm{kDa}$ for Exo VIII may suggest a fusion of RecE and RecT to form an active Exo VIII protein (23). This seemed reasonable since the combined estimated mass of the two gene products $(96.2 \mathrm{kDa}$ and $33 \mathrm{kDa}$ ) closely matches the number observed from SDS-PAGE. In order to test the fusion protein theory they constructed a series of insertions and deletions to the recT gene whereby observing the new estimated masses by SDS-PAGE would indicate whether or not it was fused to the recE gene product. None of these had an effect on the mobility of the Exo VIII protein, so the possibility of a fusion between the recE and $\operatorname{rec} T$ gene products as an explanation for the observed mass of Exo VIII was discounted (23). The RecE and RecT proteins do, however, interact. In fact, they will co-purify through several steps, indicating that this may indeed be another reason for the overestimation of the mass of Exo VIII. Later sequencing of the C-terminal portion of recE showed that the Chu lab predicted size of RecE, based on an estimation of the location of the C-terminus closely matched its actual location, indicating that reduced migration in SDSPAGE is the likely reason for the discrepancy in mobility (19).

2. Sequencing the recE gene. The complete sequence of the recE gene is spread over two publications. The first paper presents the sequence of the $\mathrm{N}$ - 
terminal portion, along with a neighboring gene, $\operatorname{racC}(19)$. A $2.45 \mathrm{~kb}$ fragment derived from one of a series of plasmids that were created in a previous experiment had been hypothesized to contain a portion of the amino-terminal of the RecE protein and was sequenced. The second publication would show that the original clone, pRAC1, contained the complete sequence of the recE gene, although it is inactive due to a frameshift mutation located after the seventh codon of that gene (23). Although this mutation may have initially been looked upon as misfortune, it turned out to be a blessing in disguise. Through the creation of a series of deletions aimed to suppress the frameshift, the Clark lab discovered that the first 587 amino acids (nearly $70 \%$ of the $\mathrm{N}$-terminal half) of recE is not required to encode a functional Exo VIII (19). This truncated form of the protein cuts the mass down to only $39 \mathrm{kDa}$. In addition, further sequencing led to the discovery of the recT gene (23).

\section{Identification of the RecT protein. The RecT protein had been} hypothesized for some time prior to its discovery (48). Some of the genetic evidence which had suggested that there was an annealing protein that worked in conjunction with RecE is as follows: First, the expression of recE substitutes for two bacteriophage $\lambda$-encoded proteins required for recombination: $\lambda$ exo, encoded by the red $\alpha$ gene, and the $\operatorname{red} \beta$, protein, which is a single-stranded DNA binding protein that can promote renaturation of DNA and stimulate RecAdependent strand exchange in vitro $(15,19,21)$. Also, in phage that lack the recombination functions encoded by $\lambda(\operatorname{red} \alpha$ and $\operatorname{red} \beta)$, replacement by a portion of the E. coli-encoded Rac prophage that encodes ExoVIII allows the phage to 
grow under conditions where recombination is essential $(38,49)$. Second, some recombination events in $\operatorname{rec} B$ rec $C \operatorname{sbc} A$ mutants do not require $r e c A$, a fact suggesting that a second homologous pairing protein may exist and substitute for $\operatorname{Rec} A(15,21,23,40,57)$. This idea is consistent with the observation that $\lambda \beta$ protein is able to substitute for RecA under certain circumstances (49) and suggests that the $r e c E$ region may encode a $\lambda \beta$ protein analog.

RecT was discovered by two groups in $1993(23,40)$. The RecT protein was first purified by the Kolodner lab by using plasmids that directed the expression of RecE or a truncated version of it (40). They noted that when high levels of expression were attained with full-length RecE that a $33 \mathrm{kDa}$ protein was coexpressed at a ratio of 10:1 (RecT: RecE). N-terminal sequencing of RecT revealed that the $\mathrm{N}$-terminal Met is encoded by the Met codon of the recT ORF (40). Additional information that supported the idea that recT overlapped the recE gene was the presence of a ribosome binding site at an optimal distance upstream of this first recT Met codon, and the protein weight was consistent with the predicted product of the recT ORF by the Clark lab $(23,40)$. Biochemical analysis of the RecT protein demonstrated that it binds specifically to SsDNA and promotes the renaturation of complementary SsDNA, and deletion mutation analysis shows that it is required for conjugational recombination in $\operatorname{rec} B$ recC strains of $E$. coli. The recT gene sequence was subsequently elucidated by the Clark lab while doing sequencing work on the C-terminal of the recE gene (23). Using the predicted nucleotide sequence from the $\mathrm{N}$-terminal RecT protein they were able to find the precise location of the corresponding nucleotides which 
began with the final seven nucleotides of the $r e c E$ gene. As alluded to earlier, discovery of recT as a partially overlapping reading frame, in addition to the size discrepancy of Exo VIII, raised the possibility that ExoVIII was a RecET fusion protein. However, genetic tests showed that this was not the case (23). In addition, the Kolodner lab have performed detailed peptide mapping experiments with ExoVIII and RecT proteins and have shown that the two proteins have not "a single peptide in common." (23).

4. ET recombination. As an alternative to using Saccharomyces cerevisiae for in vivo recombination $(22,96)$, Stewart hypothesized a technique by which the expression of RecE and RecT in E. coli could induce the exchange of DNA fragments through homologous recombination (14). Using PCR-generated copies of antibiotic resistance genes flanked with homology arms of varying length Stewart was able to show that insertion of the gene(s) into an episome could be accomplished in a precise manner when strains of E. coli carrying the $s b c A$ mutation were used. $S b c A$ normally inhibits the expression of the recE and recT genes from the cryptic Rac prophage of E. coli K12 strains $(20,40,77)$ and is also a suppressor of $\operatorname{recBC}(13,21)$. To further the usability of the technique Stewart developed a vector, pBAD-ETy, to express the recE and recT genes, in addition to the Redy (gam) gene from bacteriophage $\lambda(14)$, thereby allowing this technique to be used with the more common strains used in molecular biology and not having to rely upon the $s b c A$ mutation. The significance of expressing the gam gene in addition to RecET is that it inactivates RecBCD which degrades linear fragments of dsDNA (119). 
In refining their technique, named ET cloning, Stewart found that over-expression of the annealing protein, $\operatorname{Rec} T$, increased the overall efficiency of the technique and that inducible expression of the exonuclease, RecE, had reduced instabilities caused by possible background recombination events (14). Stewart also found that the minimum length of the homology arms that was required for efficient recombination to occur was $42 \mathrm{nt}(14)$ and that nucleotide repeats at the homology arm-DNA insert decreased this efficiency (80). Efficiency of recombination also plateaus when the homology arms reach a length of $100 \mathrm{nt}$ (118), and recently has proposed a possible mechanism to account for this observation (79). Additionally, Stewart found that using Reda and Red $\beta$ (the functional equivalents of $\operatorname{RecE}$ and $\operatorname{Rec} T$ found in bacteriophage $\lambda$ ) increased recombination up to three-fold in some instances (83).

To demonstrate the versatility of ET cloning, the Stewart lab has since published a series of papers describing experimental set-ups whereby DNA fragments of virtually any size can be inserted or deleted with high precision from the $E$. coli chromosome, linear fragments of dsDNA as well as any autonomously replicating DNA source, such as plasmids or bacterial artificial chromosomes $(17,39,51$, $79,80,81,83,118)$.

5. Requirements of RecE/RecT recombination. Once the Stewart lab had established the effectiveness of using the RecET and Red $\alpha \beta$ recombination pathways to make targeted insertions and deletions they conducted several 
studies to determine the requirements of these pathways (116). As with several of the previously conducted applications they transferred the chloramphenicol resistance gene to make the presence or absence of recombination easily detectable. They first determined that both components of RecE/RecT or $\operatorname{Red} \alpha / \operatorname{Red} \beta$ were required in order for recombination to occur (81). They did this by conducting assays where either component was absent in each system. In all cases recombination products were absent. In addition to showing that either pathway required the function of both the 5'-3' exonuclease and annealing proteins they, found that the orthologous partner is required for either pathway. Experiments involving either heterologous pairs of RecE/RecT and $\operatorname{Red} \alpha / \operatorname{Red} \beta$ failed to yield a significant number of recombinants. To further show whether or not the 5'-3' exonuclease was required, conditions were set where the PCRgenerated fragment were prepared by incubation with the non-processive T7 gene 6 exonuclease or by the use of RecE to produce fragments with varying lengths of 3 ' overhang. The resected substrates were introduced into cells expressing components of either RecE/RecT or Red $\alpha / \operatorname{Red} \beta$. Regardless of preresection, recombinants were only formed in the presence of the orthologous pair, and efficiencies were reduced in approximate concordance with the complete exonuclease digestion $(80,81)$.

Precisely defined pre-resected substrates were generated using PCR products containing triplets of phosphothiolated nucleotides between the 50-nt homology regions present on each end, and the chloramphenicol resistance gene. Phosphothiolated triplets blocked RecE exonuclease activity in vitro. 
Recombination with RecE-pre-resected, phosphothiolated substrates also required an orthologous pair and again, expression of the heterologous pairs or any annealing protein alone did not support significant recombination (80). Although phosphothiolated substrates inhibit RecE in vitro, equivalent efficiencies were observed for RecE/RecT recombination in vitro regardless of whether the substrate was unmodified, phosphothiolated, or pre-resected. This indicates that any significant contribution by a $3^{\prime}-5^{\prime}$ exonuclease can be discounted. Recombination by $\operatorname{Red} \alpha / \operatorname{Red} \beta$, however, is affected by the presence of phosphothiolated nucleotides in the substrates.

After determining the pathway requirements of RecE/RecT and demonstrating that RecE and Red $\alpha$ both contribute to essential activities other than being a 5'-3' exonuclease, the Stewart lab focused on the interaction between the RecE and RecT proteins. Specific physical interactions between $\operatorname{Red} \alpha$ and $\operatorname{Red} \beta$ have been inferred from the observations that these proteins co-purify through several steps $(37,53)$. To test whether RecE and RecT interacted physically, the Stewart lab expressed RecT as a protein-A fusion protein. Positioning protein A at the carboxyl terminus of RecT did not impair recombination or recovery from UV irradiation in the assays performed. Lysates from cells which expressed the fusion proteins were passed over IgG Sepharose columns. RecE bound to RecT, as did other truncated forms of RecE, but Reda did not. RecE did not interact with protein A alone, demonstrating specificity for RecT. RecE identity was confirmed by Western analysis. The physical interaction between RecE and 
RecT was resistant to DNase I digestion. Thus RecT is able to discriminate between RecE and Red $\alpha$ through physical interaction.

\section{Pyrroloquinoline quinone}

Pyrroloquinoline quinone (PQQ) is a non-covalently bound cofactor used in several bacterial dehydrogenases and transfers redox equivalents to the respiratory chain. The physiological electron receptors vary from ubiquinone in the case of membrane-bound glucose dehydrogenase to a cytochrome $\mathrm{c}$ in the case of methanol dehydrogenases. It is commonly studied in three different bacteria with the number of genes associated with its synthesis different in each: Acinetobacter calcoaceticus (five), Klebsiella pneumoniae (six) and Methylobacterium extorquens (seven). What makes isolating the pqq genes for K. pneumoniae attractive is that, unlike the other two bacteria mentioned, they are transcribed from a single gene cluster $(73,74)$.

The nucleotide sequence of the pqq operon of $K$. pneumoniae was determined in 1992 (74) and, as mentioned previously, consists of six genes, pqqA, $B, C, D, E$ and $F$. As opposed to $M$. extorquens, all of the pqq genes of $K$. pneumoniae are required for synthesis. The exact pathway of $P Q Q$ synthesis has yet to be elucidated, but it has been determined that tyrosine and glutamate are precursory molecules $(45,106,107)$. It has been shown that the first gene in the pqq operon in both A. calcoaceticus and K. pneumoniae is a short 24- and 23amino acid polypeptide with conserved tyrosine and glutamate residues (36). Regarding K. pneumoniae (pqqA), they are at positions 15 and 19, respectively. Additionally, both bacteria possess a gene whose protein demonstrates similarity to an E. coli protease III (107), and it has been suggested that it is involved in the 
processing of the small polypeptide. For this reason it has been suggested that this small polypeptide is the precursory molecule from which PQQ is synthesized $(36,74)$. In the case of $K$. pneumoniae it is the pqqF gene that encodes the speculated protease (74). Complementation assays in $M$. extorquens have suggested that this precursory polypeptide is not essential for $P Q Q$ synthesis for this particular organism (104).

Expressing the pqq operon in E. coli serves the function of increasing the overall substrate availability for the production of 2-ketogluconic acid. Instead of relying solely upon the limited quantity of D-gluconate in the area immediately surrounding the rhizosphere, the ability now exists to convert the more abundant sugar, D-glucose into D-gluconate through the activation of GDH by the co-factor pqq.

The membrane-bound glucose dehydrogenase (GDH) of $E$. coli is a quinoprotein with PQQ as the prosthetic group $(4,5,7,8,29,84,85)$. Under certain growth conditions this enzyme makes an important contribution to energy metabolism because it presents an alternative means to metabolize glucose $(35,44)$. Predominantly, glucose is phosphorylated upon its uptake and therefore directed to the glycolytic pathway (42). Alternatively, glucose can be oxidized to form gluconate, whereby it is metabolized through the Entner-Doudoroff pathway to yield glyceraldehyde-3-phosphate or pyruvate, and subsequently fed into the glycolytic pathway. The oxidation of glucose is carried out by GDH when the 
cofactors $\mathrm{PQQ}$ and $\mathrm{Mg}^{2+}$ are present. Oddly, E. coli is unable to produce $\mathrm{PQQ}$ $(43,44,103)$.

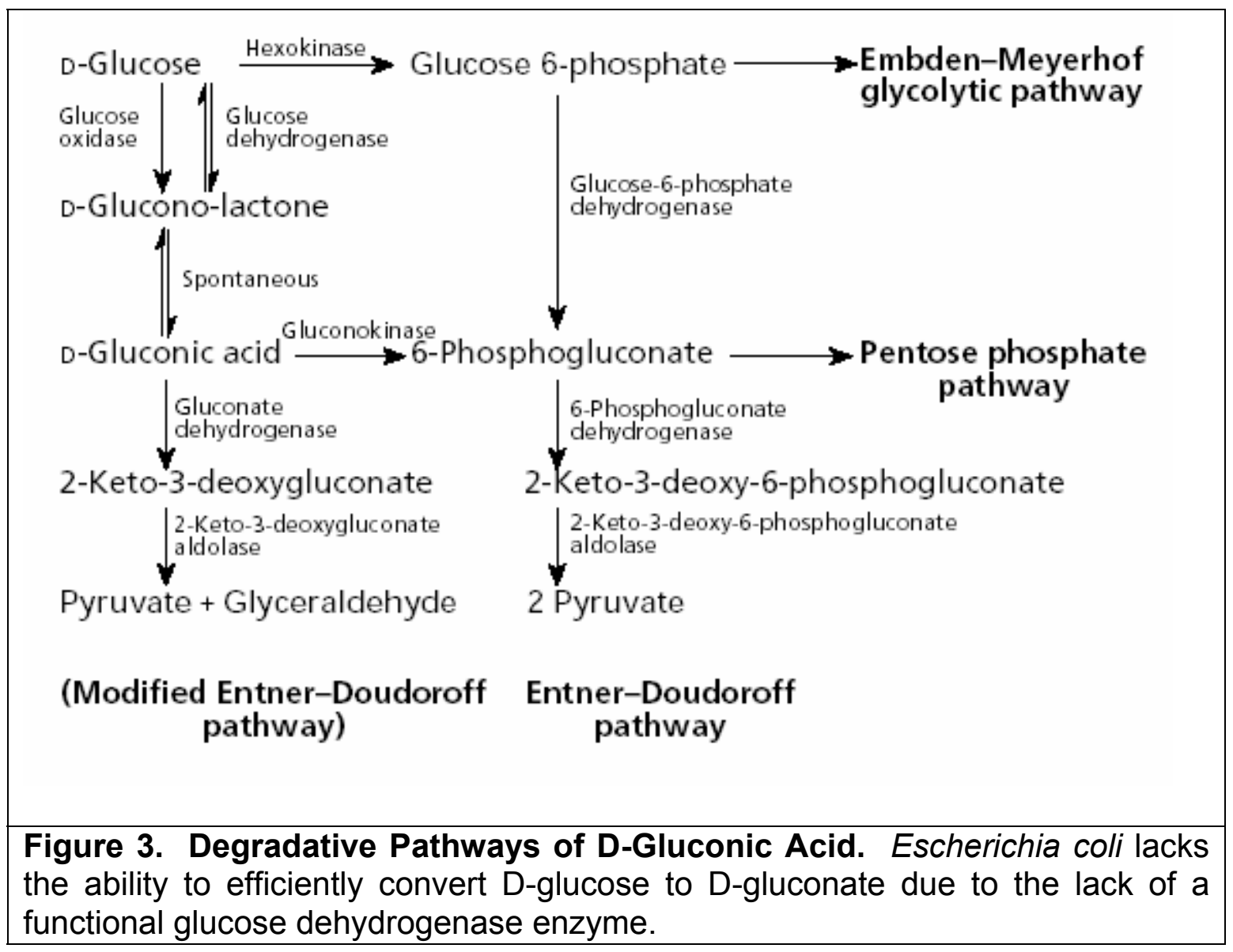

$\mathrm{GDH}$, although transcribed constitutively, is therefore always produced in the apoenzyme form (110). It is readily activated by the addition of $P Q Q$ and $\mathrm{Mg}^{2+}$ to the growth media $(4,5,35)$. Because the holoenzyme can be formed so readily from the apoenzyme by addition of $P Q Q$ it is has been proposed that it is in an almost completely folded form (27). The final step in production of the active 
holoenzyme is the binding of $P Q Q$. The role of apo-GDH remains unclear, although it has been postulated that $P Q Q$ serves as a chemotactic attractant for E. coli (85) and as an adaptive measure to environments which is where soluble phosphate is in low concentration (2).

In most cases GDH is membrane-bound and oxidizes glucose to gluconate in the periplasmic space, although a soluble form is also present in the periplasm (28). The formed gluconate is subsequently taken up by various transporters and further metabolized (87). The reducing equivalents are donated via PQQ to ubiquinone and then to the respiratory chain. Expression of the six pqq genes from K. pneumoniae in E.coli results in $\mathrm{PQQ}$ synthesis and an active GDH (73, 74). The $P Q Q$-binding site of $G D H$ faces the periplasm, so the $P Q Q$ is most likely synthesized in the cytoplasm and subsequently released into the periplasm (111). Several of the PQQ-producing bacteria make it in great enough abundance to where it is often excreted into the surrounding media. The concentration can vary from $1 \mu \mathrm{g} / \mathrm{ml}$ to as high as $1 \mathrm{mg} / \mathrm{ml}$ and is largely dependant upon the availability of precursory molecules.

PQQ was discovered in 1979 in methylotropic bacteria as the cofactor for methanol dehydrogenase (28). The cofactor was originally named methoxatin, but was subsequently changed to pyrroloquinoline quinone. 


\section{Gluconate Dehydrogenase}

Gluconate dehydrogenase (GADH) has been characterized in Pseudomonas aeruginosa by the Matsushita lab $(69,99)$. GADH catalyzes the oxidative conversion of D-gluconate to 2-keto-D-gluconic acid (2KG). In $P$. aeruginosa this conversion occurs in the periplasmic space $(3,69,75,91)$ and the product is detectable in the growth media (67). The enzyme itself consists of three subunits; a 68-kDa flavoprotein dehydrogenase subunit, a 47-kDa cytochrome c subunit and a 24-kDa subunit of unknown function. Although sequence data for all three of the subunits has been published (114) and a general biochemical basis of operation has been established, no further work on the function of the 24-kDa subunit has been reported. GADH from $P$. aeruginosa, strain PAO1 has been the focus of prior research in our lab making the continued use of this organism a logical choice for this project, although the enzyme has been characterized in several other bacterial species $(71,97)$.

\section{Phosphate availability in Soil}

In agriculture, phosphorous $(\mathrm{P})$ is second only to nitrogen as an essential mineral fertilizer and, as such, represents the world's second largest agricultural chemical. Soluble phosphorous is often the limiting mineral nutrient for biomass production in natural ecosystems. This low availability stems mainly from two major soil-associated factors: inorganic interaction with cations and conversion into inorganic complexes by microbes. Even if the total $\mathrm{P}$ content of a given area of soil is high, much of the available $\mathrm{P}$ rapidly becomes fixed to forms that are 
unavailable to the plant. The availability of soil $P$ is largely controlled by biologically mediated processes such as gross mineralization and immobilization rates (120). Changes in $\mathrm{pH}$ and chelation by organic acids which bind phosphate anions also bring about phosphate in soil solution $(1,47,109)$. Over $60 \%$ of all arable soils are at a $\mathrm{pH}$ level above 7.0 , leaving most mineral phosphate in the form of poorly soluble calcium mineral phosphates (CaPs). Dissolution of CaPs to $\mathrm{Pi}_{\mathrm{i}}\left(\mathrm{H}_{2} \mathrm{PO}_{4}{ }^{-}\right.$or $\left.\mathrm{HPO}_{4}{ }^{2-}\right)$ is considered essential to the global phosphorous cycle since it is unusable to plants in an insoluble form. The concentration of available phosphorus is generally in the micromolar range which is below that of many micronutrients $(9,12)$.

Crop productivity is often limited by phosphate $(\mathrm{Pi})$ availability (11). Many genes including Pi transporters, phosphatases, RNases, and $\beta$-glucosidase are induced during $\mathrm{Pi}$ starvation (89). Low phosphate availability also alters the root architecture of some plants such as Arabidopsis. Under these conditions some plants will favor lateral root growth over primary root growth through an increase in lateral root density and length (108). Pi transporters are involved in acquiring $\mathrm{Pi}$ against the concentration gradient by an energy-mediated proton symport mechanism (105).

The kinetics characterization of the Pi-uptake system by whole plants and cultured cells indicates a high-affinity transport activity operating at low concentrations (micromolar concentrations) and a low-affinity activity operating at higher concentrations. Since $\mathrm{P}$ is in such low concentrations the high-affinity 
transporter is thought to be the primary system in plants (90) and is induced under conditions of Pi deficiency (32).

Arbuscular mycorrhizae (AM) occur in most terrestrial plant communities and associate with up to $80 \%$ of land plants (98). The influence of AM fungi in the structure and productivity of agricultural and natural ecosystems has been widely accepted $(41,98)$. The principle mechanism of AM-mediated $\mathrm{P}$ acquisition is the growth of fungal hyphae to a region well beyond (up to $10 \mathrm{~cm}$ ) the rhizosphere depletion zone (root-soil interface), which results in a sequestration of $\mathrm{P}$ from the bulk soil. Mycorrhizal roots achieve higher rates of $\mathrm{P}$ uptake than nonmycorrhizal roots (98), especially in P-deficient soils.

Some bacteria possess the ability to dissolve poorly soluble mineral phosphates. This phenotype has been termed mineral phosphate solubilizing (MPS). MPS bacteria release soluble orthophosphate $\left(\mathrm{P}_{\mathrm{i}}\right)$ from rock phosphate ore. MPS bacteria using the direct oxidative pathway can release significant amounts of $\mathrm{Pi}$ from calcium phosphates via this acid acidification of their extracellular environment $(10,34,62)$. It has been demonstrated that the MPS phenotype is the result of gluconic acid and 2-ketogluconic acid production via the direct oxidative pathway (62). 2-ketogluconic acid is one of the strongest naturally occurring organic acids (pKa 2.6) and its production is a goal of this research project. 


\section{Targeting Cassette Diagram}

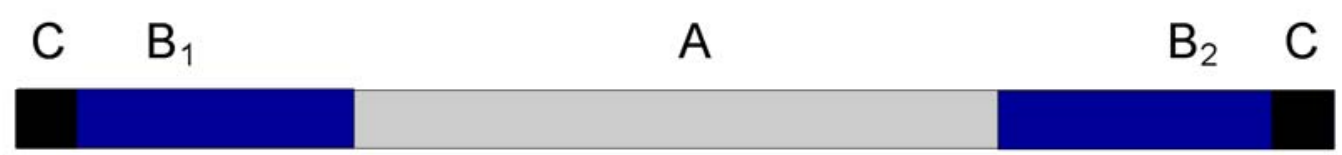
A. Insertion of interest (any size)
B. Homology sequences ( $50 \mathrm{nt})$
C. I-Scel recognition sequences (18 nt)

Figure 4. Targeting Cassette Diagram. A sequence that is to be inserted into the genome is flanked by homology sequences that directs it to the desired area of recombination. The I-Scel sites allow the targeting cassette to be excised from the plasmid which carries it into the bacterium. The dsDNA breaks that result from this incision also activates the RecET/Reda $\beta$ recombination process. If a deletion is desired then the insertion sequence is simply omitted and any sequence on the genome between the homology sequences will be deleted. Insertion without replacement of existing genomic sequences can also be achieved through selecting homology sites that are adjacent to each other on the genome. 
Objectives

1. To develop a pair of tandem, inducible and site-specific recombination vector systems for the purpose of transferring large segments of genetic material into the Escherichia coli genome in a precise manner.

2. To confer the Mineral Phosphate Solubilization (MPS) phenotype upon Escherichia coli through the insertion of the pyrroloquinoline quinone and gluconate dehydrogenase operons via site-specific recombination, thereby diversifying the substrates required in order to produce the organic acid 2ketogluconate.

The original aim of this project was to locate and sequence the genes responsible for the MPS phenotype in Pseudomonas aeruginosa. Before the research could be completed, the $P$. aeruginosa PAO1 genome sequence had been published (109). Since publication of sequence data prompted the decision to change the overall focus of the research.

Modifying DNA sequences in vivo has, and continues to be an area of active research by several laboratories and factored greatly in selecting the research presented. Not wanting to abandon the mineral phosphate solubilization efforts, the genes responsible for this phenotype and those of the pyrroloquinoline quinone biosynthetic pathway were incorporated into the present study through their use as insert targets for the plasmid vectors that were developed. 
Methods

Gene Targeting, Heading A (Co-transformed with all required DNAs).

The methods described below are generalized and apply to all bacterial strains, targeting cassettes and chromosomal targets used, as opposed to a separate description for each combination investigated in this study.

\section{Co-transforming: integrated targeting cassette.}

$50 \mu \mathrm{l}$ of competent $E$. coli strains were co-transformed with pBS-t-recE + pACYC-recE/I-Scel or pBS-bet + pACYC-exo/l-Scel (approximately $0.2 \mu \mathrm{g}$ of each tandem plasmid) by heat shock at $42^{\circ} \mathrm{C}$ for $90 \mathrm{sec}$. and supplemented with $500 \mu \mathrm{l}$ of $2 \mathrm{XYT}$ media containing $150 \mathrm{mM}$ arabinose. The tubes were then placed in a $37^{\circ} \mathrm{C} \mathrm{H}_{2} \mathrm{O}$ bath for 60 min., after which time $250 \mu \mathrm{l}$ of the transformation reaction was plated on the appropriate agar.

\section{Co-transforming: linearized targeting cassette.}

Conditions are identical to those above, except approximately $0.3 \mu \mathrm{g}$ of linear targeting vector was included in the transformation.

\section{Pre-high copy transformation: integrated targeting cassette.}

$50 \mu \mathrm{l}$ of competent $E$. coli strains were co-transformed with pBS-t-recE or pBSbet (approximately $0.2 \mu \mathrm{g}$ of either plasmid) by heat shock at $42^{\circ} \mathrm{C}$ for $90 \mathrm{sec}$. and supplemented with $500 \mu \mathrm{l}$ of $2 \mathrm{xYT}$ media. The tubes were then placed in a 
$37^{\circ} \mathrm{C} \mathrm{H}_{2} \mathrm{O}$ bath for 60 min., after which time $250 \mu \mathrm{l}$ of the transformation reaction was plated on the LB agar containing $100 \mu \mathrm{g} / \mathrm{ml}$ ampicillin. Colonies were selected and grown overnight in SOB media, $100 \mu \mathrm{g} / \mathrm{ml}$ ampicillin at $37^{\circ} \mathrm{C}, 200$ rpm. Bacteria was then made competent by the Inoue method (104) and used for subsequent transformation by either pACYC-recE/I-Scel or pACYC-exo/I-Scel (approximately $0.2 \mu \mathrm{g}$ of either plasmid) and supplemented with $500 \mu \mathrm{l}$ of $2 \mathrm{xYT}$ media containing $150 \mathrm{mM}$ arabinose. The tubes were then placed in a $37^{\circ} \mathrm{CH}_{2} \mathrm{O}$ bath for 60 min., after which time $250 \mu$ l of the transformation reaction was plated on the appropriate agar.

\section{Pre-high copy transformation: linear targeting cassette.}

Conditions are identical to those above, except approximately $0.3 \mu \mathrm{g}$ of linear targeting vector was included in the transformation.

\section{Pre-low copy transformation: integrated targeting cassette.}

$50 \mu \mathrm{l}$ of competent $E$. coli strains were co-transformed with pACYC-recE/I-Scel or pACYC-exo/I-Scel (approximately $0.2 \mu \mathrm{g}$ of either plasmid) by heat shock at $42^{\circ} \mathrm{C}$ for 90 sec. and supplemented with $500 \mu$ of $2 x Y T$ media. The tubes were then placed in a $37^{\circ} \mathrm{C} \mathrm{H}_{2} \mathrm{O}$ bath for 60 min., after which time $250 \mu \mathrm{l}$ of the transformation reaction was plated on the LB agar containing $15 \mu \mathrm{g} / \mathrm{ml}$ chloramphenicol. Colonies were selected and grown overnight in SOB media, 15 $\mu \mathrm{g} / \mathrm{ml}$ chloramphenicol at $37^{\circ} \mathrm{C}, 200 \mathrm{rpm}$. Bacteria was then made competent by the Inoue method and used for subsequent transformation by either pBS-t-recE or pBS-bet (approximately $0.2 \mu \mathrm{g}$ of either plasmid) and supplemented with $500 \mu \mathrm{l}$ 
of $2 x Y T$ media containing $150 \mathrm{mM}$ arabinose. The tubes were then placed in a $37^{\circ} \mathrm{C} \mathrm{H}_{2} \mathrm{O}$ bath for 60 min., after which time $250 \mu \mathrm{l}$ of the transformation reaction was plated on the appropriate agar.

\section{Pre-low copy transformation: linear targeting cassette.}

Conditions are identical to those above, except approximately $0.3 \mu \mathrm{g}$ of linear targeting vector was included in the transformation.

\section{Isolating the Gluconate Dehydrogenase Operon (GADH).}

$P$. aeruginosa PAO1 was first streaked on Luria-Bertani (LB) agar plates containing no antibiotics overnight at $37^{\circ} \mathrm{C}$. Round, normal colonies were selected and transferred to $3 \mathrm{ml}$ of SOB media and grown overnight at $37^{\circ} \mathrm{C}$ with shaking at $200 \mathrm{rpm} .1 \mathrm{ml}$ of this culture was then used to inoculate $20 \mathrm{ml}$ of identical media and grown to mid-log phase. Genomic DNA was then isolated using GenElute (Sigma) kits as described in the appendix and completely digested using $\mathrm{Kpn} \mathrm{I}$. The DNA was then separated on $1 \%$ TAE-agarose at $65 \mathrm{~V}$ for $2 \mathrm{~h}$ in order to resolve fragments in the $4-$ to $5 \mathrm{~kb}$ range. These fragments were then ligated into Kpn I/SAP-treated pBLUESCRIPT (Stratagene) and used to transform E. coli XL1-Blue MRF' (Stratagene). Bacteria were then plated on SOB agar containing $100 \mu \mathrm{g} / \mathrm{ml}$ ampicillin, plus $100 \mathrm{mM}$ sodium gluconate to induce enzyme activity and grown overnight at $37^{\circ} \mathrm{C}$. All colonies were screened in situ by soaking Whatmann paper with the GADH detection assay (see appendix). Positive colonies were subsequently transferred to $1 \mathrm{ml}$ LB media 
supplemented with $100 \mu \mathrm{g} / \mathrm{ml}$ ampicillin, plus $100 \mathrm{mM}$ sodium gluconate and grown overnight at $37^{\circ} \mathrm{C}$ with shaking at $200 \mathrm{rpm}$. The bacteria was then pelleted at $12,000 \times \mathrm{g}(1 \mathrm{~min}$ at room temperature), resuspended in warm 50 mM Tris- $\mathrm{HCl}, \mathrm{pH} 7.5$ containing $250 \mathrm{mM}$ sodium gluconate. The bacteria was then re-pelleted and resuspended in assay solution. After the addition of substrate (gluconate), positives were selected through the observation of rapid color change. Positives were streaked onto SOB agar containing $100 \mu \mathrm{g} / \mathrm{ml}$ ampicillin and grown overnight at $37^{\circ} \mathrm{C}$. Colonies were then transferred to liquid media and grown overnight. Plasmid DNA was isolated using either procedure listed on the appendix and digested with $K p n I$ and SAP. The DNA was then separated on $1 \%$ TAE-agarose at $65 \mathrm{~V}$ for $2.5 \mathrm{~h}$ in order to resolve fragments in the 5 - to $6 \mathrm{~kb}$ range. DNA in the $4.5-5.0 \mathrm{~kb}$ range was extracted and treated with Apa I. Electrophoresis was repeated in order to resolve and extract the 2.0 and 2.7 kb DNA bands. These were combined, ligated to each other, cleaned and ligated to Kpn I-treated pBLUESCRIPT. Repeat transformation, plasmid isolation, Kpn I digest and electrophoresis. The $4.7 \mathrm{~kb}$ band contains the gluconate dehydrogenase operon. Label as pBS-GADH.

\section{Isolating the pyrroloquinoline quinone operon (PQQ).}

Klebsiella pneumoniae was first streaked on Luria-Bertani (LB) agar plates containing no antibiotics overnight at $37^{\circ} \mathrm{C}$. Round, normal colonies were selected and transferred to $3 \mathrm{ml}$ of SOB media and grown overnight at $37^{\circ} \mathrm{C}$ with shaking at $200 \mathrm{rpm} .1 \mathrm{ml}$ of this culture was then used to inoculate $20 \mathrm{ml}$ of identical media and grown to mid-log phase. Genomic DNA was then isolated 
using GenElute (Sigma) kits as described in the appendix and completely digested with Kpn I/Xba I. The DNA was then separated on 1\% TAE-agarose at $65 \mathrm{~V}$ for $2 \mathrm{~h}$ in order to resolve fragments in the 8 - to $9 \mathrm{~kb}$ range. These fragments were then ligated into Kpn I/Xba I, SAP-treated pBLUESCRIPT (Stratagene) and used to transform E. coli XL1-Blue MRF' (Stratagene). Bacteria were then plated on S-Gal agar containing $100 \mu \mathrm{g} / \mathrm{ml}$ ampicillin and grown overnight at $37^{\circ} \mathrm{C}$. Transfer all white colonies to $2 \mathrm{ml} \mathrm{SOB}$ media containing 100 $\mu \mathrm{g} / \mathrm{ml}$ ampicillin, IPTG/X-gal. Grow to mid-log phase and isolate plasmid DNA from all positive tubes. Transform E. coli JM1109 (pts) and plate on M9 agar supplemented with glucose. Incubate $48 \mathrm{~h}$ at $37^{\circ} \mathrm{C}$. All colonies present should contain the $p q q$ operon. Isolate plasmid DNA and partially Bam $\mathrm{HI}$ digest, followed by electrophoresis. Isolate the $6.9 \mathrm{~kb}$ fragment and ligate to $\mathrm{Bam} \mathrm{HI}$, SAP-treated pACYC 184. Amplify, isolate and completely digest with Bam $\mathrm{HI}$. The presence of three bands (4.70-, 4.25- and 2.2-kb) confirms the presence of the $p q q$ operon. Label as $p A C Y C-P Q Q$.

\section{Conversion of glucose to 2-ketogluconate in E. coli.}

The following methodology is based on the pre-established facts that $E$. coli cannot convert glucose into gluconate and the isolated DNA fragment containing the GADH operon is not expressed in the absence of gluconate.

E. coli XL1-Blue MRF' (Stratagene) was co-transformed with pBS-GADH and pACYC-PQQ. Bacteria was then plated on LB-agar containing $100 \mu \mathrm{g} / \mathrm{ml}$ ampicillin and $15 \mu \mathrm{g} / \mathrm{ml}$ chloramphenicol to confirm the presence of both plasmids. Colonies were transferred to $1 \mathrm{ml}$ LB media containing $100 \mu \mathrm{g} / \mathrm{ml}$ 
ampicillin and $15 \mu \mathrm{g} / \mathrm{ml}$ chloramphenicol and supplemented with $100 \mathrm{mM}$ gluconate and grown to mid-log phase and pelleted at $12,000 \times \mathrm{g}$ (1 min at room temperature). Pellets were resuspended in $37^{\circ} \mathrm{C} 50 \mathrm{mM}$ Tris- $\mathrm{HCl}, \mathrm{pH} 7.5$ containing $50 \mathrm{mM}$ glucose, re-pelleted and resuspended in assay solution. After the addition of substrate (glucose), positives were selected through the observation of rapid color change. Positives were streaked onto LB agar, 100 $\mathrm{mM}$ gluconate, containing $100 \mu \mathrm{g} / \mathrm{ml}$ ampicillin and $15 \mu \mathrm{g} / \mathrm{ml}$ chloramphenicol and grown overnight at $37^{\circ} \mathrm{C}$. Colonies were then transferred to $2 \mathrm{ml} \mathrm{M9}$ liquid media containing $150 \mathrm{mM}$ glucose and grown to mid-log phase, pelleted at $12,000 \times \mathrm{g}$ (1 min at room temperature) and resuspended in $2 \mathrm{ml} 37^{\circ} \mathrm{C} 50 \mathrm{mM}$ Tris- $\mathrm{HCl}, \mathrm{pH}$ 7.5 containing $50 \mathrm{mM}$ glucose. Each tube was then divided into $1 \mathrm{ml}$ aliquots and placed into separate tubes The bacteria was then re-pelleted and resuspended in assay solution. After the addition of substrate (glucose to one tube and gluconate to the other), positives were selected through the observation of rapid color change. If both tubes give a rapid color change then both pBSGADH and $\mathrm{pACYC}-\mathrm{PQQ}$ are present and functioning correctly.

The reasoning behind doing the final assay to bacteria grown on minimal media plus glucose is that the gadh operon is expressed only in the presence of gluconate. Since there is no gluconate in the media it has to be produced through the action of glucose dehydrogenase $(\mathrm{GDH})$ which is only active in the presence of the co-factor PQQ. The effect of an active GDH on the assay was not investigated. Therefore, a lone GADH assay using glucose as the substrate may, in part, reflect the conversion of glucose to gluconate. Performing the 
second GADH assay with gluconate as the substrate eliminates any possible ambiguity since the presence of GADH in the cell is dependent solely upon an active GDH. 


\section{Results}

The results are broken into four categories:

- Preliminary evidence of RecET activity

- Plasmid construction and DNA evidence

a Biochemical assays

a Targeting efficiencies

Recombination efficiencies of $E$. coli strains using only linear dsDNA are listed in Table 1. Each strain was transformed with $0.3 \mu \mathrm{g}$ of DNA and plated on LB agar containing $50 \mu \mathrm{g} / \mathrm{ml}$ ampicillin. It is clear to see that are only two instances of recombination. What these strains share are an $s b c A$ mutation, a non-functional RecBCD complex and functional RecE and RecT proteins.

\begin{tabular}{|c|c|c|c|c|}
\hline . & Strain & Genotype $^{*}$ & Colonies & Efficiency $\left(A m p^{R}\right)$ \\
\hline 1. & BL21(DE3) & & 0 & 0 \\
\hline 2. & JM1109 & ** & 0 & 0 \\
\hline 3. & JC9366 & recA & 0 & 0 \\
\hline 4. & JC5519 & $r e c B C$ & 0 & 0 \\
\hline 5. & JC5547 & $r e c A, r e c B C$ & 0 & 0 \\
\hline 6. & JC8691 & $\operatorname{rec} B C, s b c A, r e c E$ & 0 & 0 \\
\hline 7. & JC8672 & $r e c A, r e c B, s b c A$ & 64 & $2.13 \times 10^{7}$ \\
\hline 8. & JC8679 & $r e c B C, s b c A$ & 212 & $7.07 \times 10^{7}$ \\
\hline 9. & JC9387 & $r e c B C, s b c B C$ & 0 & 0 \\
\hline 10. & JC15329 & $r e c A, r e c B C, s b c B C$ & 0 & 0 \\
\hline 11. & $\mathrm{JC} 8111$ & $r e c B C, s b c B C, r e c F$ & 0 & 0 \\
\hline 12. & JM109 (DE3) & recA & 0 & 0 \\
\hline 13. & $X L 1-$ Blue MRF' & $\operatorname{rec} A$ & 0 & 0 \\
\hline 14. & JC13031 & recJ & 0 & 0 \\
\hline
\end{tabular}

A goal of this work is to temporarily transfer this expression profile to any strain of E. coli in order to achieve targeted recombination. Upon first thought, it could be 
reasoned that using strains JC8672 and JC8679 would be a logical choice for doing this type of work as opposed to constructing the vectors. To an extent, this is true, but being $\operatorname{RecBCD}$ deficient does not lend to a stable genotype, not to mention the lack of benefits reaped by using many of the more common cloning and expression strains.

The DNA evidence presented within the results section consists of electrophoresis data for both tandem recombination vector design (Figures 2-5) and the PCR-based detection of inserted DNA sequences (Figure 7). The construction of each vector is illustrated in a stepwise fashion, from plasmid backbone to completed vector.

When constructing the vectors the genes were ordered in such a way that the annealing protein and targeting cassette were always on the high copy plasmid, and the exonuclease and intron-homing endonuclease were always placed on the low copy plasmid. The primary reasoning behind this assembly is to differ the levels of expression; the genes on the high copy plasmid need to be present in higher levels, relative to those of the low copy plasmid. A secondary reason is that the combined size of both plasmids lends to instability. The GADH operon is used as the example insert in the targeting cassette for both vector systems. Vector maps (Figures 4A-7A) and electrophoresis gels (Figures 4B-7B) are provided for each. The gels show the stepwise addition of DNA elements to complete construction of each, from plasmid backbone to finished product. 


\section{Targeting Plasmid Tandems}

\section{5. pACYC-exo/I-Scel}

A.
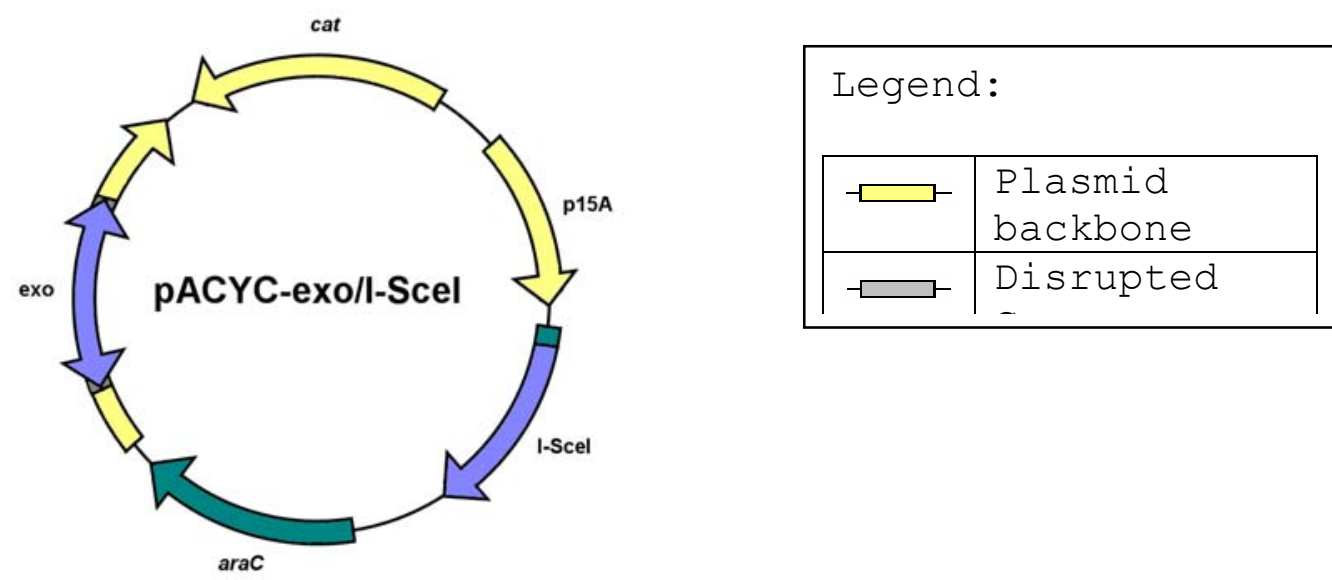

Figure 5A. The low-copy pACYC-exo/l-Scel vector. Original sequences are denoted with yellow. The exo gene was inserted through a single restriction site and therefore cannot be given a defined orientation on the plasmid. Expression of the I-Scel gene is driven by the arabinose inducible $P_{B A D}$ promoter and repressed by expression of the araC gene.

B.

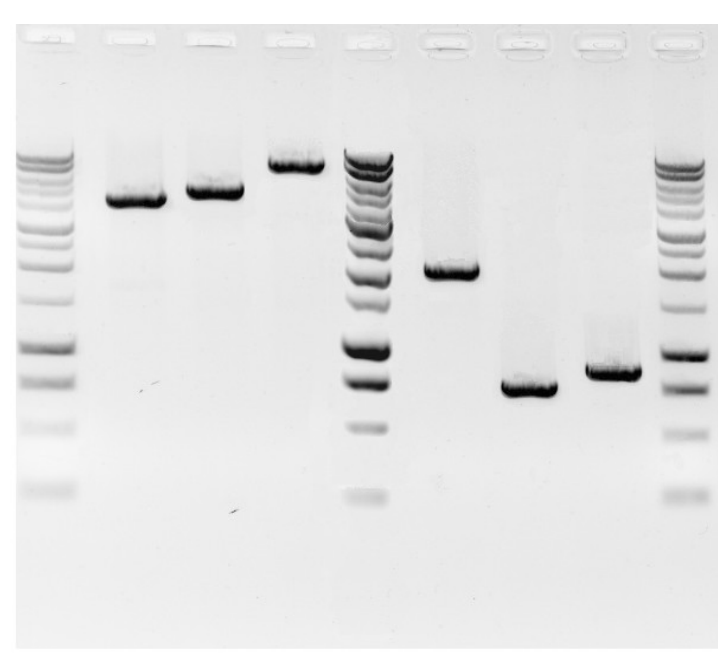

Lanes

Sizes

1. $1 \mathrm{~kb}$ Ladder

2. pACYC 184

3. $\mathrm{pACYC}+$ exo

5.04

4. $\mathrm{pACYC}+\mathrm{P}_{\mathrm{BAD}} /-$ Scel+araC

5. $1 \mathrm{~kb}$ Ladder

6. $\mathrm{P}_{\mathrm{BAD}} /-\mathrm{Scel}+\mathrm{araC}$

7. exo

0.68

8. I-Scel

0.70

9. $1 \mathrm{~kb}$ Ladder

Figure 5B. Agarose gel displaying the construction of pACYC-exo/l-Scel vector. The bands represented in lanes 2-4 represent the plasmid backbone, as well as the two subsequent additions, the exo gene and the $\mathrm{P}_{\mathrm{BAD}} /-S c e /+a r a C$ DNA fragment which was assembled prior to insertion on the pBAD22 plasmid. Lanes 6-8 represent the individual fragments of DNA which were used to assemble the plasmid. 


\section{Targeting Plasmid Tandems, continued.}

\section{6. pBS-bet/gam with and without the gadh operon}

A.

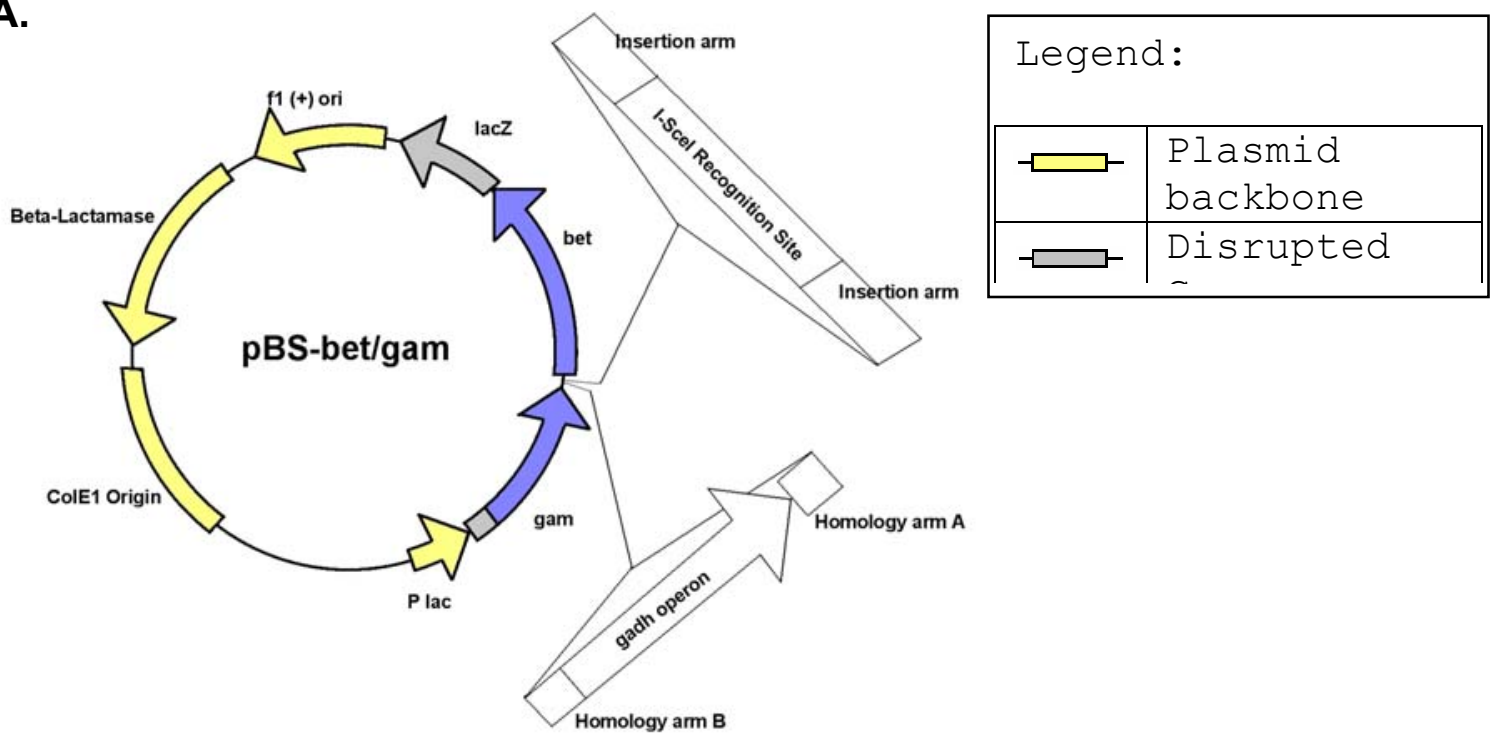

Figure 6A. The high-copy pBS-bet/gam vector. Original sequences are denoted with yellow. All ligations are made to the Multi-Cloning Site within the lacZ gene fragment. Not shown on the diagram are I-Scel recognition sites located at either end of the exo gene for the purpose of linearizing the plasmid for exonuclease degradation.

B.

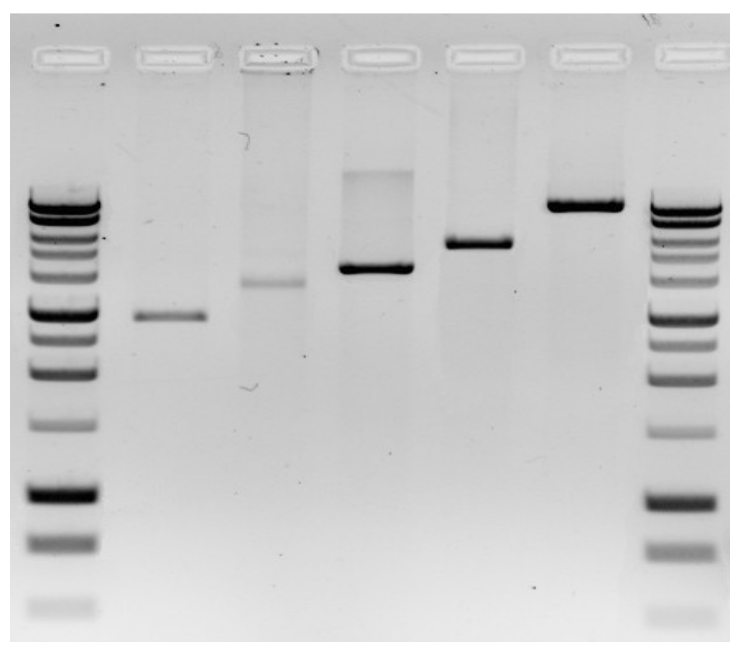

\begin{tabular}{llr}
\multicolumn{2}{l}{ Lanes } & Sizes \\
\hline 1. $1 \mathrm{~kb}$ Ladder & \\
2. pBluescript & 2.96 \\
3. pBS + bet & 3.48 \\
4. pBS + bet + gam & 5.45 \\
5. gadh operon & 5.40 \\
6. & pBS + bet + gam + & 10.85 \\
& gadh
\end{tabular}

7. $1 \mathrm{~kb}$ Ladder

Figure 6B. Stepwise construction of the pBS-bet/gam vector. Although all gene and operons were individually substituted into the targeting cassette, only the gadh operon is displayed as an example. Band sizes are given in kilobases to the right of the gel. 


\section{Targeting Plasmid Tandems, continued}

\section{7. pACYC-t-recE/I-Scel}

A.

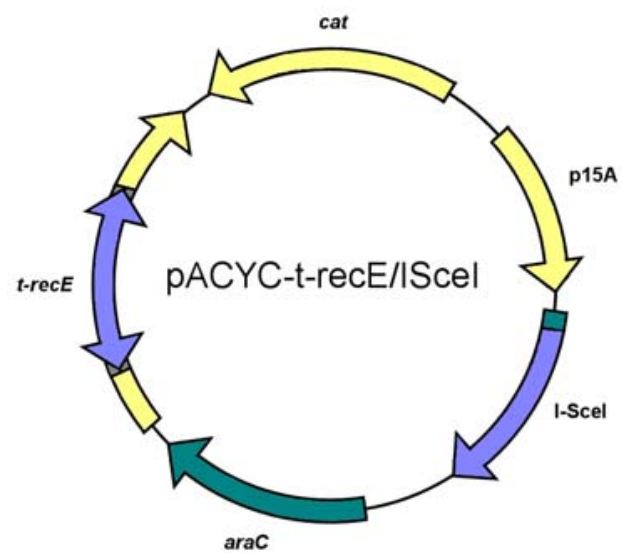

\begin{tabular}{|l|l|}
\hline Legend: \\
\begin{tabular}{|l|l|}
\hline$\square$ & $\begin{array}{l}\text { Plasmid } \\
\text { backbone }\end{array}$ \\
\hline$\square$ & Gene \\
\hline
\end{tabular}
\end{tabular}

Figure 7A. The low-copy pACYC-exo/l-Scel vector. Original sequences are denoted with yellow. The truncated $r e c E$ gene was inserted through a single restriction site and therefore cannot be given a defined orientation on the plasmid. Expression of the I-Scel gene is driven by the arabinose inducible $P_{B A D}$ promoter and repressed by expression of the araC gene.

B.

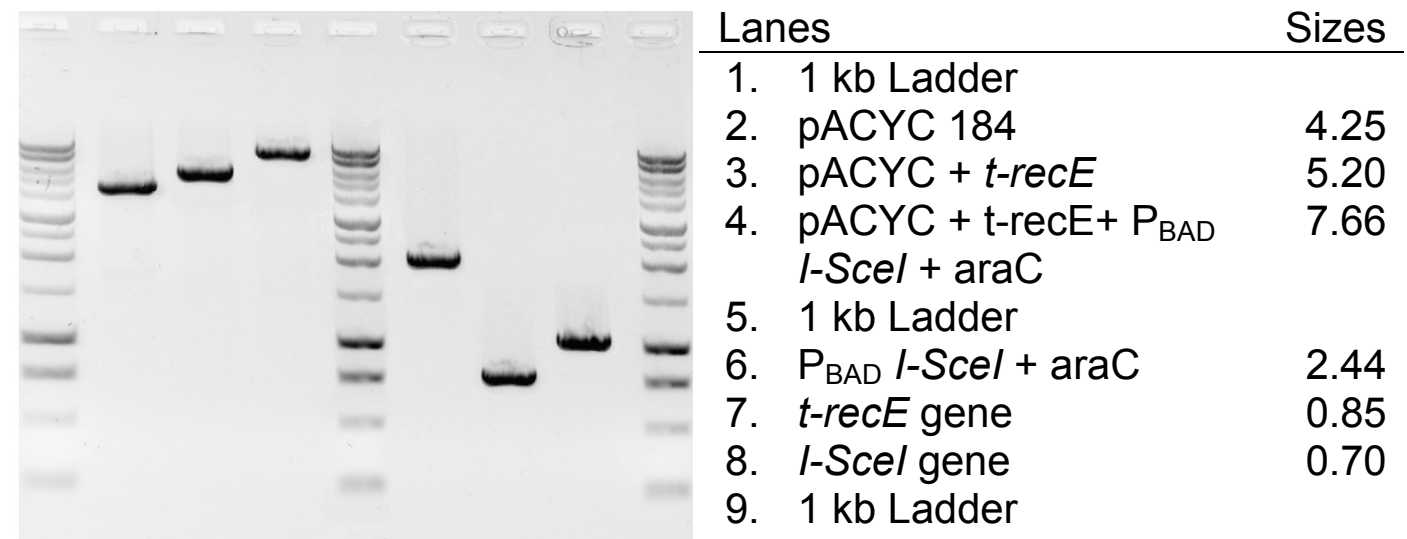

Figure 7B. Agarose gel displaying the construction of pACYC-exo/l-Scel vector. The bands represented in lanes 2-4 represent the plasmid backbone, as well as the two subsequent additions, the exo gene and the $\mathrm{P}_{\mathrm{BAD}} /-\mathrm{Sce} /+$ araC DNA fragment which was assembled prior to insertion on the pBAD22 plasmid. Lanes 6-8 represent the individual fragments of DNA which were used to assemble the plasmid. 


\section{Targeting Plasmids, continued}

\section{8. pBS-recT/gam with and without the gadh operon}

A.

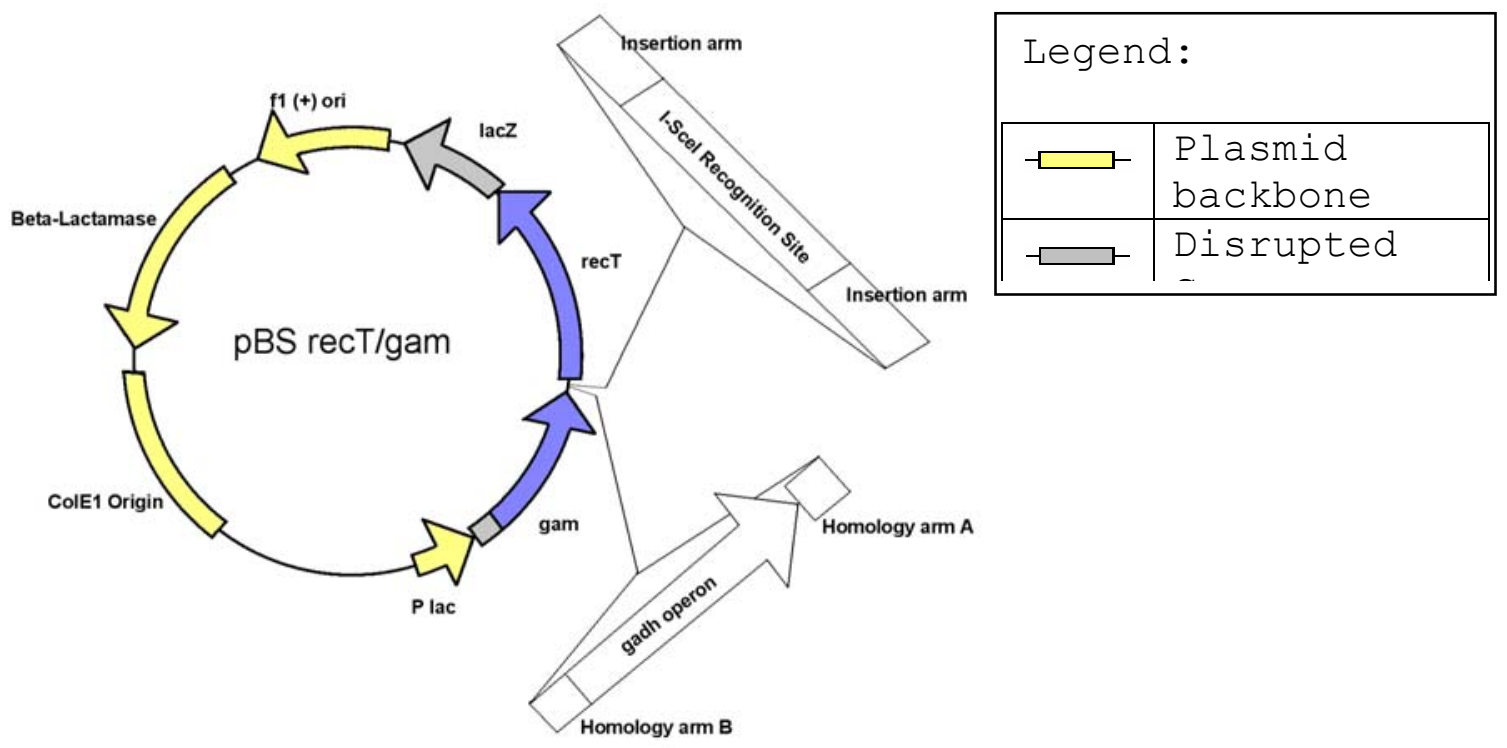

Figure 8A. The high-copy $\mathrm{pBS}$-recT/gam vector. Original sequences are denoted with yellow. All ligations are made to the Multi-Cloning Site within the lacZ gene fragment. Not shown on the diagram are I-Scel recognition sites located at either end of the exo gene for the purpose of linearizing the plasmid for exonuclease degradation.

B.

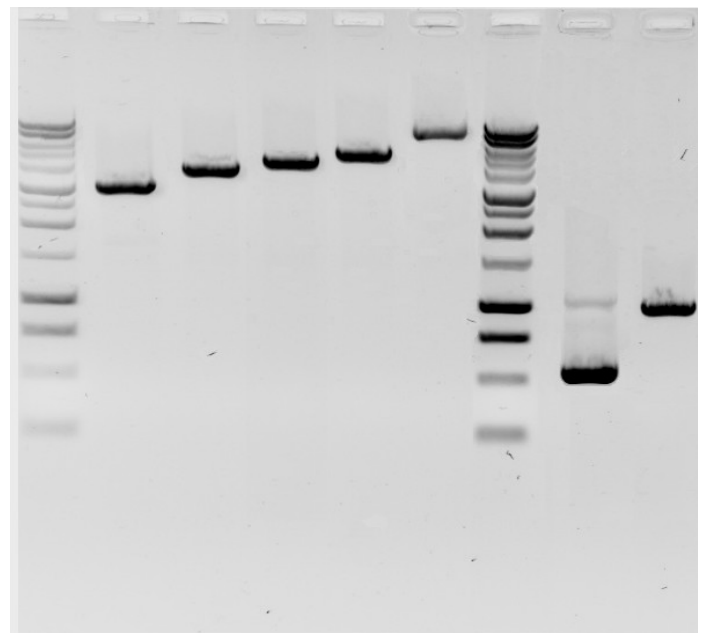

\begin{tabular}{|c|c|c|}
\hline \multirow{2}{*}{\multicolumn{3}{|c|}{ Lanes }} \\
\hline & & \\
\hline 2. & pBluescript & 2.96 \\
\hline 3. & $\mathrm{pBS}+\mathrm{rec} T$ & 3.86 \\
\hline 4. & $\mathrm{pBS}+\operatorname{rec} T+g a m$ & 4.38 \\
\hline 5. & gadh operon & 5.40 \\
\hline 6. & $\begin{array}{l}\text { pBS }+ \text { recT }+ \text { gam }+ \\
\text { gadh }\end{array}$ & 9.78 \\
\hline 7. & $1 \mathrm{~kb}$ Ladder & \\
\hline 8. & gam & 0.52 \\
\hline & rect & 0.87 \\
\hline
\end{tabular}

Figure 8B. Stepwise construction of the pBS-recT/gam vector. Although all gene and operons were individually substituted into the targeting cassette, only the gadh operon is displayed as an example. 


\section{Detecting Recombination}

The vectors used in figures $2-5$ were used in tandem to induce targeted recombination in E. coli. As stated previously, orthologous pairs need to be present in the bacterium in order for recombination to occur, so all possible combinations of Rec and Red genes were not attempted. After induction of $I$ Scel and plating, colonies were subsequently screened for the detection of recombination with the $E$. coli chromosome using PCR. To do this, all primers were selected using the following rationale: the forward primer is always specific to the sequence immediately $5^{\prime}$ to the upstream homology arm and the reverse primer is always specific to the gene(s) that are being recombined with the chromosome (Figure 6).
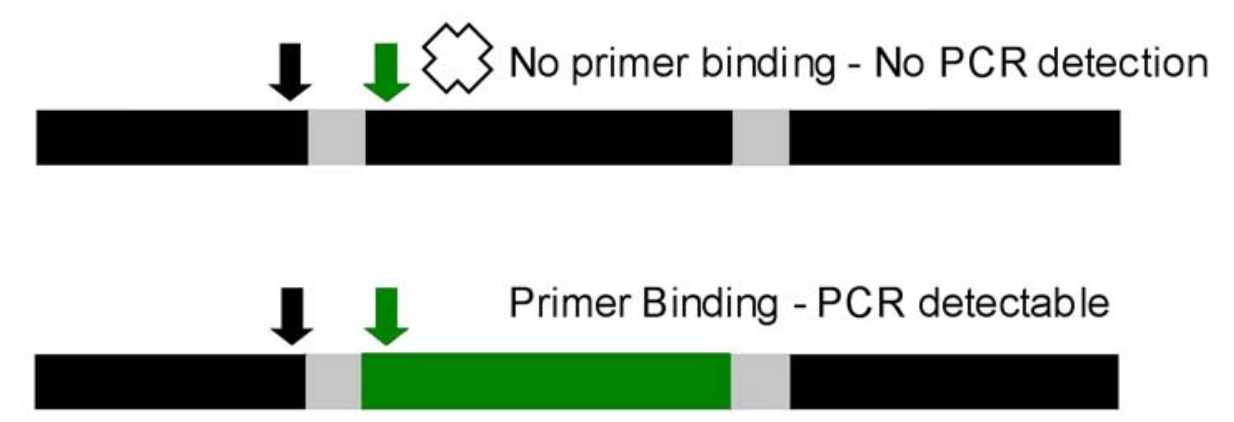

Homology sites Chromosomal DNA Inserted Sequence Forward Primer Reverse Primer

Figure 9. Detecting Recombination. The forward primer is specific to an area of the chromosome that is unchanged by recombination, while the reverse primer is specific to the insert DNA sequence. Without proper recombination, PCR amplification would not produce a detectable DNA fragment of known length. 
By selecting primers in this manner it is assured that differentiation between recombinants and non-recombinants is achieved simply due to the fact that amplification will not occur if the reverse primer cannot bind to the chromosome. Referring to figures 7B-D, the position of the reverse primers are better visualized. Since the sequences of both the chromosomal region and insertion sequence are known the size of the amplification product can also be used as a further measure of assurance that the recombination event occurred in the proper location (Figure 7A).

Figure 10. PCR-Detected Inserts

A.

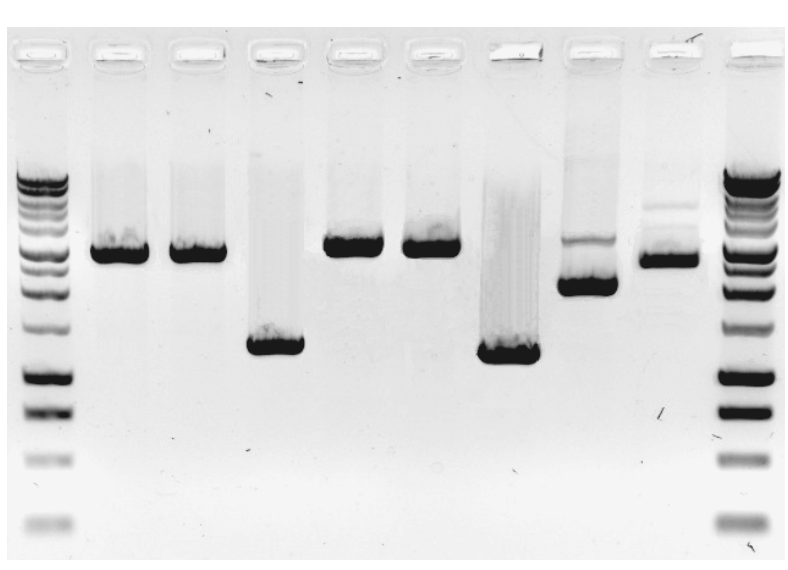

\begin{tabular}{clc}
\multicolumn{2}{l}{ Lane } & Sizes \\
\hline 1. $1 \mathrm{~kb}$ Ladder & \\
2. Kanamycin & 2.79 \\
3. Ampicillin & 2.80 \\
4. & Conserved Prot. & 1.26 \\
5. Gadh) & 3.05 \\
6. Cyconate DH & c precursor & 3.17 \\
7. pqqB & 1.13 \\
8. pqqC & 2.05 \\
9. pqqD & 2.77 \\
10. $1 \mathrm{~kb}$ Ladder &
\end{tabular}

Figure 10A. PCR-detection of DNA fragments inserted into the E. coli genome using targeted recombination. The forward primer for each band was specific to the E. coli chromosomal sequence immediately 5' of the targeted site and the reverse primer specific to the particular gene(s) inserted into the chromosome. This selection scheme ensures only amplification of genes that have been inserted into the chromosome at proper locations on the chromosome. 

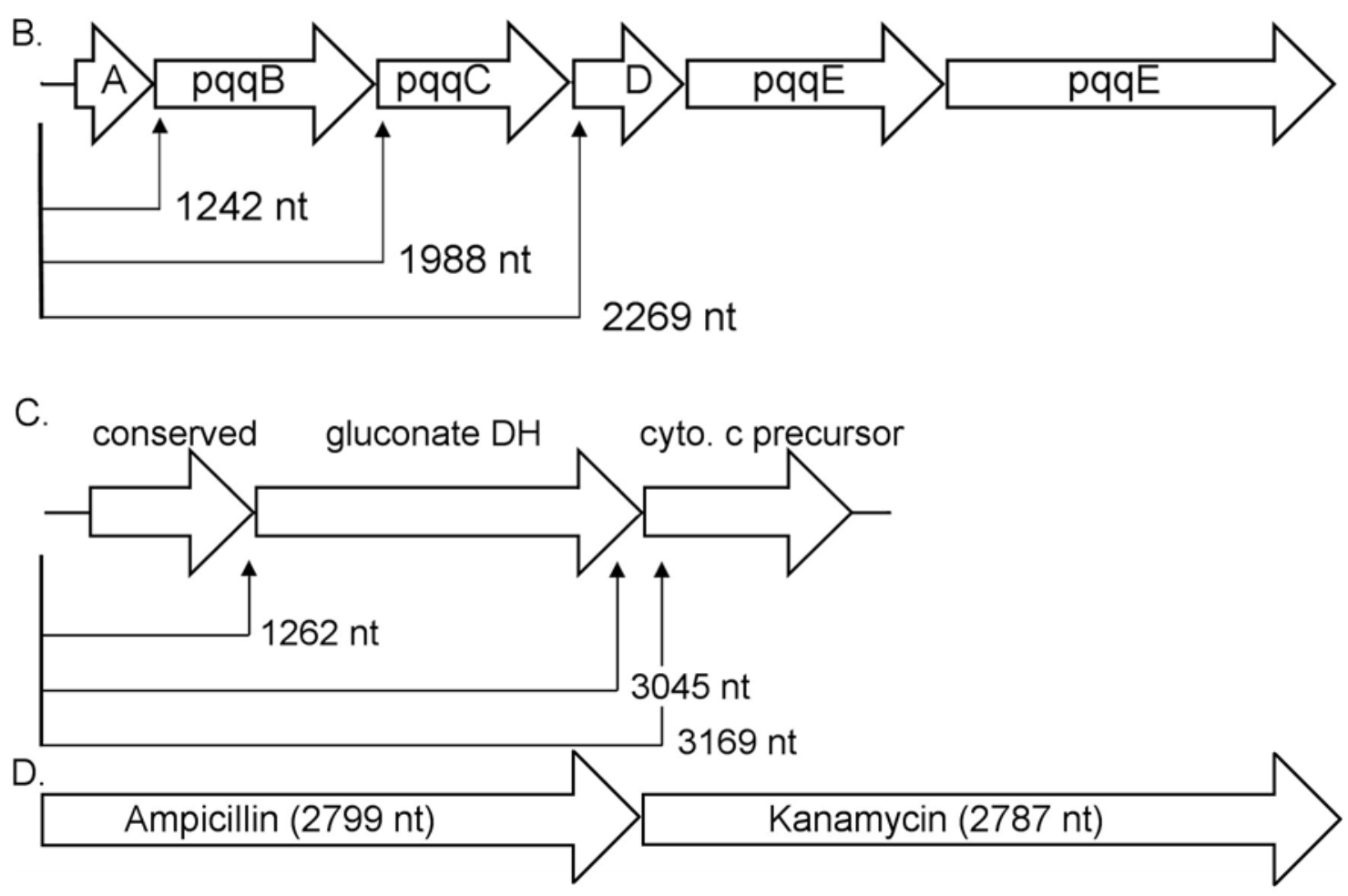

Figure 10B-D. Schematic outlay of PCR-Based Detection Assay. Genes were detected using a forward primer specific to an unmodified portion of the $E$. coli chromosome immediately upstream of the insertion site and reverse primers specific to the particular which were inserted. Each reaction therefore produces a band of pre-determined length (indicated for each gene in the figure above), provided a targeted recombination event occurred. The results of these PCRdetection assays are displayed in Figure 7A.

Biochemical detection was achieved solely through colorimetric detection of the production of 2-ketogluconate. In Table 3 each of the bacterial strains used for recombination were tested for gluconate dehydrogenase activity and compared to levels achieved by $P$. aeruginosa, the source of the gluconate dehydrogenase operon, using dichlorophenol-indolphenol and phenazine methosulfate as an electron acceptor/carrier. As expected, only the bacteria carrying the integrated genes yielded a significant level of absorbance at the indicated wavelength. Background color change is expected since dichlorophenol-indolphenol and 
phenazine methosulfate are not electron acceptors specific to gluconate dehydrogenase. Overcoming this background level is easily achieved through the addition of substrate to the assay solution at levels that saturate the available active sites. Absorption at $600 \mathrm{~nm}$ is then converted into units of gluconate dehydrogenase activity by dividing by 3.3 as described by Matsushita (66).

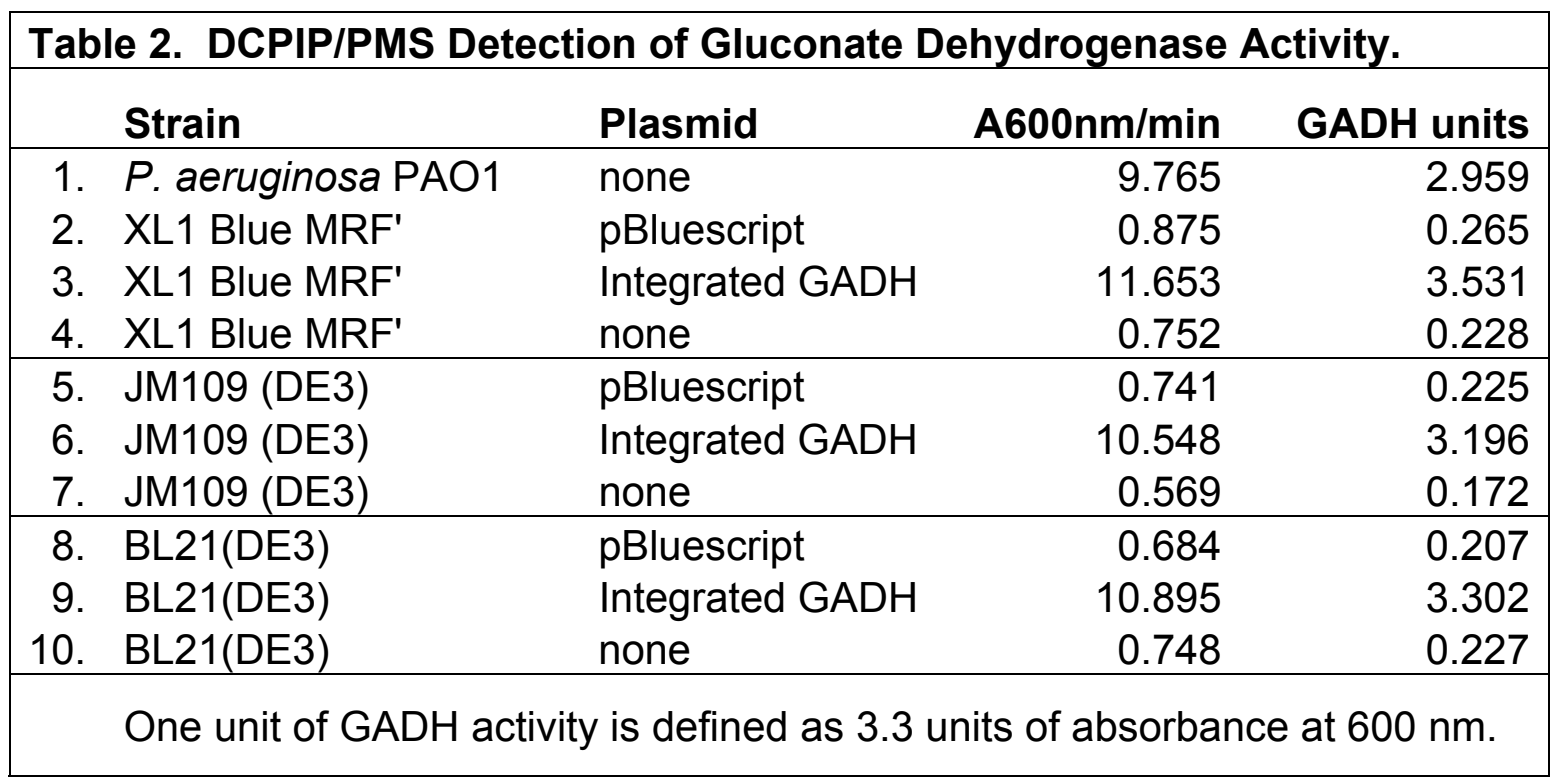

Detection of pqq expression was done indirectly using the same strains of bacteria (Table 3). The difference here is that glucose was used as the substrate instead of sodium gluconate. Since pqq is a required cofactor for the normally inactive glucose dehydrogenase in E. coli, its presence should result in the conversion of glucose to gluconate, the substrate of GADH. This will, in turn, be metabolized by gluconate dehydrogenase and a color change will result. 


\section{Table 3. GADH Activity in E. coli containing both pqq and gadh Operons and grown on M9 minimal media, plus glucose.}

\begin{tabular}{|c|c|c|c|c|}
\hline & Strain & Plasmid & A600 $\mathrm{nm} / \mathrm{min}$ & GADH units \\
\hline 1. & XL1 Blue MRF' & pBluescript & 0.721 & 0.218 \\
\hline 2. & XL1 Blue MRF' & pBS-GADH & 1.175 & 0.356 \\
\hline 3. & XL1 Blue MRF' & PACYC-PQQ & 0.569 & 0.172 \\
\hline 4. & XL1 Blue MRF' & $\mathrm{pPQQ}+\mathrm{pGADH}$ & 9.823 & 2.977 \\
\hline 5. & XL1 Blue MRF' & none & 0.763 & 0.231 \\
\hline 6. & JM109 (DE3) & pBluescript & 0.636 & 0.193 \\
\hline 7. & JM109 (DE3) & pBS-GADH & 1.022 & 0.310 \\
\hline 8. & JM109 (DE3) & PACYC-PQQ & 0.649 & 0.197 \\
\hline 9. & JM109 (DE3) & $\mathrm{pPQQ}+\mathrm{pGADH}$ & 7.984 & 2.419 \\
\hline 10. & JM109 (DE3) & none & 0.633 & 0.192 \\
\hline & BL21(DE3) & pBluescript & 0.599 & 0.182 \\
\hline & BL21(DE3) & pBS-GADH & 0.974 & 0.295 \\
\hline 13. & BL21(DE3) & pACYC-PQQ & 0.521 & 0.158 \\
\hline 14. & BL21(DE3) & $p P Q Q+p G A D H$ & 8.596 & 2.605 \\
\hline 15. & BL21(DE3) & none & 0.670 & 0.203 \\
\hline
\end{tabular}

To demonstrate the usability of this system, experiments were performed using four distinct DNAs for recombination (two antibiotic resistance genes and two operons). Recombination was carried out in three separate strains of $E$. coli, whereby each of the four DNAs used for insertion were located to three separate locations on the chromosome. Various expression strategies were employed with either the RecET or Reda $\beta$ recombination proteins. The table below (Table 4) represents the average recombination and transformation efficiencies for each gene at each targeted location in each strain of $E$. coli. Recombination and transformation values for each insert/target/strain combination tested are listed individually in Appendix. 


\begin{tabular}{|c|c|c|c|c|c|c|c|c|c|c|c|c|c|}
\hline & & \multicolumn{12}{|c|}{ Reaction Conditions } \\
\hline & & \multicolumn{4}{|c|}{$A$} & \multicolumn{4}{|c|}{$B$} & \multicolumn{4}{|c|}{ C } \\
\hline & & & 1 & & 2 & & 3 & 2 & 4 & & 5 & 6 & \\
\hline \multirow[b]{2}{*}{ Gene } & & $E T$ & $\alpha \beta$ & $E T$ & $\alpha \beta$ & $E T$ & $\alpha \beta$ & $E T$ & $\alpha \beta$ & $E T$ & $\alpha \beta$ & $E T$ & $\alpha \beta$ \\
\hline & Transform & 3.65 & 5.31 & 5.27 & 5.64 & 2.57 & 3.42 & 5.96 & 5.64 & 0.27 & 0.44 & 6.01 & 5.76 \\
\hline & $\operatorname{Rec}$ & 98 & 98 & 64 & 73 & 99 & 99 & 46 & 53 & 98 & 99 & 9 & 12 \\
\hline \multirow{3}{*}{ Operon } & Transform & 3.76 & 5.02 & 6.07 & 5.76 & 2.86 & 3.80 & 5.65 & 5.40 & 0.27 & 0.44 & 5.79 & 5.71 \\
\hline & $\operatorname{Rec}$ & 99 & 100 & 35 & 48 & 99 & 99 & 36 & 47 & 100 & 99 & 12 & 17 \\
\hline & & & & & & & & & \multicolumn{5}{|c|}{ Transform. in $10^{\prime}$, Rec. in \% } \\
\hline
\end{tabular}

\section{Interpreting Table 4.}

Table 4 represents the condensation of twelve identical tables that list the values of each recombination event by either system (ET or $\alpha \beta$ ) into each of three targets on the E. coli chromosome in three different stains of the bacteria. Here, transformation and recombination values are divided between gene insertions and operon insertions by three tiers: order of expression of the recombinatory genes, type of targeting cassette employed (circular or pre-linearized) and means of recombination $(E T$ or $a \beta)$.

Recombination events falling under heading $A$ represent the normal means by which targeted recombination should occur. The bacteria is co-transformed with both plasmids, with or without an integrated targeting cassette. in cases where a pre-linearized cassette is required, a second round of transformation was 
performed. Events falling under heading B represent the cases where the high copy plasmid, carrying the annealing protein and gam gene, is first used to transform the bacteria, followed by a second round of transformation using the low copy plasmid and, when applicable, the linearized targeting cassette. Recombination events falling under heading $C$ represent the cases where the transformation order is opposite; the low copy plasmid, carrying the exonuclease and intron-homing endonuclease, is used to first transform the bacteria, followed by a second round of transformation using the high copy vector and, when applicable, the linearized targeting cassette.

Subheadings 1-6 represent the use of either plasmids that do not contain a targeting cassette, but instead use a pre-linearized one, or plasmids that have the targeting cassette integrated into the high copy plasmid. All of the values that fall under the odd-numbered subheadings use pre-linearized targeting cassettes, while the even-numbered ones must rely upon excision via I-Scel to generate double-stranded termini. ET and $\alpha \beta$ simply state which binary vector system was used, the RecET plasmids or the Reda $\beta$ plasmids. Therefore the recombination efficiencies falling under "A. 1. ET" represent all experiments where E. coli was co-transformed with the recE- and recT- containing plasmids, plus a prelinearized targeting cassette. "B. 4. $\alpha \beta$ " represents all experiments where E. coli was first transformed with the bet-containing plasmid with an integrated targeting cassette, followed by a second round of transformation using the exo-containing plasmid. 


\section{Interpreting Recombination and Transformation efficiencies}

It should be noted that recombination efficiency values are based on phenotypic expression of the genes/operons that were used in the targeting cassettes and that this tends to elevate the efficiency with which recombination occurs. Direct screening for the phenotype, especially in the case of gene insertions (kanamycin- and ampicillin-resistance) immediately eliminates any bacteria which did not receive all DNAs required to induce recombination, or did not undergo recombination at all. For this reason, all odd-numbered experiments (where a pre-linearized targeting cassette was used) have recombination efficiencies at or near the $100 \%$ level. All colonies must have the resistance gene inserted into their genomes in order to maintain a sustained level of expression. While this may not provide an accurate measure with which recombination occurs, it does have merit when considering the accuracy with which recombination occurs. Since PCR primers detect only recombination events that occur in the proper location, and all colonies tested showed a positive result, it can be inferred that this system works with high precision. This is not the case when operon insertion is considered since survivability is not contingent upon phenotypic expression. In these cases, colonies to be tested for recombination were screened for activity prior to determining the efficiency of recombination. Measuring efficiency without screening would certainly decrease this value, but this would raise questions as to which factor causes this to occur; the absence of recombination or incomplete transformation, since recombination cannot occur unless all DNAs are present. When comparing transformation efficiencies of pre-linearized targeting cassettes to that of the integrated cassettes it is clear to see that there is a significant 
increase in transformations, suggesting that incomplete transformation is indeed occurring in cases where an integrated targeting cassette is employed. Here, recombination need not occur in order to pass phenotypic screening. This also offers an explanation for the observation that in cases where integrated cassettes are employed there is a reduction in the efficiency of recombination. If the low copy vector is not present then recombination will not occur, yet the phenotype will be expressed in a sustained fashion since the gene(s) responsible are on the high copy plasmid.

When considering the overall usability of the system developed, focus needs to be given to the even-numbered conditions $(2,4$ and 6$)$ since these are the cases where the targeting cassette is integrated into one of the vectors, namely the high copy vector. Condition 2 falls under heading " $A$ " and is therefore the ideal condition for real world application since the bacteria is transformed with all DNA required to achieve targeted recombination in one step. Average, correct gene insertion occurred in the range of $64-$ to $73 \%$ of all colonies tested under these conditions and can be considered to be a success since it minimizes the total number of colonies required for PCR screening in order to obtain a correct insertion. Operon insertion seems to occur at a lower frequency, with an observed success range of 35 - to $48 \%$. Initially, it was thought that the reduction in success may be due, in part, in a deficiency in the pre-screening process. Assaying for GADH expression directly on the agar plate is a finesse procedure which gave mixed results when initially isolating the operon from $P$. aeruginosa, and this could perhaps explain the drop in efficiency were it not for the data 
obtained by using pre-linearized targeting cassettes under identical conditions. Here, recombination is still occurring at near $100 \%$ levels, indicating that the screening process used to select colonies for PCR verification is indeed functioning properly. Again, this does not mean that recombination has occurred in $100 \%$ of the colonies on these plates, but rather in $100 \%$ of the colonies that indicated a positive result during the pre-screening. Attributing a cause to this reduction is purely speculative, but the effect of insert size and the relative expression levels of the exonuclease and annealing proteins are two factors that come to mind. Nevertheless, PCR screening of ten colonies gives three to five positives.

Condition 4 falls under heading "B" and therefore is carried out over two rounds of transformation. Here, the high copy vector is first used to transform strains of E.coli which can then be selected for using ampicillin. These bacteria are then made to be chemically competent and are subsequently transformed with the low copy vector. I-Scel is induced immediately after transformation and the bacteria is plated, pre-screened with either the proper antibiotic or DCIP/PMS and finally selected for PCR detection of targeted recombination. Results for gene insertion are little lower than that of condition "A-2", but it is reasonable to foresee the percentage of positives approaching equality with an increase in the number of replications performed. Operon insertions were essentially the same under these conditions as they were under condition "A", further underlining the possible effect of insert size and expression ratios. 
When initially considering the recombination system, condition $C$ is the most attractive condition whereby this system may be employed. Here the low copy vector is first used to transform the bacteria. Unlike the high copy plasmid, this plasmid receives no further modification when targeting cassettes are changed. Given the rationale that co-transformation with multiple DNAs occurs less frequently than transformation with a single DNA, it would be beneficial to the experimenter to first transform with the low copy vector and grow a large volume of bacteria for downstream applications. Unfortunately, these conditions give the lowest rates of recombination. The problem here is believed to be with the expression of the gam gene. Since gam is located on the high copy plasmid, there isn't an early expression of the Gam gene. Since I-Scel is already present, simultaneous expression occurs after the second round of transformation and pre-existing active RecBCD complexes are able to effectively degrade the majority of targeting cassettes available for recombination. This problem can be possibly circumvented by delaying the expression of the I-Scel gene. Since it is induced by the presence of the sugar arabinose this is an achievable condition. If this avenue were to be further explored it would be beneficial to also modify expression of the gam gene by also making it inducible. Research has shown that in some strains of $E$. coli that over-expression of Gam is toxic (112.) 


\section{Discussion}

A novel approach to targeting recombination in the $E$. coli genome has been developed. Two sets of binary vectors were developed which offer the general benefits of differential expression levels of exonuclease to annealing proteins, transient inactivation of the RecBCD complex and targeted recombination that have been demonstrated previously. Current approaches have focused on the use of PCR-generated linear targeting cassettes with either RecET or Red $\alpha \beta$ from plasmids $(24,61,78,79,80,81,82,83119)$, the E. coli chromosome (59, $116,119)$ or replication-deficient $\lambda$ prophage (112) as the driving force in recombination. Recently, research has demonstrated that single stranded DNA fragments can also be used for targeted recombination in the absence of the exonuclease (RecE or Reda) and only the annealing protein (RecT or Red $\beta$ ) $(113,118)$. This approach may shed new light on the mechanism by which recombination through these pathways occur.

Where this approach differs is in the means by which the linear DNA fragment is generated. Instead of using pre-linearized, PCR-generated DNA targeting cassettes, here the targeting cassette is integrated within one of the vectors and released through the inducible expression of an intron-homing endonuclease. Doing this provides the added benefit of degrading both plasmids once recombination has occurred. Through the addition of recognition sites in strategic locations on both plasmids, efficient removal of residual DNA is achieved. 
The usability of this system has been demonstrated through the insertion of two antibiotic-resistance genes, as well as two operons, into three distinct locations on the E. coli chromosome. The versatility of the system has also been demonstrated through the use of three separate E. coli strains. As an example of an application of this recombination system, the operons inserted resulted in the stable expression of gluconate dehydrogenase, previously shown to confer the MPS phenotype. The usefulness of this phenotype was then expanded by recombining the genes responsible for the biosynthesis of pyrroloquinoline quinone, thereby allowing for the activation of glucose dehydrogenase and subsequent conversion of extra-cellular glucose to gluconate, the substrate of GADH. The following paragraphs summarize the primary areas addressed by this study.

Locating the inserted genes. In order to determine whether or not the genes were inserted at the proper locations, a PCR-based detection system was employed. All recombination events were essentially replacement of one gene for another, or an operon, so the homology arms were designed such that the twenty beginning and ending nucleotides of each targeted gene were left behind when recombination occurred. Primers were designed based on these remaining portions of each gene and used on tandem with a primer specific to the gene or operon inserted into the chromosome. In the case of the pqq and gadh operons, primers were designed for the detection of each of the constituent genes. Here again, the forward primer would be based on the E. coli chromosomal gene that was replaced and the reverse primers would correspond to each of the genes of 
the operon. In the case of the gadh operon, the first two genes had primers based on their three prime ends, while the third primer was based on the five prime end in order to keep the overall length of the PCR product within the range of the particular brand of Taq polymerase employed. The $p q q$ operon from $K$. pneumoniae consists of six genes ( $p q q A-\mathrm{E})$ and is too long to detect all using the five prime primer of the deleted gene, so only $p q q B-D$ were detected using this primer. The $p q q E$ and $p q q F$ genes were subsequently detected using the three prime primer from the deleted gene (data not included). Detection at the nucleotide level could have been achieved through sequencing, but was not performed.

Proper Expression. All of the genes/operons could easily be detected by the change in phenotype that they induced. This provided the benefit of rapid detection of positive colonies directly from the agar plate. In the case of the antibiotic genes, ampicillin and kanamycin resistance, selection was simply achieved through the addition of the antibiotics to the plates. Detection of gluconate dehydrogenase was carried out by soaking filter paper in the PMS/DCIP colorimetric assay solution and placing it on top of the plates once colonies were observed. The accuracy of this method is not absolute; roughly fifty percent of the initial positives usually turn out to be negative when restriction analysis is used for confirmation, although repeated use of this assay sharpens the ability to discern the positives from the background. The pyrroloquinoline quinone operon was initially detected and subsequently isolated by using a strain of $E$. coli, JM1109 that is pts and therefore requires glucose to be converted to 
gluconate through glucose dehydrogenase. Since GDH requires $P Q Q$, a cofactor not synthesized in E. coli, the only colonies that would grow on M9+ glucose had to contain the $p q q$ operon. This is a slow growing strain, and was not used in the targeting experiments. Therefore, an indirect method of detection was established. All E. coli strains used for the $P Q Q$ experiments were first modified by the insertion of the gluconate dehydrogenase operon. These cells were subsequently grown on M9 + glucose, then tested for the expression of gluconate dehydrogenase. Since glucose is the only carbon source available, gluconate dehydrogenase has no substrates unless $P Q Q$ is present, allowing for the conversion of glucose to gluconate.

Removal of the targeting system. Once recombination has occurred, it is beneficial to remove the targeting system to eliminate the potential for unwanted, background DNA recombination along with the possibility of plasmid incompatibility in subsequent, downstream applications. An intron-homing endonuclease was therefore employed to not only excise the targeting cassette from the system but also to ensure the degradation of both plasmids. This system was found to be highly effective, with approximately eighty-eight percent of all recombination-modified bacteria being found to not contain a plasmid after being grown overnight in liquid media containing ampicillin and chloramphenicol.

Induction of the MPS phenotype. Locating the genes responsible for the mineral phosphate solubilization phenotype (MPS) via production of 2ketogluconate was the original aim of this project and was still utilized although 
the overall focus of the project had changed to that of a gene targeting system. Detection of a functional gluconate dehydrogenase was achieved directly through a colorimetric assay described by Matsushita (67) involving phenazine methosulfate (PMS) and 2,6-dichlorophenol-indolphenol (DCIP), whereby electrons are transferred from gluconate to DCIP causing a loss of color that is easily detected via visible light spectrometer, as well as visually. Visual detection of the deep blue-to-clear change was a very beneficial property of this assay because it allows colonies to be pre-screened directly on the agar plate by soaking Whatmann filter paper in the assay mix and placing them directly over the colonies. False-positives are common to this procedure but it provides the benefit of avoiding the labor-intensive transfer of all colonies present on the plates to liquid media, after which each overnight culture is then centrifuged, washed and resuspended in buffer for assaying spectrophotometrically in solution.

The underlying principle for all detection assays is the speed by which positives are detected. It was common to have to assay several dozens of colonies at once and, in the case of MPS phenotype detection, the amount of time that the bacteria were exposed directly affected the overall level of protonation of DCIP. A quick means of detection was therefore necessitated for the accurate screening of samples. As mentioned in the methods, when detecting the conversion of glucose to 2-ketogluconate the possibility exists where this assay may be misleading due to the conversion of glucose to gluconate, but this has been taken into account by assaying these bacteria separately using glucose and 
gluconate as the substrate. Since both result in a color change, it can be inferred that glucose is indeed being converted to gluconate, then to 2-ketogluconate. Expression of GADH is dependant upon the presence of gluconate; adding it to the bacteria as substrate at the time of the assay does not provide enough time for expression to occur. Therefore, pre-existing levels of gluconate exist. Given that the bacteria are grown on defined media containing glucose as the sole carbon source, pqq must be activating GDH.

\section{Factors that limit the efficiency of insertion.}

The efficiency of targeted DNA insertion can be affected by several factors. Listed below are the four primary reasons:
A. Vector Design
B. Target sequence
C. Homology Arm Design
D. Transformation Efficiency

Vector Design. Four individual vectors were constructed over the course of the project. One half are $\mathrm{pACYC184-derived} \mathrm{and} \mathrm{the} \mathrm{remaining} \mathrm{two} \mathrm{are} \mathrm{pBluescript}$ II SK(+)-derived. In general, orientation, promoter selection and relative location of genes within the plasmid dictate the overall functionality of the vector.

1. pACYC184-derived vectors. Both vectors have the S. cerevisiae I-Scel intron-homing endonuclease, driven by the $\mathrm{P}_{\mathrm{BAD}}$ promoter and regulated by the araC gene product, inserted in identical positions. They differ only by the type of 
single-stranded exonuclease they carry: $t-r e c E$ or exo, both of which were inserted into the tetracycline resistance gene of the vector backbone.

The $\mathrm{P}_{\mathrm{BAD}}-\mathrm{I}-\mathrm{Scel} /$ araC DNA fragment was initially assembled in pBAD22 and inserted at a Cla I site that does not fall within either antibiotic resistance gene or the $\mathrm{p} 15 \mathrm{~A}$ origin of replication. Additionally, an I-Scel recognition site was placed immediately upstream of the $\mathrm{P}_{\mathrm{BAD}}$ promoter. The location of this site was selected with hopes that its proximity to the promoter sequence would delay the cleaving of the site through competition with RNA polymerase long enough to allow for an adequate amount of $I-S c e l$ to be transcribed. The positional effects of the site were not investigated to determine an optimal location of the cut site, although residual intact pBS II SK(+)-derived plasmid was observed in some cases.

The exo gene is a Sal I/Bam $\mathrm{HI}$ and is in reverse orientation with respect to the tetracycline resistance gene, while the t-recE gene is a Sal I insert. Both restriction sites are in-frame with the tetracycline resistance gene so the occurrence of fusion proteins affecting the expression of these genes is a concern, especially so with $t-r e c E$ which can be inserted in either orientation. An additional factor is the competition between RNA polymerases that transcribe off either the t-recE/exo promoter or the tetracycline resistance gene. However, a reduction in the overall level of expression of either of these genes is an acceptable, even desirable effect since the repair of double stranded DNA breaks via RecET or Reda $\beta$ is more efficient when the annealing protein is overexpressed, relative to the exonuclease (117). However, it is not known how the 
presence of a functional gene fusion product would affect the interaction of the exonuclease with the annealing protein. Since recombination was observed there it is clear to see that a functional interaction had occurred, although the affect of inserting these genes into the tetracycline resistance gene was not investigated.

2. pBluescript II SK(+)-derived vectors. Both vectors derived from pBluescript share the bacteriophage lambda gam gene, driven by the araE promoter and an I-Scel recognition site, flanked on either side by three stop codons an Eco RI site, a Pst I site and a Sal I site. The stop codons were inserted as a precautionary measure due to the proximity of the gam gene to that of the other inserted gene, either the lambda bacteriophage bet or E. coli recT gene. Both genes are inserted in the same orientation and are spaced by only sixty-four nucleotides when used without an insertion cassette. The addition of the I-Scel site increases the distance by an additional sixty-six nucleotides with the final stop codon being forty-five nucleotides upstream of the recT/bet promoter site. When an insertion cassette is incorporated into the plasmid, as opposed to situations where it was introduced to the bacteria in linear, doublestranded form, any possibility of positional effects negatively affecting gene expression is ablated.

An additional source of concern is the promoter that drives expression of the gam gene. When expressed at high levels, the gam gene product can be cytotoxic to some strains of $E$. coli $(37,53)$. Here, the $a r a E$ promoter was selected and 
apparently does not produce deleterious levels of the gam gene, although it should be noted that it could not be determined through a journal search if any of the strains of $E$. coli employed in this study were susceptible to cytotoxic effects from gam.

Target Sequence. When selecting chromosomal targets for insertion some factors to consider are the distance between sites of insertion and sequence effects. Here, a total of three sites were selected: the gntT gene, which encodes an inner-membrane, high-affinity gluconate transporter, the galK gene, which when disrupted causes E. coli colonies on MacConkey agar to appear as white, and the lac operon. The distances selected within each of these targets are as follows: (galK, $1000 \mathrm{bp})$, (lac l, $853 \mathrm{bp}$ ) and (gntT, $1151 \mathrm{bp})$.

In general, Stewart et al noted that the overall complexity of the DNA source affected the overall efficiency of targeted recombination. That is to say that it is easier to achieve success using the $E$. coli chromosome as a target than it is when targeting DNA from an exogenous source. In the case of Stewart, they used genomic DNA from mouse embryonic stem cells and genomic DNA from yeast and E. coli.

A significant experiment that was not performed was showing the efficiency of insertion where a large fragment of DNA without deleting any of the chromosomal sequence. 
Homology Arms. Second only to the proper expression of all genes required to induce double stranded break repair is the design of the homology arms that direct the exogenous DNA fragment to the intended site of recombination. There are two components of the homology arm that are of significance, the length and nucleotide sequence. The arm length requirement has been examined previously (117), and the occurrence of correct recombination events was found to have a second order parabolic relationship to the length of the arm. No correct recombinants are observed when the length of the homology arm is below twenty-seven nucleotides and maximal efficiency is reached when the arms are greater than or equal to sixty nucleotides. This is an attractive feature of recombination via RecET and Reda $\beta$ in $E$. coli because it makes it a more suitable alternative over that of RecA-dependent methods of engineering which require homology arms in the range of one kilobase $(86,88)$.

Restrictions on nucleotide sequence are of particular importance due to the role it may play in the selection of a target site. It had been noted previously that areas with short, repeating nucleotide sequences, either at the 5' end or internal to the homology arm are not efficient locations for replication (117), although repeating sequences of four or less nucleotides do not appear to have a significant effect. In addition, the effect of terminal non-homology had to be taken into consideration due to the use of I-Scel to excise the insertion cassettes from the targeting vectors. I-Scel recognizes a sixteen nucleotide sequence and cuts it symmetrically, therefore leaving eight nucleotides at the termini of each cassette that will often have a different sequence than that of the targeted site. Although 
not inhibitory to the process of recombination, it had been noted in prior experiments that terminal non-homology will decrease the efficiency of recognition and recombination $(64,94,117)$. This is observed in the "Transformation and Recombination Efficiencies under varying Transformation Conditions" tables. All of the conditions where an independent linear targeting cassette was used had a recombination efficiency of $100 \%$ (all of the oddnumbered conditions), whereas conditions where the targeting cassette was integrated into one of the plasmid vectors (requiring excision) shows a lower efficiency of recombination. The range of positives varies from fifty to ninety percent (all of the even-numbered conditions). It should also be noted that conditions one through four are the most applicable, since they allow for early expression of the gam gene, thereby inactivating the exonuclease activity of the RecBCD complex.

Transformation and recombination efficiency. All E. coli strains were made chemically competent using the Inoue method (46) from the same solution of reagents to reduce the variability of transformation from strain to strain. Determination of this efficiency differs from that of the standard means by which this is done due to the fact that this value is directly affected by the presence or absence of the phenotype conferred through recombination. This has to be the case for gene insertions, since the ability to resist antibiotics is immediately obvious by the presence or absence on plates containing the antibiotic. This approach was therefore applied similarly to operon insertions by screening for the phenotype prior to calculating transformation efficiency. 
This same approach was applied to calculating recombination efficiency. Cases where linearized targeting cassettes necessitated this because expression cannot be achieved without recombination. Recombination values for these experiments were therefore always in the $100 \%$ range. In order to make comparisons between the two, the integrated targeting cassettes had to also be screened prior to selection. 


\section{Future Directions}

1. Potential Improvements. It should be noted that the vectors described in this study are still in the "design" state. While they are functional, several modifications can be made in order to increase the overall size and efficiency of the system. The first of which would be the choice of promoters selected to drive expression of the genes that cause recombination to occur. In this study the genes on the high copy pBS plasmids (recT, bet and gam) were all driven by the strong, constitutive promoter EM7, while the genes on the low copy pACYC plasmids ( $t$-recE and exo) were driven by either $\mathrm{P}_{\mathrm{TET}}, \mathrm{P}_{\text {araE }}, \mathrm{P}_{\text {bla }}$ or $\mathrm{P}_{\text {lacz. }}$. The $I-$ Scel gene and araC genes were also on the $\mathrm{PACYC}$ and were driven by the $\mathrm{P}_{\mathrm{BAD}}$ and $\mathrm{P}_{\text {arac }}$ promoters, respectively. The $\mathrm{P}_{\mathrm{BAD}}$ promoter allows for controlled expression of $I-S c e l$ but $t-r e c E$ and exo are expressed constitutively at a level that is unknown relative to the recT and bet genes. As stated previously, recombination occurs more efficiently when the annealing protein is expressed at a level ten times greater than the exonuclease. It was my postulation that placing the annealing protein on a high copy plasmid and the exonuclease on a low copy plasmid would help to offset their expression levels, relative to one another. This was, in fact, the primary reason for splitting the targeting system over two vectors, as opposed to including everything on a single plasmid. Measurement of the relative levels of expression was not explored and therefore no assessment of expression levels can be given. Using promoters with preestablished levels of expression with regards to one another instead of relying on plasmid copy number would therefore be an advantageous modification to the 
present system. Additionally, regulating the expression of the exonuclease genes would also be an improvement to the system because it would further limit the recombinogenic window. Insertion of the targeting cassette is presently limited by the controlled expression of the I-Scel gene, but background events may be occurring throughout the time at which the plasmids are introduced until that of $I$-Scel expression. Replacing the current promoters with an inducible promoter would limit recombination to a more defined time and reduce the potential of unwanted cross-over events.

The overall outlay of the vector could be also refined in order to reduce possible inefficiencies in transcription. Two areas of concern for the present system are the spacing and orientation of the inserted genes with respect to each other and the antibiotic resistance genes that are included in the plasmid backbone.

Lastly, the detection of expression and metabolites could be further quantitated through more sophisticated genetic and biochemical approaches. Quantitative PCR could possibly be employed by isolating mRNA from bacteria containing the recombination genes to determine the ratio of expression. Determining the amounts of 2-ketogluconate and pqq could also be made accurately through the use of either mass spectrometry or high-pressure liquid chromatography.

It would be ideal to start with a plasmid that possesses little more than an origin of replication, an extensive poly-cloning region and a means of selection. 
2. Potential uses of targeting system. Targeted recombination can be a powerful tool in molecular biology because it allow for the in vivo modification of any DNA within E. coli, not necessarily the chromosome. While replacement of chromosomal genes with different genes or operons was the focus of this study there is a myriad of possibilities for which this system can be employed where either insertion or deletion can be achieved with or without the insertion of new DNA sequences.

a. Chromosomal Modifications. In addition to replacement of segments of DNA, insertions and deletions in the range spanning a single nucleotide to several kilobases can be made in a precise manner. All that is required is enough sequence information corresponding to the sites of recombination; approximately fifty nucleotides for the design of each homology arm. Regardless of the distance between them, all of the DNA between can be deleted or replaced with a new sequence of equal, lesser or greater length.

b. Plasmid Modifications. A secondary reason for placing all genes required for targeted recombination on to a single plasmid is that it allows for the modification of other plasmids in vivo. In fact, it would be a worthwhile venture to make several copies of the plasmid with differing origins of replications in order to make modifications to any plasmid without the concern of incompatibility. Plasmids could then be modified in the same manner as chromosomal DNA which was stated above. Of greater use however, would be the sub-cloning of chromosomal DNA in vivo. This can be achieved by co-transforming bacteria 
with the recombination vector plus a linearized vector. All that is required here is terminal sequences of the section of DNA that is of interest. Homology arms could then be designed and attached to either end of the linearized vector. Once co-transformed, the recombination vector could then be induced to express its genes, resulting in the strand invasion of the plasmid into the chromosome at the locations of homology. Not only will the chromosomal DNA be transferred to the plasmid, but the process itself will result in a circularized plasmid.

c. BAC/YAC modifications. Transferring DNA from the E. coli chromosome to plasmids in vivo is a useful technique in many labs, but many researchers often study DNA from different, often eukaryotic, sources. The use of bacterial artificial chromosomes (BACs) and yeast artificial chromosomes (YACs) has greatly simplified the study of genetic material from these organisms. Oftentimes, particular areas of interest are sought after and sub-cloned into different vectors. This can be a delicate process due to the size of the BAC or YAC, and also is limited to the occurrence of restriction sites. Using targeted recombination, both of these concerns can be eliminated. Here again, E. coli could be co-transformed with a targeting vector and a linearized vector with homology arms at either end. The region of interest would be sub-cloned in vivo, removing the need to isolate the BAC/YAC, restriction digest, gel separate, ligate, transform, re-isolate and sequence/restriction digest to confirm the correctness of the insert.

3. Detection of gluconate and 2-ketogluconate. Throughout this study detection of the functionality of genes and operons was determined through the 
observation of the anticipated change in phenotype. In some instances this can be a suitable means of detection, but in other cases it would be preferable to have a quantitative measure of the levels of expression. This point was touched on previously in the discussion of how to improve the efficiency of the target system as a whole, and here again it bears repeating. In this study, several genes were used to demonstrate the principle of the recombination system. The antibiotic resistance genes made for simple detection due to the phenotypic changes they induce. A worthwhile experiment would have be to plate the positive clones on plates of increasing antibiotic concentration to see if the expression was similar to that of the plasmids from which they were transferred. It should be stated that the clones were plated using antibiotic concentrations equal to standard plating conditions. The initial goal of this study though was conversion of gluconate to 2-ketogluconate, and a second addition of the conversion of glucose to gluconate to increase the availability of substrate. In both cases the operons, along with all known regulatory elements, were isolated and transferred to plasmids for the eventual use as DNA to be inserted into the E. coli genome. Paramount to the success of this goal is the level of expression achieved by each of these operons once they have been transferred to the chromosome. For this reason, quantitative measurements were necessitated, although not carried out. Mass Spectrometry is a powerful detection technique that was explored but not taken advantage of $(18,101)$. Given the status of the laboratory, off-site location and the additional costs and time required in order to become familiar with the necessary equipment it was decided that these experiments could not be completed in a timely manner. 
4. Use of gabY from Pseudomonas cepacia. A late discovery found during a journal search for additional information regarding the MPS phenotype was the gabY gene, isolated from $P$. cepacia. As a result of the expression of this 396-base open reading frame in E. coli grown on glucose is the production of gluconic acid (10) and conveys the ability to solubilize hydroxyapatite. Interestingly, when PQQ is present in the medium, the gabY gene product interacts with it synergistically, resulting in a ten-fold enhancement of gluconic acid production.

\section{Employing different intron-homing endonucleases. The}

endonuclease used in all of the experiments was the I-Scel universal coding sequence which has a sixteen nucleotide recognition sequence that is cut in the center of the sequence. It had been originally intended to use a different intronhoming endonuclease to conduct the excision of the targeting cassette, I-Tevl, which is found in T-even bacteriophage which recognizes a larger, twenty-five nucleotide sequence that is not cut in the center of the sequence. The cut site is such that it leaves less of an overhang which provides the possible benefit of greater pairing of the homology arm to its targeted sequence. The larger recognition sequence would also seem to be beneficial in terms of the frequency of cut sites throughout the E. coli genome. In reality, a wild-type form of the ITevl gene product appears to have enough recognition sites throughout the genome to be deleterious to $E$. coli (16). A mutated form of the gene exists that allows for a reduction of functionality to the point where it can be safely 
expressed in E. coli (26). I had sought a copy of this mutated form early in the development of the project and had, in fact, a lengthy correspondence with the research group that made the mutation, but in these attempts were in vain. Ironically, this mutation could now be made fairly easily using the targeting system that it was intended to be used with. Nevertheless, several other intronhoming endonucleases have been, and continue to be discovered and could be potentially used in place of I-Scel. An ideal endonuclease would be highly specific, not recognize the host genome and cut its recognition sequence in an asymmetrical manner, such that the portion of the remaining recognition sequence that is attached to the homology arm is minimized. This would undoubtedly result in an increase in the overall efficiency of the system. 


\section{Bibliography}

1. Abd-Alla, M.H. (1994) Phosphatases and the utilization of organic phosphate by Rhizobium leguminosarum biovar viceae. Lett. Appl. Microbiol. 18, 294296.

2. Adamowicz M, Conway T, Nickerson KW. (1991) Nutritional complementation of oxidative glucose metabolism in Escherichia coli via pyrroloquinoline quinone-dependent glucose dehydrogenase and the Entner-Doudoroff pathway. Appl Environ Microbiol. 57(7):2012-5.

3. Ameyama, M., K. Matsushita, E. Shinagawa, and O. Adachi. (1987). Sugaroxidizing respiratory chain of Gluconobacter suboxydans. Evidence for a branched respiratory chain and characterization of respiratory chain-linked cytochromes. Agric. Biol. Chem. 51:2943-2950.

4. Ameyama, M., Nonobe, M., Hayashi, M., Shinagawa, E., Matsushita, K. and Adachi, O. (1985) Method of enzymatic determination of pyrroloquinoline quinone. Agric. Biol. Chem. 49, 1227-1231.

5. Ameyama, M., Nonobe, M., Shinagawa, E., Matsushita, K., Takimoto, K. and Adachi, O. (1986) Reconstitution of pyrroloquinoline quinone-dependent Dglucose oxidase respiratory chain of Escherichia coli with cytochrome 0 oxidase. J Bacteriol. 1987 Jan;169(1):205-9.

6. Angrand, P-O, Daigle, N., van der Hoeven, F., Schöler, H. R., and A. F. Stewart (1999) Simplified Generation of Targeting Constructs using ET Recombination. Nucleic Acids Res. 27: e16: i-vi. 
7. Anthony, C. (1996) Quinoprotein-catalysed reactions. Biochem J. 320 ( Pt 3):697-711.

8. Anthony, C. and Ghosh, M. (1998) The structure and function of the PQQcontaining quinoprotein dehydrogenases. Prog Biophys Mol Biol. 1998;69(1):1-21.

9. Ayling, S.M. et al. (2000) Transmembrane electric potential difference of germ tubes of arbuscular mycorrhizal fungi responds to external stimuli. New Phytol. 147: 631-639.

10. Babu-Khan, S., T.C. Yeo, W.L. Martin, M. Duron, R.D. Rogers and A.H. Goldstein. (1995). Cloning of a mineral phosphate-solubilizing gene from Pseudomonas cepacia. Applied and Environmental Microbiology , 61(3) 972978.

11. Barber, S.A. (1980) Soil-Plant interactions in the phosphorous nutrition in plants. In FE Khasawneh, EC Sample, EJ Kamprath, Role of phosphorous in agriculture. American Society of Agronomy, Madison, WI, 591-616.

12. Barber, S.A., Walker, J.M. and Vasey, E.H. (1963). Mechanisms for the movement of plant nutrients from the soil and fertilizer to the plant root. $\mathrm{J}$ Agric Food Chem 11: 204-207.

13. Barbour, S. D., Nagaishi, H., Templin, A., and A. J. Clark (1970) Biochemical and Genetic Studies of Recombination Proficiency in Escherichia coli, II. Rec+ Revertants Caused by Indirect Suppression of Rec- Mutations. PNAS 67: 128-135. 
14. Bhargava, J. et al. (1999) Direct Cloning of Genomic DNA by Recombinogenic Targeting Method using a Yeast-Bacterial Shuttle Vector, $p$ Clasper. Genomics 62: 285-288.

15. Bianco, P. R., Tracy, R. B., and S. C. Kowalczykowski (1998) DNA Strand Exchange Proteins: A Biochemical and Physical Comparison. Frontiers in Bioscience 3: 570-603.

16. Bryk M, Belisle M, Mueller JE, Belfort M. (1995) Selection of a remote cleavage site by I-Tevl, the td intron-encoded endonuclease. J Mol Biol. 1995 Mar 24;247(2):197-210.

17. Buchholz, F., Angrand, P-O, and A. F. Stewart (1996) A Simple Assay to Determine the Functionality of Cre or FLP Recombination Targets in Genomic Manipulation Constructs. Nucleic Acids Res. 24: 3118-3119.

18. Buffoni F, Cambi S and Moneti G (1992) Pyrroloquinoline quinone, a method for its isolation and identification by mass spectrometry. Biochimica et Biophysica Acta 1116, 297-304.

19. Chu, C. C., Templin, A., and A. J. Clark (1989) Suppression of a Frameshift Mutation in the recE Gene of Escherichia coli K-12 Occurs by Gene Fusion. J. Bacteriol. 171: 2101-2109.

20. Clark A. J., Satin, L., and C. C. Chu. (1994) Transcription of the Escherichia coli recE gene from a Promoter in Tn5 and IS50. J. Bacteriol. 176: 70247031.

21. Clark, A. (1974) Progress Toward a Metabolic Interpretation of Genetic Recombination of Escherichia coli and Bacteriophage Lambda. Genetics 78: 259-271. 
22. Clark, A.J. (1984) Genes of the RecE and RecF pathways of conjugational recombination in Escherichia coli. Cold Springs Harbor Symposium on Quantitative Biology. 49: 453-462.

23. Clark. A.J. Sharma, V., Brenowitz, S., Chu, C. C., Sandler, S., Satin, L., Templin, A., Berger, I., and A. Cohen. (1984) Genetics and Molecular Analysis of the C-Terminal Region of the recE Gene from the Rac Prophage of Escherichia coli K-12 Reveal the recT Gene. J. Bacteriol. 175(23); 76737682.

24. Cotta-de-Almeida, V., Schonhoff, S., Shibata, T., Leiter, A. and S.B. Snapper (2003) A New Method for Rapidly Generating Gene-Targeting Vectors by Engineering BACs Through Homologous Recombination in Bacteria. Genome Research 13:2190-2194.

25. de Jonge, R., MJ Teixeira de Mattos, JB Stock, and OM Neijssel (1996) Pyrroloquinoline quinone, a chemotactic attractant for Escherichia coli. J. Bacteriol. 178: 1224-1226.

26. Derbyshire V, Kowalski JC, Dansereau JT, Hauer CR and Belfort M. (1997) Two-domain structure of the td intron-encoded endonuclease I-Tevl correlates with the two-domain configuration of the homing site. J Mol Biol. 265(5):494-506

27. Dewanti AR, Duine JA. (1998) Reconstitution of membrane-integrated quinoprotein glucose dehydrogenase apoenzyme with $P Q Q$ and the holoenzyme's mechanism of action. Biochemistry. 37(19):6810-8. 
28. Duine, J. A. (1991) Quinoproteins: enzymes containing the quinonoid cofactor pyrroloquinoline quinone, topaquinone or tryptophan-tryptophan quinone. Eur J Biochem 200, 271-284.

29. Duine, J. and Jongejan, J. (1989) Quinoproteins, enzymes with pyrroloquinoline quinone as cofactor. Annu Rev Biochem. 1989;58:403-26.

30. Elias MD, Tanaka M, Izu H, Matsushita K, Adachi O, Yamada M. (2000) Functions of amino acid residues in the active site of Escherichia coli pyrroloquinoline quinone-containing quinoprotein glucose dehydrogenase. $\mathrm{J}$ Biol Chem. 275(10):7321-6.

31. Foy, R. H., and P.J.A. Withers. (1995) The contribution of agricultural phosphorus to eutrophication. Proc. No. 365. The Fertilizer Society, Peterborough, England.

32. Furihata, T., Suzuki, M. \& Sakurai, H. (1992) Kinetic characterization of two phosphate uptake systems with different affinities in suspension-cultured Catharanthus roseus protoplasts. Plant Cell Physiol. 33, 1151-1157.

33. Gillen, J.R., Karu, A.E., Nagaishi, H and Clark, A.J. (1977) Characterization of the deoxyribonuclease determined by lambda reverse as exonuclease VIII of Escherichia coli. J. Mol. Biol.113; 27-41.

34. Goldstein, A.H., R.D. Rogers and G. Mead. (1993) Separating Phosphate From Ores Via Bioprocessing. Nature Biotechnology, 11:1250-1254.

35. Goodwin, P. M. and Anthony, C. (1998) The biochemistry, physiology and genetics of PQQ and PQQ-containing enzymes. Adv. Microbial. Physiol. 40, $1-80$. 
36. Goosen N, Huinen RG, van de Putte P. (1999) A 24-amino-acid polypeptide is essential for the biosynthesis of the coenzyme pyrrolo-quinoline-quinone. $\mathrm{J}$ Bacteriol. 174(4):1426-7.

37. Greer, H. (1975) The kil gene of bacteriophage lambda. Virology 66, 589604.

38. Hall, S., and R. D. Kolonder (1994) Homologous Pairing and Strand Exchange Promoted by the Escherichia coli RecT Protein. PNAS 91: 32053209.

39. Hall, S., and R. D. Kolonder. Unpublished Results.

40. Hall, S.D., Kane, M.F. and Kolodner, R.D. (1993) Identification and Characterization of the Escherichia coli RecT Protein, a Protein Encoded by the recE Region that Promotes Renaturation of Homologous Single-Stranded DNA. J Bacteriol. 175(1); 277-287.

41. Hartnett, D.C. and Wilson, G.W.T. (1999) Mycorrhizae influence plant community structure and diversity in tallgrass prairie. Ecology $80 ; 1187-1195$.

42. Hommes RW, van Hell B, Postma PW, Neijssel OM, Tempest DW. (1985) The functional significance of glucose dehydrogenase in Klebsiella aerogenes. Arch Microbiol. 1985 Nov;143(2):163-8.

43. Hommes, R. W. J., J. A. Simons, J. L. Snoep, P. W. Postma, D. W. Tempest, and O. M. Neijssel. (1991) Quantitative aspects of glucose metabolism by Escherichia coli $\mathrm{B} / \mathrm{r}$, grown in the presence of pyrroloquinoline quinone. Antonie Leeuwenhoek 60:373-382.

44. Hommes, R. W. J., Postma, P. W., Neijssel, O. M., Tempest, D. W., Dokter, P. and Duine, J. A. (1984) Evidence of a quinoprotein glucose 
dehydrogenase apoenzyme in several strains of Escherichia coli FEMS Microbiol. Lett. 24, 329-333.

45. Houck, D. R., J. L. Hanners, and C. J. Unkefer. (1991) Biosynthesis of pyrroloquinoline quinone. 2. Biosynthetic assembly from glutamate and tyrosine. J. Am. Chem. Soc. 113:3162-3166.

46. Inoue, H., H. Nojima, and H. Okayama. (1990) High efficiency transformation of Escherichia coli with plasmids. Gene 96:23-28.

47. Jones, D.L. and Darrah, P.R. (1994) Role of root derived organic acids in the mobilization of nutrients from the rhizosphere. Plant Soil. 166, 247-257.

48. Joseph, J.W. and Kolodner, R. (1983) Exonuclease VIII of Escherichia coli II. Mechanism of Action. J. Biol. Chem. 258(17); 10418-10424.

49. Joseph, J.W. and Kolodner, R. (1983) Exonuclease VIII of Escherichia coli I. Purification and Physical Properties. J. Biol. Chem. 258(17); 10411-10417.

50.Kaiser, K and Murray, N.E. (1979) Physical characterization of the "Rac prophage" in E. coli K12. Mol Gen Genet. 175(2):159-74.

51. Kmiec, E. and Holloman, W.K. (1981) Beta protein of bacteriophage lambda promotes renaturation of DNA. J. Biol. Chem. 256: 12636-12639.

52. Kolodner, R., Hall, S., and C. Luisi-DeLuca (1994) Homologous Pairing Proteins Encoded by the Escherichia coli recE and recT genes. Mol. Micro. 11: 23-30.

53. Kourilsky, P. \& Knapp, A. (1974) Lysogenization by bacteriophage lambda. III. Multiplicity dependent phenomena occurring upon infection by lambda. Biochimie 56, 1517-1523. 
54. Koyama H, Kawamura A, Kihara T, Hara T, Takita E, Shibata D. (2000) Overexpression of mitochondrial citrate synthase in Arabidopsis thaliana improved growth on a phosphorus-limited soil. Plant Cell Physiol. 2000 Sep;41(9):1030-7.

55. Koyama H, Takita E, Kawamura A, Hara T, Shibata D. (1999) Over expression of mitochondrial citrate synthase gene improves the growth of carrot cells in Al-phosphate medium. Plant Cell Physiol. 40(5):482-8.

56. Krappmann S, Braus GH. (2003) Deletion of Aspergillus nidulans aroC using a novel blaster module that combines ET cloning and marker rescue. Mol Genet Genomics. 268(5):675-83. Epub 2003 Jan 15.

57.Kusano, K., Takahashi, N. K., Yoshikura, H., and I Kobayashi (1994) Involvement of RecE Exonuclease and RecT Annealing Protein in DNA Double-Strand Break Repair by Homologous Recombination. Gene 138: 1725.

58. Kushner, S.R., Nagaishi, H. and Clark, A.J. (1974) Isolation of Exonuclease VIII: The Enzyme Associated with the sbcA Indirect Suppressor. PNAS 71(9); 3593-3597.

59. Lee EC, Yu D, Martinez de Velasco J, Tessarollo L, Swing DA, Court DL, Jenkins NA, Copeland NG. (2001) A highly efficient Escherichia coli-based chromosome engineering system adapted for recombinogenic targeting and sub-cloning of BAC DNA. Genomics. 73(1):56-65.

60. Li XF, Ma JF, Matsumoto H. (2000) Pattern of aluminum-induced secretion of organic acids differs between rye and wheat. Plant Physiol.123(4):153744. 
61.Liu, P., Jenkins, N.A. and N.G. Copeland (2003) A Highly Efficient Recombineering-Based Method for Generating Conditional Knockout Mutations. Genome Research 13:476-484.

62. Liu, S.-T., L.-Y. Lee, C.-Y. Tai, C.-H.-Horng, Y.-S. Chang, J.H. Wolfram, R. Rogers and A.H. Goldstein. (1992) Cloning of an Erwinia herbicola Gene Necessary for Gluconic Acid Production and Enhanced Mineral Phosphate Solubilization in E. coli strain HB101. J. Bacteriol. 174(18):5814-5819.

63. Lopez-Bucio J, de La Vega OM, Guevara-Garcia A, Herrera-Estrella L. (2000) Enhanced phosphorus uptake in transgenic tobacco plants that overproduce citrate. Nat Biotechnol. 18(4):450-3.

64. Luisi-Deluca, C. and R. D. Kolodner (1992) Effect of Terminal Non-Homology on Intramolecular Recombination of Linear Plasmid Substrates in Escherichia coli. J. Mol. Biol. 227: 72-80.

65. Matsushita K, Adachi O, Shinagawa E, Ameyama M. (1978) Isolation and characterization of outer and inner membranes from Pseudomonas aeruginosa and effect of EDTA on the membranes. J Biochem (Tokyo). 83(1):171-81 .

66. Matsushita K, Shinagawa E, Adachi O, Ameyama M. (1979) Membranebound D-gluconate dehydrogenase from Pseudomonas aeruginosa. Its kinetic properties and a reconstitution of gluconate oxidase. J Biochem (Tokyo). 86(1):249-56.

67. Matsushita K, Shinagawa E, Ameyama M. (1982) D-Gluconate dehydrogenase from bacteria, 2-keto-D-gluconate-yielding, membranebound. Methods Enzymol. 1982;89 Pt D:187-93. 
68. Matsushita K, Yamada M, Shinagawa E, Adachi O, Ameyama M. (1980) Function of ubiquinone in the electron transport system of Pseudomonas aeruginosa grown aerobically. J Biochem (Tokyo). 88(3):757-64.

69. Matsushita, K., E. Shinagawa, O. Adachi, and M. Ameyama. (1979). Membrane-bound D-gluconate dehydrogenase from Pseudomonas aeruginosa. Purification and structure of cytochrome-binding form. J. Biochem. 85:1173-1181.

70. Matsushita, K., JC Arents, R Bader, M Yamada, O Adachi, and PW Postma (1997) Escherichia coli is unable to produce pyrroloquinoline quinone (PQQ). Microbiology 143: 3149-3156.

71. Matsushita, K., T. Yakushi, Y. Takaki, H. Toyama, and O. Adachi. (1995) Generation mechanism and purification of an inactive form convertible in vivo to the active form of quinoprotein alcohol dehydrogenase in Gluconobacter suboxydans. J. Bacteriol. 177:6552-6559.

72. McIntire W, Singer TP, Ameyama M, Adachi O, Matsushita K, Shinagawa E. (1985) Identification of the covalently bound flavins of D-gluconate dehydrogenases from Pseudomonas aeruginosa and Pseudomonas fluorescens and of 2-keto-D-gluconate dehydrogenase from Gluconobacter melanogenus. Biochem J. 231(3):651-4.

73. Meulenberg, J. J. M., Sellink, E., Loenen, W. A. M., Riegman, N. H., van Kleef, and P. W. Postma (1990) Cloning of Klebsiella pneumoniae pqq and PQQ Biosynthesis in Escherichia coli. FEMS Micro. Letts. 71: 337-344. 
74. Meulengerg, J. J. M., Sellink, Riegman, N. H., and P.W. Postma (1992) Nucleotide Sequence and Structure of the Klebsiella pneumoniae pqq Operon. Mol Gen. Genet. 232: 284-294.

75. Midgley, M. and Dawes, E. (1973) The regulation of transport of glucose and methyl alpha-glucoside in Pseudomonas aeruginosa. Biochem. J. 132(2): 141-154.

76. Muniyappa, K. and Radding, C.M. (1986) The homologous recombination system of phage lambda. Pairing activities of beta protein. J. Biol. Chem. 261: 7472-7478.

77. Murphy, K. C. (1991) I Gam Protein Inhibits the Helicase and c-Stimulated Recombination Activities of Escherichia coli RecBCD Enzyme. J. Bacteriol. 173: 5808-5821.

78. Murphy, K.C. and K.G. Campellone (2003) Lambda Red-mediated recombinogenic engineering of enterohemorrhagic and enteropathogenic $\mathrm{E}$. coli. BMC Molecular Biology 4:11. http://www.biomedcentral.com/1471$2199 / 4 / 11$

79. Muyrers J.P.P., Zhang, Y., Testa, G. and Stewart, A.F. (1999) Rapid modification of bacterial artificial chromosomes by ET-recombination. Nucleic Acids Res. 15;27(6):1555-7.

80. Muyrers, J. P. P., Zhang, Y., Buchholz, F., and A.F. Stewart. (2000) RecE/RecT and Reda/Redb Initiate Double-Stranded Break Repair by Specifically Interacting with their Respective Partners. Genes \& Dev. 14: 1971-1982. 
81. Muyrers, J. P. P., Zhang, Y., Buchholz, F., and F. Stewart. (2000) RecE/RecT and Reda/Redb Initiate Double-Stranded Break Repair by Specifically Interacting with their Respective Partners. Genes \& Dev. 14: 1971-1982.

82. Muyrers, J. P. P., Zhang, Y., Buchholz, F., and F. Stewart. (2000) RecE/RecT and Reda/Redb Initiate Double-Stranded Break Repair by Specifically Interacting with their Respective Partners. Genes \& Dev. 14: 1971-1982.

83. Muyres, J. P. P., Zhang, Y., Benes, V., Testa, G., Ansorge, W., and A. F. Stewart (2000) Point Mutation of Bacterial Artificial Chromosomes by ET Recombination. EMBO Reports 1: 239-243.

84. Neijjssel, O. (1987) PQQ-linked enzymes in enteric bacteria. Microbiol Sci. 1987 Mar;4(3):87-90.

85. Neijjssel, O., Tempest, D., Postma, P., Duine, J. and Frank, J. (1983) Glucose metabolism by K+-limited Klebsiella aerogenes: Evidence for the involvement of a quinoprotein glucose dehydrogenase. FEMS Microbiol. Lett. v20(1); 35-39.

86. O'Connor, M. Peifer, M. and Bender, W. (1989) Construction of Large DNA Segments in Escherichia coli. Science 244(4910), 1307-1312.

87. Porco A, Alonso G, Isturiz T. (1998) The gluconate high affinity transport of Gntl in Escherichia coli involves a multi-component complex system. J Basic Microbiol. 38(5-6):395-404.

88. Poustka, A., Rackwitz HR, Frischauf AM, Hohn B, Lehrach H. (1984) Selective isolation of cosmid clones by homologous recombination in Escherichia coli. 
89. Raghothama K.G. (1999) Phosphate acquisition. Annu. Rev. Plant Physiol Mol Biol 50: 665-693.

90. Raghothama, K. G., Muchhal, U. S., Kim, D. H. \& Bucher, M. (1998) in Phosphorus in Plant Biology: Regulatory Roles in Molecular, Cellular, Organismic, and Ecological Processes, eds. Lynch, J. P. \& Deikman, J. (Am. Soc. Plant Physiologists, Rockville, MD), pp. 271-280.

91. Roberts BK, Midgley M, Dawes EA. (1973) The metabolism of 2oxogluconate by Pseudomonas aeruginosa. J Gen Microbiol. 1973 Oct;78(2):319-29.

92. Salisbury, S.A., Forrest, H.S., Cruse, W.B.T and Kennard, O. (1979) A novel coenzyme from bacterial primary alcohol dehydrogenases. Nature 280; 843844.

93. Schleissner C, Reglero A, Luengo JM. (1997) Catabolism of D-glucose by Pseudomonas putida U occurs via extracellular transformation into D-gluconic acid and induction of a specific gluconate transport system. Microbiology. 143 (Pt 5):1595-603.

94.Shafikhani S. (2002) Factors affecting PCR-mediated recombination. Environ Microbiol. 4(8):482-6.

95. Sharpley, A. N., R. J. Foy, and P. J. A. Withers. (2000) Practical and innovative measures for the control of agricultural losses to water: An overview. J. Environ. Quality. 29:1-9.

96. Shashikant, C.S. et al. (1998) Recombinogenic Targeting: a new approach to genomic analysis - a review. Gene 223: 9-20. 
97. Shinagawa, E., K. Matsushita, O. Adachi, and M. Ameyama. (1984) DGluconate dehydrogenase, 2-keto-D-gluconate yielding, from Gluconobacter dioxyacetonicus: purification and characterization. Agric. Biol. Chem. 48:1517-1522.

98. Smith, S.E. and Read, D.J. (1997) Mycorrhizal Symbiosis (2nd Ed.), Academic Press.

99. Sonoyama, T., B. Kageyama, S. Yagi, and K. Mitsushima. (1988) Facultatively anaerobic bacteria showing high productivities of 2,5-diketo-Dgluconate from D-glucose. Agric. Biol. Chem. 52:667-674.

100. Stover CK. Et al (2000) Complete Genome Sequence of Pseudomonas aeruginosa PAO1, an Opportunistic Pathogen. Nature 406(6799), 959-964.

101. Suzuki O, Kumazawa T, Seno H, Urakami T and Matsumoto T. (1990) Extractions of Pyrroloquinoline quinone from Crude Biological Samples. Life Sciences 47, 2135-2141.

102. Swanson BL, Hager P, Phibbs P Jr, Ochsner U, Vasil ML, Hamood AN. (2000) Characterization of the 2-ketogluconate utilization operon in Pseudomonas aeruginosa PAO1. Mol Microbiol. 37(3):561-73.

103. Tempest, D. W., and O. M. Neijssel. (1987) Growth yield and energy distribution, p. 797-806. In F. C. Neidhardt, J. L. Ingraham, K. B. Low, B. Magasanik, M. Schaechter, and H. E. Umbarger (ed.), Escherichia coli and Salmonella typhimurium: cellular and molecular biology. American Society for Microbiology, Washington, D.C. 
104. Toyama H, Lidstrom ME. (1998) pqqA is not required for biosynthesis of pyrroloquinoline quinone in Methylobacterium extorquens AM1. Microbiology. 144 ( Pt 1):183-91.

105. Ullrich-Eberius Cl, Novacky A, Fischer E, Luttge U (1981) Relationshipbetween energy-dependent phosphate uptake and the electrical membrane potential in Lemna gibba G1. Plant Physiol. 67: 797-801.

106. Van Kleef, M. A. G., and J. A. Duine. (1988) L-Tyrosine is the precursor of PQQ biosynthesis in Hyphomycrobium X. FEBS Lett. 237:91-97.

107. Velterop, J. S., Sellink, E., Meulenberg, J. J. M., David, S., Bulder, I., and P. W. Postma (1995) Synthesis of Pyrroloquinoline Quinone In Vivo and In Vitro and Detection of an Intermediate in the Biosynthetic Pathway. J. Bacteriol. 177: 5088-5098.

108. Williamson, L.C., Sebastien, P.C.P., Ribioux, A.H.F. and Leyser, H.M.O. (2001) Phosphate Availability Regulates Root System Architecture in Arabidopsis. Plant Physiol. 126: 875-882.

109. Yadav, K.S. and Dadarwal, K.R. (1997) Phosphate solubilization and mobilization through soil microorganisms. In: Biotechnological Approaches in Soil Microorganisms for Sustainable Crop Production (Dadarwal, K.R., Ed.), 293-308. Scientific Publishers.

110. Yamada M, Asaoka S, Saier MH Jr, Yamada Y. (1993) Characterization of the gcd gene from Escherichia coli K-12 W3110 and regulation of its expression. J Bacteriol. 175(2):568-71. 
111. Yamada M, Sumi K, Matsushita K, Adachi O, Yamada Y. (1993) Topological analysis of quinoprotein glucose dehydrogenase in Escherichia coli and its ubiquinone-binding site. J Biol Chem. 15;268(17):12812-7.

112. Yu D, Ellis HM, Lee EC, Jenkins NA, Copeland NG, Court DL. (2000) An efficient recombination system for chromosome engineering in Escherichia coli. Proc Natl. Acad. Sci U S A. 97(11):5978-83.

113. Yu, D., Sawitzke, J.A., Ellis, H. and D.L. Court (2003) Recombineering with overlapping single-stranded DNA oligonucleotides: Testing a recombination intermediate. Proc. Nat'l Acad. Sci. 100(12): 7207-7212.

114. Yum, D.-Y., Lee, Y.-P., Pan, J.-G. (1997) Cloning and Expression of a Gene Cluster Encoding Three Subunits of Membrane-Bound Gluconate Dehydrogenase from Erwinia cypripedii ATCC 29267 in Escherichia coli. J Bacteriol. 179(21): 6566-6572.

115. Zhang, X. and Huang, J. (2003) Combination of overlapping bacterial artificial chromosomes by a two-step recombinogenic engineering method. Nucleic Acids Research 31(15) e81.

116. Zhang, Y., Buchholz, F., Muyrers, J. P. P., and A. F. Stewart (1998) A New Logic for Recombination in Escherichia coli. Nature Genetics 20: 123128.

117. Zhang, Y., Buchholz, F., Muyrers, J. P. P., and A. F. Stewart (1998) A New Logic for Recombination in Escherichia coli. Nature Genetics 20: 123128.

118. Zhang, Y., Muyrers, J. P. P., Rientjes, J. and A.F. Stewart. (2003) Phage annealing proteins promote oligonucleotide-directed mutagenesis in 
Escherichia coli and mouse ES cells. BMC Molec. Biol. 4: http://www.biomedcentral.com/1471-2199/4/1.

119. Zhang, Y., Muyrers, J. P. P., Testa, G., and A. F. Stewart (2000) DNA Cloning by Homologous Recombination in Escherichia coli. Nature Biotech. 18: $1314-1317$.

120. Zou, K., Binkley, D and Doxader, K.G., (1992) New method for estimating gross phosphate mineralization and mobilization rates in soils. Plant Soil 147, 243-250. 


\section{Appendix A: Gene Sequences}

All sequences obtained from the National Center for Biotechnology Information website: http://www.ncbi.nlm.nih.gov/entrez/

\section{GADH - Conserved Hypothetical Protein ${ }^{*}$}

ATGCCCGATGACAAGGCCGTCAACGGCCGCCGCGACTTCCTGCGCAAGACCCTGACCGTGATCCCGGCGGT GACCCTGGCCGGCTATGGCGTCGGCCATGCCATGCAGACGCCCGCCGCCGAGCAGGACAAACCCCGCGAAC GCTACCAGCCTCGCTTCTTCACCAACACCGAATGGGCTTTCGTCAACGCCGCGGTGGCGCGACTGATCCCC AGCGACGACAACGGCCCCGGCGCCATCGAGGCCGGGGTGCCGGAGTTCATCGACCGACAGATGGAAACCCC CTACGGGCACGGCGCACTCTGGTACATGCAGGGGCCGTTCGTCACCGACGCCGCGCCGGAGTTCGGCCATC AGTTGAAGCTGGTGCCACGCGACATCTACCGGGTCGGCATCGCCGCCCTGGAACGCTGGAGCAAGGCCAAC AGGGCAAGCCGTTCGCCGAGCTGGAGCCGTCGGCGCAGGACGACATCCTGCAACGCCTGGAAGCCGGCCAG ATCGACCTGCAGGACCTGCCGGCCAAGCTGCTCTTCGGCCAGTTGCTGCAAAACACCCACGAAGGCTTCTT CTCCGATCCGCAGCACGGCGGCAATCGCGGCCTGGTGGGCTGGAAGCTGGTCGGTTTCCCCGGCGCCCGCG CCGACTTCATGGACTGGGCCGACCGCGGCGAGAAGTATCCCTTCCCGCCGGTGGCGATTTCCGGCGAGAGG GGTTGA

\section{GADH - Gluconate Dehydrogenase*}

ATGGCGACGACACTCAAACCGGTGGACGCGGTGGTGGTCGGCTTCGGCTGGACCGGAGCGATCCTGGCCAA GGAGCTGACCGAGGCCGGGCTCAACGTGGTGGCGCTGGAGCGCGGCGAGAACCGCGATACCTATCCCGACG GTGCCTACCCCAACACCCTCGACGAGCTGACCTACAACACCCGCGGCAAGCTGTTCCAGAATCTCTCCAAG AGCACCGTGAGCATCCGCCACGGGATCAACGATACCGCGCTGCCCTACCGCCAGCTCTCCGCCTTCCTTCC CGGCGACGGCGTCGGTGGCGCCGGCCTGCACTGGTCCGGCGTGCATTTCCGGATCATGCCCGAGGAACTGC GCTTGCGCAGTCACTACGAGGAACGCTACGGCAAGAAATTCATCCCCGAAGGCATGACCATCCAGGACTAC GGGGTCAGCTACGAGGAGCTGGAACCGCACTTCGATTTCGCCGAGAAGGTCTTCGGCACCTCCGGCACCGC GCATACGGTCAAGGGCCAGGTGGTCGGCAAGGGCAATCCGTTCGCCGCCGACCGCTCGGACGACTTCCCGC TGCCGGCACTGCGCCAGGTGTACTCCGCGCAACTGTTCCGCAAGGCCGCCGAGGAACTCGGCCTGCACCCC TACGACCTGCCGGCGGCCAACGCTTCGGGGCCCTGGACCAACCCCTACGGGGTGCAGATGGGGCCGTGCAA CTTCTGCGGCTTCTGCAGCGGCTACGCCTGCTACATGTATTCCAAGGCCTCGCCGAACCTGAACATCCTGC CGGCGCTGCGCCAGACCCCGCTGTTCGAACTGCGCGCCAACTGCAACGTGCTCAAGGTCAACCTCGACAGC GACGGCAGGCAAGCCACCGGCGTGACCTACGTCGACGCCCAGGGGCGCGAGATCGTGCAGCCGGCGAAGCT GGTGATCATCAGTGCCTTCCAGTTCCACAACGTACGCCTGCTGCTGCTCTCCGGCATCGGCAAGCCCTATG ACCCGCGTACCGGCGAGGGCGTGGTGGGGAAGAACTTCGCCTACCAGAACATGGCCACCATCAAGGCGTTC TTCGACAAGGACGTGCATACCAACCCCTTCGTCGGCACCGGCGGCGGCGGCGTGGCGGTGGACGACTTCAA CGCCGACAACTTCGACCACGGACCGCTGGGCTTCGTCGGCGGCTCGCCGATGTGGGTCAACCAGGCCGGCT CCAAGCCGATCGGCGGCCTCGCCGTGCCGCCCGGCACGCCGAGCTGGGGCAGCGGCTGGAAACAGGCGGTC AAGGACGCCTACACGCACACCGTGTCGATGGACGCCCACGGCAGCAACATGACCTACCGCGACAACTACCT CGACCTCGACCCGACCTACAAGGACGCCTACGGCCAGCCACTGCTGCGCATGACCTTCGACTGGAAGGACA ACGAGATCCGCATGAGCCGCTACGTCACCGAGCACATGCGCAAGATCGCCGAAGCGATGAACCCGAAGGCC ATCTCGGTGAGCGTCAAGAACTTCGGCGACCACTTCAATACACGGGTCTACCAGACCACCCACCTGCTCGG CGGGGCGATCATGGGCAGCGATCCGAAGACCAGTGTGCTCAACCGCTACCTGCAGAGCTGGGACGTGCACA ACGTCTTCGTCATGGGCGCCTCGGCCTTCCCCCAGGGCACCGGCTACAACCCCACTGGGCTGGTGGCGGCG CTGGCCTACTGGTCGGCCAAGGCGATCCGCGAGCAATACCTGAAGAACCCCGGTCCGCTGGTGCAGGCATG A

\section{GADH - Cytochrome C Precursor}

ATGAAACCGACAGCCTTCCTCGCCCTCTCCGCCCTCGCCTGCGGCATCGCCCAGGCCGCCGCAGCGCCGGA CCCGGCCCTGGTCAGGCAGGGTGAATACCTGGCCCGCGCCGGCGATTGCGTGGCCTGCCACACCGCCAGGG ACGGCAAGCCGTTCGCCGGGGGCCTGCCGATGGAAACGCCGATCGGCGCGGTGTACTCGACCAACATCACC CCGGACCGCAAGACCGGCATCGGCGACTACAGCTTCGAGGACTTCGACCGTGCCGTGCGCCACGGCGTGGC CAGATCCGGCGACACGCTCTACCCGGCGATGCCCTACCCGTCCTACGCGCGAGTCAGCGAAGCGGACATGC GCGCCCTCTACGCCTACTTCATGCATGGCGTGGAGCCGGTGGAGCAGCCCAACAAGGCCAGCGACATCCCC TGGCCGCTGTCGATGCGCTGGCCGCTGGCATTCTGGCGCTGGACCTTCGCTCCCGAGGTGAAGGACTTCCA GGCCGCCGCCGGGCAGGACCCGGTGCTGGCGCGCGGCGCCTACCTGGTCGAAGGCCTTGGCCACTGTGGCG 
CCTGCCATACCCCGCGTGGGCTGGGCATGCAGGAGAAGGCCCTGGCGGCGAGCGATGGCGCGGCCTACCTG TCCGGCAGCGCGCCGCTGGAGAACTGGATCGCCAAGAGCCTGCGCGGCGACCACCGGACCGGACTGGGCAG CTGGAGCGAAGCCGACCTGGTCAGCTTCCTGCGTACCGGCCGCAGCGAGCGCAGCGCGGTGTTCGGCGGCA TGTCCGACGTGGTGGTGCACAGCATGCAGTACATGACCGACGCCGACCTCACCGCCATCGCCCGCTACCTC AAGTCGCTGCCGCCGGCGGACCCCGCCGACCAGCCGCACGTCTACGACGAGAGCGTGGCCCAGGCACTGTT CCACGGCGATGACAGCAAGACCGGCGCGGCGCTCTACGTCGACAACTGCGGGGCCTGCCACCGCACCGACG GCAAGGGCTATGCGCGGGTCTTCCCGGCCCTGGCCGGCAACCCGGTAGTGACCGGCAGCGACCCGACCTCC CTGGTGCACATCGTGCTCAAGGGCGGCACCCTGCCGGCCACCCACCAGGCACCGTCGAGCTTCACCATGCC GCCGTTCGGCTGGCGGATGAACGACCAGGAGATCGCCGACGTGGTCAACTTCATCCGCACCAGCTGGGGCA ACCAGGCGCCAAGCGTCAGCGTCGACGAGGTCAGGCGCCTGCGCAAGGACACCGGCGCGGCGGGTGGGCGA CATTCCGCCGCCGGGATCGGCCGCGGCGGATCGCGGCTGA

\section{4. $P Q Q-A^{*}$}

ATGTGGAAGAAACCTGCTTTTATCGATTTACGTCTCGGTCTGGAAGTGACGCTGTACATTTCTAACCGTTA A

\section{5. $P Q Q-B^{*}$}

ATGTTCATTAAAGTCCTCGGTTCCGCCGCCGGCGGCGGTTTCCCGCAATGGAACTGCAACTGCGCCAACTG TCAGGGTCTGCGCGATGGCACCATTCAGGCTGCCCCCCGCACCCAGTCGTCAATTATCGTCAGCGACAACG GTAAAGAGTGGGTGCTGTGCAACGCCTCGCCGGATATCAGCCAGCAGATTGCCCATACCCCCGAGTTAAAT AAAGCCGGCGTACTGCGCGGAACGCATATCGGCGGCATTATTCTCACCGACAGCCAGATCGACCACACCAC CGGGTTGCTGAGCCTGCGGGAAGGCTGCCCACATCAGGTCTGGTGCACCCCGGAGGTTCATGAGGATCTCT CCACCGGCTTCCCGGTGTTTACCATGCTGCGGCACTGGAACGGCGGCCTGGTGCATCATCCCATCGCTCCG CAGCAGCCTTTTACCGTTGACGCCTGTCCTGATTTGCAGTTTACCGCGGTGCCTATCGCCAGCAACGCGCC GCCCTATTCGCCGTATCGCGACCGGCCGCTGCCGGGTCATAACGTGGCGCTGTTTATCGAAAACCGCCGCA ACGGGCAGACGCTGTTCTATGCCCCGGGGCTGGGTGAGCCGGATGAAACCCTTCTGCCCTGGCTGCAAAAA GCGGACTGTCTGCTGATCGATGGCACCGTCTGGCAGGATGATGAGCTGCAGGCCGCCGGCGTCGGGCGCAA TACCGGCCGCGATATGGGCCACCTGGCGCTCGGCGACGAGCACGGGATGATGGCCCTGCTGGCCTCTCTGC CGGCAAAACGCAAAATTCTCATTCATATTAATAACACCAACCCGATCCTTAACAAGCAGTCTCCCCAGCGC CAGGCGCTAACGCAACAGGGGATCGAAGTGAGCTGGGACGGGATGGCAATCACCCTTCAGGATACCGCATG CTGA

\section{6. $P Q Q-C^{*}$}

ATGCTGATCACTGACACGCTGTCGCCGCAGGCCTTTGAAGAGGCTCTGCGGGCTAAAGGCGCCTTCTACCA TATTCACCACCCTTACCACATCGCCATGCATAACGGCGACGCGACCCGCAAGCAAATTCAGGGTTGGGTGG CGAACCGGTTTTATTACCAGACCACTATTCCGCTGAAAGACGCGGCGATTATGGCCAACTGCCCGGATGCG CAGACCCGGCGCAAATGGGTGCAGCGGATCCTCGACCACGACGGCAGCCACGGCGAGGACGGCGGGATTGA AGCCTGGCTGCGGCTGGGGGAAGCGGTCGGTTTGAGCCGCGACGATCTGCTCAGCGAGCGTCACGTGCTGC CCGGCGTGCGCTTCGCAGTGGATGCCTATCTCAATTTCGCTCGTCGCGCCTGCTGGCAGGAGGCGGCCTGC AGCTCCCTGACCGAGCTGTTCGCCCCGCAGATCCATCAGTCGCGCCTCGACAGCTGGCCGCAGCACTATCC ATGGATCAAAGAGGAAGGCTACTTTTACTTCCGCAGTCGTCTGAGCCAGGCTAACCGCGACGTTGAGCATG GTCTGGCGCTGGCGAAGGCCTACTGCGACAGCGCTGAAAAACAGAACCGGATGCTGGAGATCCTGCAGTTT AAGCTCGACATTCTGTGGTCGATGCTCGATGCCATGACCATGGCCTATGCCCTGCAGCGCCCGCCCTATCA CACGGTCACCGACAAGGCGGCCTGGCACACGACCCGACTGGTGTAA

\section{7. $P Q Q-D^{*}$}

ATGCAGAAAACGTCCATCGTTGCCTTTCGTCGCGGCTACCGACTGCAGTGGGAAGCCGCCCAGGAGAGCCA TGTGATCCTCTATCCGGAGGGTATGGCCAAACTCAATGAGACCGCCGCGGCGATCCTAGAGCTGGTCGATG GCCGGCGCGACGTCGCGGCGATTATCGCCATGCTTAATGAACGTTTCCCGGAAGCCGGCGGCGTCGATGAC GACGTCATCGAGTTCCTGCAGATCGCCTGTCAACAGAAGTGGATCACCTGCCGTGAGCCAGAGTAA

\section{8. $P Q Q-E^{*}$}

GTGAGCCAGAGTAAACCCACCGTCAATCCGCCACTGTGGCTGCTGGCGGAGCTGACCTACCGCTGCCCGCT GCAGTGTCCCTACTGTTCCAATCCGCTGGACTTCGCCCGGCAGGATAAGGAGCTGACCACCGAACAATGGA 
TCGAGGTCTTTCGCCAGGCGCGGGCGATGGGCAGCGTTCAGCTGGGCTTTTCCGGCGGCGAGCCGCTGACC CGTAAAGATCTGCCGGAGCTGATCCGCGCCGCGCGCGACCTCGGGTTCTATACCAACCTGATCACCTCCGG GATAGGGCTGACGGAGAGCAAACTGGACGCCTTCAGCGAGGCCGGGCTGGACCATATCCAGATTAGCTTCC AGGCCAGCGATGAAGTGCTCAACGCCGCGCTGGCCGGCAACAAAAAAGCCTTCCAGCAGAAGCTGGCCATG GCCAAAGCAGTGAAAGCGCGCGACTACCCGATGGTGCTCAACTTCGTTCTCCATCGGCACAACATCGACCA GCTCGATAAAATTATCGAGCTGTGCATTGAGCTGGAAGCCGATGACGTTGAGCTGGCCACCTGCCAGTTCT ACGGTTGGGCGTTTCTTAATCGCGAAGGGCTGCTGCCGACCCGGGAACAGATCGCCCGCGCCGAGCAGGTG GTCGCTGACTACCGGCAGAAAATGGCCGCCAGCGGCAACCTCACCAACCTGCTGTTCGTCACCCCGGACTA TTACGAAGAGCGGCCGAAAGGCTGCATGGGCGGCTGGGGATCGATTTTCCTCAGCGTTACCCCGGAAGGCA CCGCCCTGCCTTGCCACAGCGCGCGCCAGCTGCCGGTGGCGTTTCCGTCGGTGCTGGAGCAGAGTCTGGAA TCGATCTGGTATGACTCATTCGGCTTCAATCGCTACCGCGGGTATGACTGGATGCCGGAGCCGTGCCGCTC CTGTGATGAAAAAGAGAAGGACTTCGGCGGCTGTCGCTGCCAGGCCTTTATGCTGACCGGCAGCGCCGATA ACGCCGACCCGGTGTGCAGCAAATCTCCGCATCATCACAAAATCCTCGAGGCCCGGCGCGAAGCGGCCTGC AGCGACATAAAAGTCAGCCAGCTGCAGTTCCGCAACCGTACCCGCTCGCAGCTGATCTACCAAACCCGGGA CCTGTAA

\section{9. $P Q Q-F^{*}$}

ATGACGCTGGCGACCCGCACCGTCACTTTGCCGGGCGGCCTGCAGGCCACCCTGGTCCATCAGCCGCAGGC GGATCGCGCGGCTGCCCTGGCGCGGGTCGCCGCCGGCAGCCACCACGAACCGTCGCGCTTCCCTGGGCTGG CGCACCTGCTGGAACACCTGCTGTTTTACGGCGGAGAGCGCTACCAGGATGATGACCGACTGATGGGCTGG GTGCAGCGCCAGGGCGGAAGCGTGAATGCCACCACCCTGGCTCGCCATAGCGCGTTCTTTTTCGAGGTTGC CGCCGATGCTCTGGCTGATGGTGTCGCGCGTCTACAGGAGATGCTGCAGGCCCCGCTGCTGCTCAGGGAAG ATATTCAGCGCGAAGTGGCGGTGATTGACGCCGAGTACCGCCTGATCCAGCAGCATGAGCCATCGCGCCGG GAAGCCGCGGTGCGCCACGCCGCCAGCGCGCCCGCGGCGTTTCGCCGCTTTCAGGTAGGCAGCGCCGACGC GCTGGCGGGCGATCTCGCTGCGCTGCAGGCCGCCTTAGGCGATTTTCACCGCACCCATTACGTCGCCCGGC GAATGCAGCTCTGGCTGCAGGGGCCGCAGTCGCTGGAGGCGCTCGGCGAGCTGGCGGCCCGTTTCGCCGCC GGGCTTGCCGCAGGCGAGGCTCCGCCGCCGGCGCCGCCGCTGCGCCTGGGCGAGTTCACTGCACTGCAGCT GGCGGTCTCCAGCCAGCCCGCGCTGTGGCGCTGCCCGCTGATCGCTTTAAGTGACAACGTCACGTTACTGC GCGAGTTTTTGCTGGATGAAGCCCCCGGCAGCCTGATGGCCGGCCTGCGCCAGCGCCGGCTGGCCGGGGAT GTGGCGCTGAACTGGCTGTATCAGGATCGGCACCTCGGCTGGCTGGCGCTGGTCTTCGCCAGCGACCGGCC GGAAGAGGTCGACCGGCAGATAACCCACTGGCTGCAGGCGCTACAGCAAACGACGCCTGAGCAGCAGCAAC ACTACTATCAGCTATCCCGCCGCCGCTTTCAGGCGCTGTCGCCTCTCGATCAGCTGCGCCAGCGGGCATTC GGCTTTGCCCCCGGCGCGCCGCCCGCCGGGTTCGCCGATTTTTGCGCCGCCCTGCAGGTCGCCCCGTCAGT CAGCCTGGCCTGTCAGACCGTTTCCCCAGGGGAGCCTGTTGCCACCCAGGGCTTTAGCCTGCCGCTTAGCC GCTGGCGCCGCCGCCCTGAGTCTGACCCGGCGCTGGCGTTCGCTTTCTATCCGCAGGCCGCTGGCGATCTC GTTGCCAAATGCCCGGAGAAAGCCGCGCCGCTGCTCCATCTCCCGTCACCGGGAGATCCGCCGAGGCTCCT GCTGCGACCGCCCTTCTACTGCTCGCCCGATCAGGCCGAGGGGCTGGCGCGTGGGGAACAGCTGCGCCCAC TGCTTGCCGCCCTGCGCCATGCCGGGGGACACGGCGAGTGGCATCTGTTCGACGGCAGCTGGCAGTTGACC CTCCAGCTGCCGGAGCCAGGCCGACGGCCGGAAGCGATCCTGCAGGCCATCCTGCGGCAGCTCGCGCTCCC GGTCGCCTCGCTGACCCCATCGCCGGAAAGTATCGCTATCCGTCATCTCATGGCTCAACTCCCCGAACGGC TGGGTACATCCGGGCATCAGAAAGGTTGGCTGGCGGCCCTGGCCGGCGGCAGCGCAGAAGATGCGCAGTGG GTAGCGCGTCAGCTGAGCCTGATTACCGCCCCGGTTAATCCGCCGATGCCCGCTCCGGCACCCTGCCGCCG CGGCGTCGAACGTCTGGTTTATCCGGGAGGCGATACGGCGCTGCTGGTCTTCATTCCGCTGCCGGATGGCG CCTCGCTGGCGGCCCTGCGGCTGCTGGCGCAGCATTGTGAGCCGCTATTTTTCCAGCGCCTGCGGGTGGAG CAGCAGATTGGCTATGTGGTGAGCTGCCGCTATCAGCGGGTCGCCGATCGCGACGGGCTGCTGATGGCGCT CCAGTCCCCGGATCGCCGCGCCGGGGAATTGCTGCGCTGTGGTAAAGACTTTCTGCGCCAGCTGGCCCCCA TGGATGAGGCGACCTTCAGACCGCTACAGCAGCGCCTGGCCGCTCAGATCCGCGCCAGCAGGCCGCCAGAG GCGCGGGCGCTGTCCGCCCTGCGTCAGGAGTATGGATTACCAGAGCTAACGCCGCAGGCGGTTGACGCGCT GCGCGTTGCAGAGGTGGCCGATCTGGCACGCGAAATGACCCGCCGGCGTCGCCGCTGGCAGGTGCTATTCA CGACAGGGGATTAA

\section{0. $\lambda \operatorname{exo}^{*}$}

ATGACACCGGACATTATCCTGCAGCGTACCGGGATCGATGTGAGAGCTGTCGAACAGGGGGATGATGCGTG GCACAAATTACGGCTCGGCGTCATCACCGCTTCAGAAGTTCACAACGTGATAGCAAAACCCCGCTCCGGAA AGAAGTGGCCTGACATGAAAATGTCCTACTTCCACACCCTGCTTGCTGAGGTTTGCACCGGTGTGGCTCCG GAAGTTAACGCTAAAGCACTGGCCTGGGGAAAACAGTACGAGAACGACGCCAGAACCCTGTTTGAATTCAC TTCCGGCGTGAATGTTACTGAATCCCCGATCATCTATCGCGACGAAAGTATGCGTACCGCCTGCTCTCCCG 
ATGGTTTATGCAGTGACGGCAACGGCCTTGAACTGAAATGCCCGTTTACCTCCCGGGATTTCATGAAGTTC CGGCTCGGTGGTTTCGAGGCCATAAAGTCAGCTTACATGGCCCAGGTGCAGTACAGCATGTGGGTGACGCG AAAAAATGCCTGGTACTTTGCCAACTATGACCCGCGTATGAAGCGTGAAGGCCTGCATTATGTCGTGATTG AGCGGGATGAAAAGTACATGGCGAGTTTTGACGAGATCGTGCCGGAGTTCATCGAAAAAATGGACGAGGCA CTGGCTGAAATTGGTTTGTATTTGGGGAGCAATGGCGATGA

\section{1. $\lambda$ bet}

ATGAGTACTGCACTCGCAACGCTGGCTGGGAAGCTGGCTGAACGTGTCGGCATGGATTCTGTCGACCCACA GGAACTGATCACCACTCTTCGCCAGACGGCATTTAAAGGTGATGCCAGCGATGCGCAGTTCATCGCATTAC TGATCGTTGCCAACCAGTACGGCCTTAATCCGTGGACGAAAGAAATTTACGCCTTTCCTGATAAGCAGAAT GGCATCGTTCCGGTGGTGGGCGTTGATGGCTGGTCCCGCATCATCAATGAAAACCAGCAGTTTGATGGCAT GGACTTTGAGCAGGACAATGAATCCTGTACATGCCGGATTTACCGCAAGGACCGTAATCATCCGATCTGCG TTACCGAATGGATGGATGAATGCCGCCGCGAACCATTCAAAACTCGCGAAGGCAGAGAAATCACGGGGCCG TGGCAGTCGCATCCCAAACGGATGTTACGTCATAAAGCCATGATTCAGTGTGCCCGTCTGGCCTTCGGATT TGCTGGTATCTATGACAAGGATGAAGCCGAGCGCATTGTCGAAAATACTGCATACACTGCAGAACGTCAGC CGGAACGCGACATCACTCCGGTTAACGATGAAACCATGCAGGAGATTAACACTCTGCTGATCGCCCTGGAT AAAACATGGGATGACGACTTATTGCCGCTCTGTTCCCAGATATTTCGCCGCGACATTCGTGCATCGTCAGA ACTGACACAGGCCGAAGCAGTAAAAGCTCTTGGATTCCTGAAACAGAAAGCCGCAGAGCAGAAGGTGGCAG CATGA

\section{2. $\lambda$ gam $^{\star}$}

ATGGATATTAATACTGAAACTGAGATCAAGCAAAAGCATTCACTAACCCCCTTTCCTGTTTTCCTAATCAG CCCGGCATTTCGCGGGCGATATTTCACAGCTATTTCAGGAGTTCAGCCATGAACGCTTATTACATTCAGG ATCGTCTTGAGGCTCAGAGCTGGGCGCGTCACTACCAGCAGCTCGCCCGTGAAGAGAAAGAGGCAGAACTG GCAGACGACATGGAAAAAGGCCTGCCCCAGCACCTGTTTGAATCGCTATGCATCGATCATTTGCAACGCCA CGGGGCCAGCAAAAAATCCATTACCCGTGCGTTTGATGACGATGTTGAGTTTCAGGAGCGCATGGCAGAAC ACATCCGGTACATGGTTGAAACCATTGCTCACCACCAGGTTGATATTGATTCAGAGGTATAA

\section{3. $\operatorname{rect}^{*}$}

ATGACTAAGCAACCACCAATCGCAAAAGCCGATCTGCAAAAAACTCAGGGAAACCGTGCACCAGCAGCAGT TAAAAATAGCGACGTGATTAGTTTTATTAACCAGCCATCAATGAAAGAGCAACTGGCAGCAGCTCTTCCAC GCCATATGACGGCTGAACGTATGATCCGTATCGCCACCACAGAAATTCGTAAAGTTCCGGCGTTAGGAAAC TGTGACACTATGAGTTTTGTCAGTGCGATCGTACAGTGTTCACAGCTCGGACTTGAGCCAGGTAGCGCCCT CGGTCATGCATATTTACTGCCTTTTGGTAATAAAAACGAAAAGAGCGGTAAAAAGAACGTTCAGCTAATCA TTGGCTATCGCGGCATGATTGATCTGGCTCGCCGTTCTGGTCAAATCGCCAGCCTGTCAGCCCGTGTTGTC CGTGAAGGTGACGAGTTTAGCTTCGAATTTGGCCTTGATGAAAAGTTAATACACCGCCCGGGAGAAAACGA AGATGCCCCGGTTACCCACGTCTATGCTGTCGCAAGACTGAAAGACGGAGGTACTCAGTTTGAAGTTATGA CGCGCAAACAGATTGAGCTGGTGCGCAGCCTGAGTAAAGCTGGTAATAACGGGCCGTGGGTAACTCACTGG GAAGAAATGGCAAAGAAAACGGCTATTCGTCGCCTGTTCAAATATTTGCCCGTATCAATTGAGATCCAGCG TGCAGTATCAATGGATGAAAAGGAACCACTGACAATCGATCCTGCAGATTCCTCTGTATTAACCGGGGAAT ACAGTGTAATCGATAATTCAGAGGAATAA

\section{4. t-recE*}

ATGGATCCCGTAATCGTAGAAGACATAGAGCCAGGTATTTATTACGGAATTTCGAATGAGAATTACCACGC GGGTCCCGGTATCAGTAAGTCTCAGCTCGATGACATTGCTGATACTCCGGCACTATATTTGTGGCGTAAAA ATGCCCCCGTGGACACCACAAAGACAAAAACGCTCGATTTAGGAACTGCTTTCCACTGCCGGGTACTTGAA CCGGAAGAATTCAGTAACCGCTTTATCGTAGCACCTGAATTTAACCGCCGTACAAACGCCGGAAAAGAAGA A.AGAAAGCGTTTCTGATGGAATGCGCAAGCACAGGAAAAACGGTTATCACTGCGGAAGAAGGCCGGAAAA TTGAACTCATGTATCAAAGCGTTATGGCTTTGCCGCTGGGGCAATGGCTTGTTGAAAGCGCCGGACACGCT GAATCATCAATTTACTGGGAAGATCCTGAAACAGGAATTTTGTGTCGGTGCCGTCCGGACAAAATTATCCC TGAATTTCACTGGATCATGGACGTGAAAACTACGGCGGATATTCAACGATTCAAAACCGCTTATTACGACT ACCGCTATCACGTTCAGGATGCATTCTACAGTGACGGTTATGAAGCACAGTTTGGAGTGCAGCCAACTTTC GTTTTCTGGTTGCCAGCACAACTATTGAATGCGGACGTTATCCGGTTGAAATTTTCATGATGGGCGAAGA AGCAAAACTGGCAGGTCAACAGGAATATCACCGCAATCTGCGAACCCTGTCTGACTGCCTGAATACCGATG AATGGCCAGCTATTAAGACATTATCACTGCCCCGCTGGGCTAAGGAATATGCAAATGACTAAGTCGAC 


\section{I-Scel $\left.\right|^{*}$}

ATGCATCAAAAAAACCAGGTAATGAACCTGGGTCCGAACTCTAAACTGCTGAAAGAATACAAATCCCAGCT GATCGAACTGAACATCGAACAGTTCGAAGCAGGTATCGGTCTGATCCTGGGTGATGCTTACATCCGTTCTC GTGATGAAGGTAAAACCTACTGTATGCAGTTCGAGTGGAAAAACAAAGCATACATGGACCACGTATGTCTG CTGTACGATCAGTGGGTACTGTCCCCGCCGCACAAAAAAGAACGTGTTAACCACCTGGGTAACCTGGTAAT CACCTGGGGCGCCCAGACTTTCAAACACCAAGCTTTCAACAAACTGGCTAACCTGTTCATCGTTAACAACA AAAAAACCATCCCGAACAACCTGGTTGAAAACTACCTGACCCCGATGTCTCTGGCATACTGGTTCATGGAT GATGGTGGTAAATGGGATTACAACAAAAACTCTACCAACAAATCGATCGTACTGAACACCCAGTCTTTCAC TTTCGAAGAAGTAGAATACCTGGTTAAGGGTCTGCGTAACAAATTCCAACTGAACTGTTACGTAAAAATCA ACAAAAACAAACCGATCATCTACATCGATTCTATGTCTTACCTGATCTTCTACAACCTGATCAAACCGTAC CTGATCCCGCAGATGATGTACAAACTGCCGAACACTATCTCCTCCGAAACTTTCCTGAAATAACTGCAG

\section{6. $\beta$-lactamase *}

ATGAGTATTCAACATTTCCGTGTCGCCCTTATTCCCTTTTTTGCGGCATTTTGCCTTCCTGTTTTTGCTCA CCCAGAAACGCTGGTGAAAGTAAAAGATGCTGAAGATCAGTTGGGTGCACGAGTGGGTTACATCGAACTGG ATCTCAACAGCGGTAAGATCCTTGAGAGTTTTCGCCCCGAAGAACGTTTTCCAATGATGAGCACTTTTAAA GTTCTGCTATGTGGCGCGGTATTATCCCGTATTGACGCCGGGCAAGAGCAACTCGGTCGCCGCATACACTA TTCTCAGAATGACTTGGTTGAGTACTCACCAGTCACAGAAAAGCATCTTACGGATGGCATGACAGTAAGAG AATTATGCAGTGCTGCCATAACCATGAGTGATAACACTGCGGCCAACTTACTTCTGACAACGATCGGAGGA CCGAAGGAGCTAACCGCTTTTTTGCACAACATGGGGGATCATGTAACTCGCCTTGATCGTTGGGAACCGGA GCTGAATGAAGCCATACCAAACGACGAGCGTGACACCACGATGCCTGTAGCAATGGCAACAACGTTGCGCA AACTATTAACTGGCGAACTACTTACTCTAGCTTCCCGGCAACAATTAATAGACTGGATGGAGGCGGATAAA GTTGCAGGACCACTTCTGCGCTCGGCCCTTCCGGCTGGCTGGTTTATTGCTGATAAATCTGGAGCCGGTGA GCGTGGGTCTCGCGGTATCATTGCAGCACTGGGGCCAGATGGTAAGCCCTCCCGTATCGTAGTTATCTACA CGACGgGGAGTCAGGCAACTATGGATGAACGAAATAGACAGATCGCTGAGATAGgTGCCTCACTGATTAAG CATTGGTAA

\section{Kanamycin Resistance}

ATGAGCCATATTCAACGGGAAACGTCTTGCTCGAGGCCGCGATTAAATTCCAACATGGATGCTGATTTATA TGGGTATAAATGGGCTCGCGATAATGTCGGGCAATCAGGTGCGACAATCGATCGATTGTATGGGAAGCCCG ATGCGCCAGAGTTGTTTCTGAAACATGGCAAAGGTAGCGTTGCCAATGATGTTACAGATGAGATGGTCAGA CTAAACTGGATGACGGAATTTATGCCTCTTCCGACCATCAAGCATTTTATCCGTACTCCTGATGATGCATG GTTACTCACCACTGCGATCCCCGGGAAAACAGCATTCCAGGTATTAGAAGAATATCCTGATTCAGGTGAAA ATATTGTTGATGCGCTGGCAGTGTTCCTGCGCCGGTTGCATTCGATTCCTGTTTGTAATTGTCCTTTTAAC AGCGATCGCGTATTTCGTCTCGTCCAGGCGCAATCACGAATGAATAACGGTTTGGTTGATGCGAGTGATTT TGATGACGAGCGTAATGGCTGGCCTGTTGAACAAGTCTGGAAAGAAATGCATAAGCTTTTGCCATTCTCAC CGGATTCAGTCGTCACTCATGGTGATTTCTCACTTGATAACCTTATTTTTGACGAGGGGAAATTAATAGGT TGTATTGATGTTGGACGAGTCGGAATCGCAGACCGATACCAGGATCTTGCCATCCTATGGAACTGCCTCGG TGAGTTTTCTCCTTCATTACAGAAACGGCTTTTTCAAAAATATGGTATTGATAATCCTGATATGAATAAAT TGCAGTTTACTTTGATGCTCGATGAGTTTTCTAA

\section{EM7 Promoter}

ATTAАTTAАCTGTTGACAATTAATCATCGGCATAGTATATCGGCATAGTATAATACGACAAGGTGAGGAAC TAAACCCAGGAGG

\section{9. $P_{\text {araE }}^{*}$}

TCCAтATTTATGCTGTTTCCGACCTGACACCTGCGTGAGTTGTTCACGTATTTTTTCACTATGTCTTACTC TCTGCTGGCA

\section{0. $P_{\text {lacz }}$}

GCTCACTCATTAGGCACCCCAGGCTTTACACTTTATGCTTCCGGCTCGTATGTTGTGTGGAATTGTGAGCG GATAACAATT

\section{1. $\mathrm{P}_{\text {TetR }}{ }^{*}$}


TAATGCGGTAGTTTATCACAGTTAAATTGCTAACGCAGTCAGGCACCGTGT

\section{2. $\mathbf{P}_{\text {bla }}^{*}$}

TGAGACAATAACCCTGATAAATGCTTCAATAATATTGAAAAAGGAAGAGT 


\section{Appendix B: Escherichia coli strain genotypes.}

\author{
E. coli Strain \\ BL21(DE3)
}

JC13031

JC15329

JC5519

JC5547

JC8111

JC8672

JC8679

JC8691

JC9366

JC9387

\section{Genotype}

E. coli B F ompT hsdS $\left(r_{B}^{-} m_{B}^{-}\right) d c m+$ gal $\lambda(D E 3)$ endA

thr-1, araC14, leuB6(Am), DE(gpt-proA)62, lacY1, tsx-33, glnV44(AS), galK2(Oc), LAM-, Rac0, hisG4(Oc), rfbD1, recA13, recJ153, rpsL31(strR), kdgK51, xylA5, mtl-1, $\operatorname{argE3}(\mathrm{Oc})$, thi-1,rpsL31(strR), xylA5, $\mathrm{mtl}-1$, $\operatorname{argE3}(\mathrm{Oc})$, thi-1

thr-1, araC14, leuB6(Am), DE(gpt-proA)62, lacY1, tsx-33, qsr'0 , glnV44(AS), galK2(Oc), LAM-, Rac-0, sbcB15, hisG4(Oc), rfbD1, DE(recA-srl)306, srlR301::Tn10, recB21, recC22, rpsL31(strR), kdgK51, xylA5, mtl-1, argE3(Oc), thi-1

thr-1, araC14, leuB6(Am), DE(gpt-proA)62, lacY1, tsx-33, qsr'0 , glnV44(AS), galK2(Oc), LAM-, Rac-0, hisG4(Oc), rfbD1, mgl-51, recB21, recC22, rpsL31(strR), kdgK51, xylA5, mtl-1, $\operatorname{argE3}(\mathrm{Oc})$, thi-1

thr-1, araC14leu B6 (Am), DE(gpt-proA)62, lacY1, tsx-33, glnV44 (AS), galK2 (Oc), LAM-,hisG4(Oc), rfbD1, mgl-51, recA13, recB21, recC22, rpsL31(strR), kdgK51, xylA5, mtl-1, $\operatorname{argE3}(\mathrm{Oc})$, thi-1, rac-

thr-1, araC14, leuB6(Am), DE(gpt-proA)62, lacY1, tsx-33, qsr'0 , glnV44(AS), galK2(Oc), LAM-, Rac-0, hisG4(Oc), rfbD1, mgl-51, recB21, recC22, rpsL31(strR), kdgK51, xylA5, mtl-1, $\operatorname{argE3}(\mathrm{Oc})$, recF143, $\operatorname{argE3}(\mathrm{Oc})$, thi-1

Leu-277(Am), lac-301, LAM-, trp9851(Oc), sbcA20 (Rac)his318, recA56, recB21, In(rrnD-rrnE)1rpsL321

thr-1, araC14leu B6 (Am), DE(gpt-proA)62, lacY1, tsx-33, glnV44 (AS), galK2 (Oc), LAM-, sbc23 (Rac), his-60, rel1A, recB21, recC22, rpsL31(strR), xylA5, mtl-1, argE3 (Oc), thi-1

thr-1 leu-6 thi-1 lacY1 galK2 ara-14 xyl-5 mtl-1 proA2 his-4 argE3 str-31 tsx-33 supE44 rec ${ }^{+}$, recB21 recC22 sbcA2, recE159

thr-1, araC14, leuB6(Am), DE(gpt-proA)62, lacY1, tsx-33, qsr'0 , glnV44(AS), galK2(Oc), LAM-, hisG4(Oc), recA13, rpsL31(strR), xylA5, $m t l-1$, argE3(Oc), thi-1

thr-1, araC14, leuB6(Am), DE(gpt-proA)62, lacY1, tsx-33, qsr'0 , glnV44(AS), galK2(Oc), LAM-, sbcB15, hisG4(Oc), rfbD1, 
$D E(r e c A-s r l) 306, \quad$ srlR301::Tn10, recB21, recC22, rpsL31(strR), kdgK51, xylA5, mtl-1, argE3(Oc), thi-1

JM109 (DE3) endA1, recA1, gyrA96, thi, hsdR17 $\left(r^{\wedge}-k, m^{\wedge}+k\right)$, relA1, supE44, delta (lac-proAB), [F', traD36, proAB, lac/^ $q \mathrm{Z}$ delta M15], lambda (DE3)

JM1109 galK2(Oc), ptsG23, ptsM8, thyA111, galP64

XL1-Blue MRF' $\quad$ (mcrA)183 $D$ (mcrCB-hsdSMR-mrr)173 endA1 supE44 thi-1 recA1 gyrA96 relA1 lac [F'proAB lacl ${ }^{\circ} Z D M 15$ Tn10 (Tet $\left.\left.t^{\prime}\right)\right]$ 


\section{Appendix C: PCR Primers.}

\section{Escherichia coli \\ GALK F GCATCATGATTCTGAAAGAAAAAACACAA \\ GALKR GCATCTCAGCACTGTCCTGCTCCTTGTGA}

RecT F GCATCAACGCGTATGACTAAGCAACCACCAATC

$R e c T R \quad$ GCATCATCTAGATTATTCCTCTGAATTATCGAT

$t$-RecE $F$ GCATCAACGCGTATGGATCCCGTAATCGTAGAAGAC

$t$-RecE $R$ GCATCAGAGCTCTTACTGATTTGCATATTCCTTAGC

gnt $F \quad$ GCATCATGCCATTAGTCATTGTTGCTATCGG

gntT $R$ GCATCTCAAATCACCATATTCAGCAGCAGAC

Lac $F \quad$ GCATCGTGAAACCAGTAACGTTATACGATGCTG

Lac $R \quad$ GCATCTCACTGCCCGCTTTCCAGTCGGGAAAC

\section{Bacteriophage $\lambda$}

Bet $F \quad$ GCATCAACG CGTATGAGTACTGCACTCGCAACG

Bet $R$ GCATCATCTAGATCATGCTGCCACCTTCTGCTCTGC

EXO $F \quad$ GCATCAACGCGTATGACACCGGACATTATCCT

EXO $R \quad$ GCATCAGGATCCTCATCGCCATTGCTCCCCAAA

Gam $F \quad$ GCATCAACGCGTATGGATATTAATACTGAAAC

Gam $R$ GCATCAGGGCCCTTATACCTCTGAATCAATATCAACCTG

\section{Homology Arms}

HAS-F-Xho

HBS-R-Xho

$H B-R-X h o$

$H A-F-X H O$

$H A-R-K P N$

$H B-F-K P N$

HOMOL1F HOMOL2F

HOMOL1R

HOMOL2R

HOMOL2SR

HOMOL1SF

HK1 F

HSK1 F

$H K 1 R$

$H K 2 R$
GCATCACTCGAGTAGGGATAACAGGGTAATCTGAATTAACATTCCCAACCGCGTGGC GCATCACTCGAGTAGGGATAACAGGGTAATGCACTTCAAACTGGCTGGTAATATAT GCATCACTCGAGCACTTCAAACTGGCTGGTAATATATATTTAAAGCAGCCCACCAGCA GCATCACTCGAGCTGAATTACATTCCCAACCGCGTGGCACAACAACTGGCG GCATCAGGTACCTGTTTCCCCGCCAGTTGTTGTGCCACGCGGTTGGGAATGTAATT GCATCAGGTACCGTTCCTGCTGGTGGGCTGCTTTAAATATATTACCAGCCAGTTG

GCATCACTCGAGTAGCCTTGCCCTGATCATGGGTTTTGGCGCAATGCT

GCATCAGGTACCTGACTATCGGCGAAGACCATCAAATCCTGGTCGATGCTGGAAAC GCATCAGGTACCAGCATTTTGCCCAGCATTGCGCCAAAACCCATGATCAGGGCAAG GCATCACTCGAGATAATGGTTTCCAGCATCGACCAGGATTTGATGGTCTCGC GCATCACTCGAGTAGGGATAACAGGGTAATAGATAATGGTTTCCAGCATCGACCAG GCATCACTCGAGTAGGGATAACAGGGTAATAGATAATGGTTTCCAGCATCGACCAG

GCATCACTCGAGCAATCTCTGTTTGCCAACGCATTTGGCTACCCTGCCATT GCATCACTCGAGTAGGGATAACAGGGTAATGCAATCTCTGTTTGCCAACGC GCATCAGGTACCTAGCCAAATGCGTTGGCAAACAGAGATTGTGTTTTTTCT GCATCACTCGAGGTGATGGTTTACAAACGTAAAAAGTCTCTTAATACCTGTT 
HSK2 R GCATCACTCGAGTAGGGATAACAGGGTAATCAGCACTGTCCTGCTCCTTG

HK2 F GCATCAGGTACCAAGAGACTTTTTACGTTTGTAAACCATCACAAGGAGCAG

HLAC F GCATCCTCGAGGCAGAGTATGCCGGTGTCTCTTATCAGACCGTTTCCCGCGT

HLAC2 R GCATCCTCGAGGGGAAACCTGTCGTGCCACGTGCATTAATGAATCGGCCAA

HLACS $F$ GCATCCTCGAGACTCGAGTAGGGATAACAGGGTAATGCAGAGTATGCCGGTGT

HLAC2S $R$ GCATCACTCGAGTAGGGATAACAGGGTAATGGGAAACCTGTCGTGCCACGTGC

$H L A C R$ GCATCGGTACCTGGTTCACCACGCGGGAAACGGTCTGATAAGAGACACCGGCA

HLAC2 F GCATCGGTACCGGGAAACCTGTCGTGCCATTAATGAATCGGCCAACGCGCGGG

\section{Promoters}

EM7-F GCATCACGCGTATTAATTAACTGTTGACAATTAATCATCGGCATAGTATATCGGCATAG

EM7-RBam GCATCGTCGACGTTTAGTTCCTCACCTTGTCGTATTATACTATGCCGATATACTATGCC

EM7-R-Xba GCATCTCTAGAGTTTAGTTCCTCACCTTGTCGTATTATACTATGCCGATATACTATGCC

EM7-R-Apa GCATCGGGCCCGTTTAGTTCCTCACCTTGTCGTATTATACTATGCCGATATACTATGCC

EM7-R-Sal GCATCGTCGACGTTTAGTTCCTCACCTTGTCGTATTATACTATGCCGATATACTATGCC

EM7-R-Kpn GCATCGGATCCGTTTAGTTCCTCACCTTGTCGTATTATACTATGCCGATATACTATGCC

ParaE-F GGTACCTCCATATTTATGCTGTTTCCGACCTGACACCTGCGTGAGTTGTTCACGTA

ParaE-R ACGGCTCTGCCAGCAGAGAGTAAGACATAGTGAAAAAATACGTGAACAAG

Ptet- $F \quad$ GGATCCTAATGCGgTAGTTTATCACAGTTAAATTGCTAA

Ptet-R ACGCGTTGCCTGACTGCGTTAGCAATTTAACTGTGATAA

Pbla $F \quad$ GCATCGTCGACTGAGACAATAACCCTGATAAATGCTTCAAT

Pbla $R \quad$ GCATCACGCGTACTCTTCCTTTTTCAATATTATTGAAGCAT

PlacZ $F \quad$ GCATCCTGCAGCGCGTTGCGTTAATTACACT

PlacZ $R \quad$ GCATCACGCGTTCGACAAAGGACACACTTTA

\section{Klebsiella pneumoniae}

pqq5 $\mathrm{F} \quad$ GCATCGGATCCGTTATATTGTAAACATAAAGTTAA

pqq5 $R \quad$ GCATCGCTGCACCCATTTGCGCCGGGTCT

pqq3 $F \quad$ GCATCGTCGACCGGCAGATAACCCACTGGCTGCAG

pqq3 $R \quad$ GCATCGGATCCTTAATCCCCTGTCGTGAATAGCAC

\section{I-Scel and araC-PBAD}

I-Scel $F$ GCATCAGAATTCATGCATCAAAAAAACCAGGTA

I-Scel $R$ GCATCCTGCAGACTGCAGTTATTTCAGGAAAGT

araC- $F \quad$ GCATCATCGATTTATGACAACTTGACGGCTACATC

Pbad-R GCATCAATCGATTAGGGATAACAGGGTAATAGAGTTTGTAGAAACGCAAAAAGG

\section{Antibiotic Markers}

AMP $F \quad$ GCATCACGCGTCCAATGCTTAATCAGTGAGGCACC

AMP $R \quad$ GCATCGGTACCATGAGTATTCAACATTTCCGTGT 
KAN $F$ GCATCACGCGTATGAGCCATATTCAACGGGAAACG

KAN $R$ GCATCGGTACCTTAGAAAAACTCATCGAGCATCGA 
Appendix D: Recombination and Transformation Efficiencies.

\section{Table 5. Transformation and Recombination Efficiencies under varying Transformation Conditions.}

$\begin{array}{ll}\text { Target: } & \text { galK } \\ \text { Insert: } & \text { beta-lactamase }\end{array}$

\begin{tabular}{|c|c|c|c|c|c|c|c|c|c|c|c|c|c|}
\hline & \multicolumn{13}{|c|}{ Condition } \\
\hline \multirow{4}{*}{ BL21(DE3)pLysS } & \multirow{4}{*}{$\begin{array}{l}\text { Transf. } \\
\text { Rec. }\end{array}$} & \multicolumn{2}{|c|}{1} & \multicolumn{2}{|c|}{2} & \multicolumn{2}{|c|}{3} & \multicolumn{2}{|c|}{4} & \multicolumn{2}{|c|}{5} & \multicolumn{2}{|c|}{6} \\
\hline & & RecET & Reda $\beta$ & RecET & Reda $\beta$ & RecET & Reda $\beta$ & RecET & Reda $\beta$ & RecET & $\operatorname{Reda} \beta$ & RecET & Reda $\beta$ \\
\hline & & 4.86 & 6.58 & 6.25 & 6.76 & 2.67 & 3.10 & 7.01 & 3.78 & 0.53 & 0.70 & 6.61 & 4.19 \\
\hline & & 100 & 100 & 70 & 90 & 100 & 100 & 40 & 50 & 80 & 100 & 10 & 10 \\
\hline \multirow[t]{2}{*}{ JM109(DE3) } & \multirow{2}{*}{$\begin{array}{l}\text { Transf. } \\
\text { Rec. }\end{array}$} & 6.49 & 8.65 & 7.97 & 6.99 & 2.27 & 2.92 & 6.52 & 4.67 & 0.47 & 0.87 & 6.68 & 6.11 \\
\hline & & 100 & 100 & 70 & 80 & 100 & 100 & 40 & 40 & 100 & 90 & 20 & 10 \\
\hline \multirow[t]{2}{*}{ XL1-Blue MRF' } & \multirow{2}{*}{$\begin{array}{l}\text { Transf. } \\
\text { Rec. }\end{array}$} & 9.20 & 9.83 & 8.67 & 9.33 & 1.67 & 2.77 & 7.50 & 7.07 & 0.67 & 1.00 & 6.33 & 6.23 \\
\hline & & 100 & 100 & 70 & 70 & 100 & 100 & 40 & 50 & 90 & 100 & 10 & 20 \\
\hline
\end{tabular}

Transformation efficiency (Transf.) is measured by the number of colony forming units on LB plates containing Ampicillin (x10E7).

Recombination efficiency (Rec.) is measured by PCR detection of the inserted gene(s) on the E. coli genome ((no. of positives / total tested)*100).

1. Pre-transformed with both vectors, then a linear insert cassette.

2. Pre-transformed with both vectors containing an integrated insert cassette.

3. Pre-transformed with pBS-derived, then pACYC-derived vector (linear insertion cassette).

4. Pre-transformed with $\mathrm{pBS}$-derived vector containing an integrated insertion cassette, then $\mathrm{PACYC}$-derived vector.

5. Pre-transformed with $\mathrm{pACYC}$-derived vector, then $\mathrm{pBS}$-derived plus a linear insert.

6. Pre-transformed with $\mathrm{PACYC}$-derived vector, then $\mathrm{pBS}$-derived plus integrated insert. 


\begin{tabular}{|c|c|c|c|c|c|c|c|c|c|c|c|c|c|c|}
\hline \multirow{7}{*}{ 就 } & \multirow{5}{*}{$\begin{array}{l}\text { Target: } \\
\text { Insert: } \\
\\
\text { BL21(DE3) }\end{array}$} & \multicolumn{13}{|c|}{$\begin{array}{l}\text { gntT } \\
\text { beta-lactamase }\end{array}$} \\
\hline & & \multicolumn{13}{|c|}{ Condition } \\
\hline & & \multicolumn{3}{|c|}{1} & \multicolumn{2}{|c|}{2} & \multicolumn{2}{|c|}{3} & \multicolumn{2}{|c|}{4} & \multicolumn{2}{|c|}{5} & \multicolumn{2}{|c|}{6} \\
\hline & & \multirow{2}{*}{$\begin{array}{l}\text { Transf. } \\
\text { Rec. }\end{array}$} & RecET & Reda $\beta$ & RecET & Reda $\beta$ & RecET & Reda $\beta$ & RecET & Reda $\beta$ & RecET & Reda $\beta$ & RecET & Reda $\beta$ \\
\hline & & & 90 & 100 & 70 & 80 & 100 & 100 & 50 & 60 & 100 & 100 & 10 & 10 \\
\hline & \multirow{2}{*}{ JM109(DE3) } & \multirow{2}{*}{$\begin{array}{l}\text { Transf. } \\
\text { Rec. }\end{array}$} & 4.10 & 6.53 & 7.24 & 6.23 & 1.73 & 2.63 & 6.61 & 6.39 & 0.17 & 0.73 & 5.94 & 6.57 \\
\hline & & & 100 & 100 & 70 & 70 & 100 & 100 & 50 & 40 & 100 & 100 & 0 & 10 \\
\hline & Transformation effi & y (Trans & ) is mea & red by $t$ & he numbe & r of col & formir & units 0 & LB plate & s conta & g Amp & illin $(x 10$ & E7). & \\
\hline & $\begin{array}{l}\text { Recombination effic } \\
* 100) \text {. }\end{array}$ & (Rec.) & measu & by $\mathrm{PC}$ & $\mathrm{R}$ detectic & of the & serted & ne(s) & the $E . c$ & oligenc & ((no. & positiv & total $\mathrm{t}$ & sted) \\
\hline
\end{tabular}

1. Pre-transformed with both vectors, then a linear insert cassette.

2. Pre-transformed with both vectors containing an integrated insert cassette.

3. Pre-transformed with pBS-derived, then PACYC-derived vector (linear insertion cassette).

4. Pre-transformed with $\mathrm{pBS}$-derived vector containing an integrated insertion cassette, then $\mathrm{pACYC}$-derived vector.

5. Pre-transformed with $\mathrm{pACYC}$-derived vector, then $\mathrm{pBS}$-derived plus a linear insert.

6. Pre-transformed with $\mathrm{pACYC}$-derived vector, then $\mathrm{pBS}$-derived plus integrated insert. 


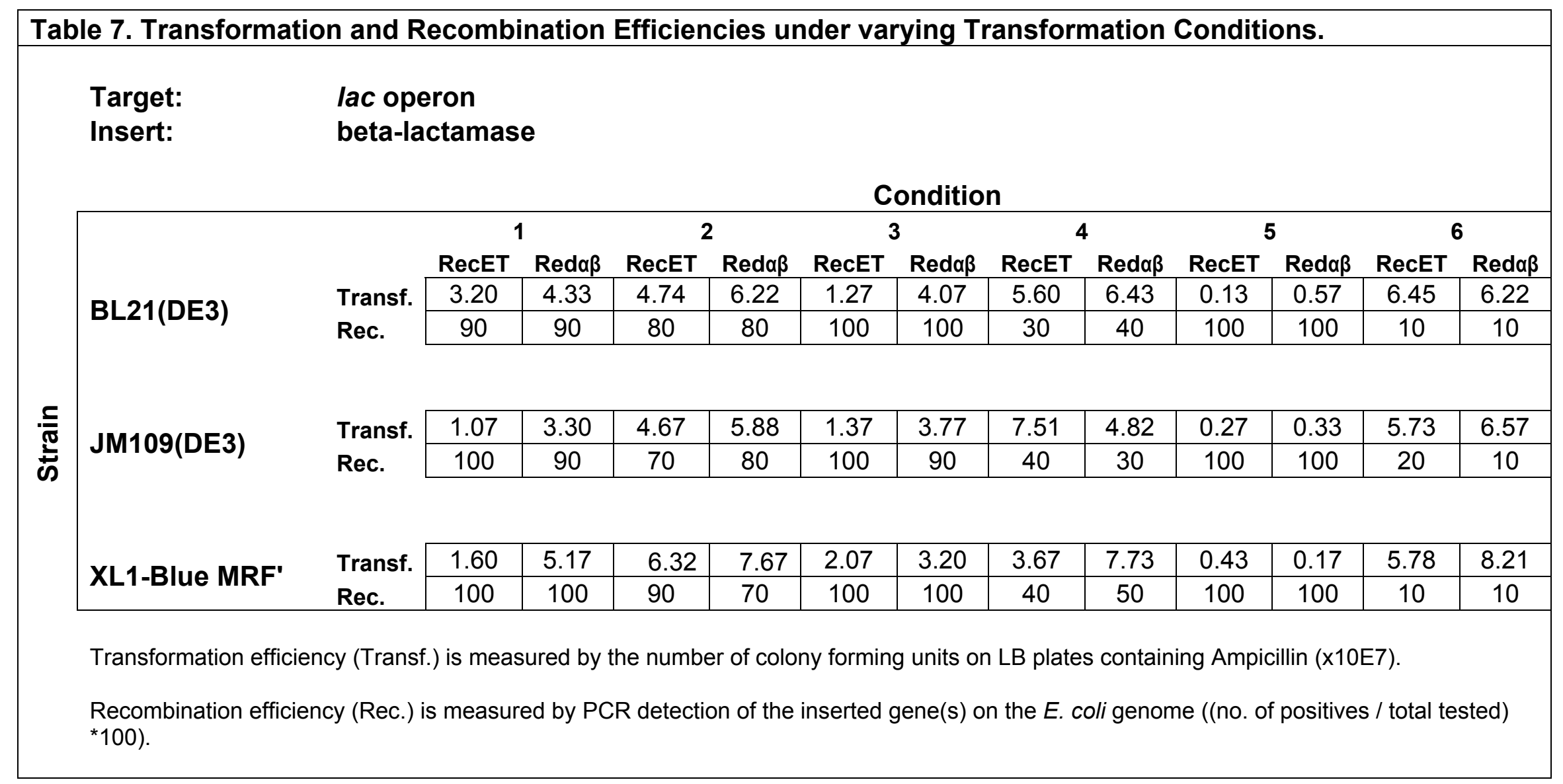

1. Pre-transformed with both vectors, then a linear insert cassette.

2. Pre-transformed with both vectors containing an integrated insert cassette.

3. Pre-transformed with pBS-derived, then PACYC-derived vector (linear insertion cassette).

4. Pre-transformed with $\mathrm{pBS}$-derived vector containing an integrated insertion cassette, then pACYC-derived vector.

5. Pre-transformed with $\mathrm{pACYC}$-derived vector, then $\mathrm{pBS}$-derived plus a linear insert.

6. Pre-transformed with $\mathrm{PACYC}$-derived vector, then $\mathrm{pBS}$-derived plus integrated insert. 


\begin{tabular}{|c|c|c|c|c|c|c|c|c|c|c|c|c|c|c|}
\hline \multirow{9}{*}{ 离 } & \multirow{3}{*}{$\begin{array}{l}\text { Target: } \\
\text { Insert: }\end{array}$} & \multicolumn{13}{|c|}{ Condition } \\
\hline & & & \multicolumn{2}{|c|}{1} & \multicolumn{2}{|c|}{2} & \multicolumn{2}{|c|}{3} & \multicolumn{2}{|c|}{4} & \multicolumn{2}{|c|}{5} & \multicolumn{2}{|c|}{6} \\
\hline & & & RecET & $\begin{array}{c}\text { Reda } \beta \\
4.10\end{array}$ & \multirow{2}{*}{\begin{tabular}{|c|} 
RecET \\
5.07 \\
70 \\
\end{tabular}} & \multirow{2}{*}{\begin{tabular}{c|} 
Reda $\beta$ \\
5.47 \\
70
\end{tabular}} & \multirow{2}{*}{$\begin{array}{c}\text { RecET } \\
3.20 \\
90\end{array}$} & \multirow{2}{*}{$\begin{array}{c}\text { Reda } \beta \\
3.77 \\
100\end{array}$} & \multirow{2}{*}{\begin{tabular}{|c|} 
RecET \\
5.87 \\
70 \\
\end{tabular}} & \multirow{2}{*}{$\begin{array}{c}\text { Reda } \beta \\
5.20 \\
50\end{array}$} & \multirow{2}{*}{\begin{tabular}{|c|} 
RecET \\
0.17 \\
100 \\
\end{tabular}} & $\begin{array}{c}\text { Reda } \beta \\
0.37 \\
\end{array}$ & \multirow{2}{*}{\begin{tabular}{|c|} 
RecET \\
6.57 \\
0
\end{tabular}} & Reda $\beta$ \\
\hline & BL21(DE3) & $\begin{array}{l}\text { Transf. } \\
\text { Rec. }\end{array}$ & 100 & 100 & & & & & & & & 100 & & 20 \\
\hline & \multirow{2}{*}{ JM109(DE3) } & \multirow{2}{*}{$\begin{array}{l}\text { Transf. } \\
\text { Rec. }\end{array}$} & 3.07 & 5.85 & 5.15 & 5.61 & 5.07 & 3.99 & 5.97 & 6.47 & 0.57 & 0.43 & 4.97 & 7.00 \\
\hline & & & 100 & 100 & 60 & 90 & 100 & 100 & 50 & 70 & 100 & 100 & 10 & 30 \\
\hline & | YI1Rlu MDE' & Transf. & 1.67 & 3.47 & 6.63 & 5.23 & 2.67 & 3.07 & 5.70 & 4.97 & 0.20 & 0.33 & 7.81 & 5.30 \\
\hline & XL1-Blue MRF' & Rec. & 100 & 100 & 50 & 60 & 100 & 100 & 70 & 60 & 100 & 100 & 10 & 30 \\
\hline & $\begin{array}{l}\text { Transformation effici } \\
\text { Recombination effici } \\
\left.{ }^{*} 100\right) \text {. }\end{array}$ & $\begin{array}{l}\text { cy (Trans } \\
\text { cy (Rec.) }\end{array}$ & ) is meas & $\begin{array}{l}\text { ured by } t \\
\text { d by PC }\end{array}$ & $\begin{array}{l}\text { ne numbe } \\
\text { R detectic }\end{array}$ & rof colo & nserted & ene(s) ol & the E.c & ligeno & $\mathrm{e}(($ no. $)$ & positives & $\operatorname{cin}(x 10 E$ & ed) \\
\hline
\end{tabular}

1. Pre-transformed with both vectors, then a linear insert cassette.

2. Pre-transformed with both vectors containing an integrated insert cassette.

3. Pre-transformed with pBS-derived, then pACYC-derived vector (linear insertion cassette).

4. Pre-transformed with $\mathrm{pBS}$-derived vector containing an integrated insertion cassette, then $\mathrm{pACYC}$-derived vector.

5. Pre-transformed with $\mathrm{pACYC}$-derived vector, then $\mathrm{pBS}$-derived plus a linear insert.

6. Pre-transformed with $\mathrm{pACYC}$-derived vector, then $\mathrm{pBS}$-derived plus integrated insert. 


\begin{tabular}{|c|c|c|c|c|c|c|c|c|c|c|c|c|c|c|}
\hline \multirow{9}{*}{$\frac{.}{\frac{5}{0}}$} & \multirow{5}{*}{$\begin{array}{l}\text { Target: } \\
\text { Insert: } \\
\text { BL21(DE3) }\end{array}$} & \multicolumn{13}{|c|}{$\begin{array}{l}\text { gntT } \\
\text { Kanamycin }\end{array}$} \\
\hline & & \multicolumn{13}{|c|}{ Condition } \\
\hline & & & \multicolumn{2}{|c|}{1} & \multicolumn{2}{|c|}{2} & \multicolumn{2}{|c|}{3} & \multicolumn{2}{|c|}{4} & \multicolumn{2}{|c|}{5} & \multicolumn{2}{|c|}{6} \\
\hline & & \multirow{2}{*}{$\begin{array}{l}\text { Transf. } \\
\text { Rec. }\end{array}$} & RecET & $\begin{array}{c}\text { Reda } \beta \\
3.20 \\
\end{array}$ & \multirow{2}{*}{\begin{tabular}{|c|} 
RecET \\
1.80 \\
90 \\
\end{tabular}} & \multirow{2}{*}{$\begin{array}{c}\frac{\text { Reda } \beta}{2.03} \\
80\end{array}$} & \multirow{2}{*}{$\begin{array}{c}\text { RecET } \\
2.70 \\
100\end{array}$} & \multirow{2}{*}{\begin{tabular}{|c|} 
Reda $\beta$ \\
3.33 \\
100 \\
\end{tabular}} & \multirow{2}{*}{\begin{tabular}{|c|} 
RecET \\
4.93 \\
50 \\
\end{tabular}} & \multirow{2}{*}{$\begin{array}{c}\text { Reda } \beta \\
4.30 \\
70\end{array}$} & \multirow{2}{*}{$\begin{array}{c}\text { RecET } \\
0.13 \\
100 \\
\end{array}$} & $\begin{array}{c}\text { Reda } \beta \\
0.33 \\
\end{array}$ & \multirow{2}{*}{$\begin{array}{c}\text { RecET } \\
5.37 \\
0\end{array}$} & $\begin{array}{c}\text { Reda } \beta \\
5.37 \\
\end{array}$ \\
\hline & & & 100 & 100 & & & & & & & & 90 & & 10 \\
\hline & \multirow{2}{*}{ JM109(DE3) } & \multirow{2}{*}{$\begin{array}{l}\text { Transf. } \\
\text { Rec. }\end{array}$} & 4.67 & 5.50 & 3.37 & 4.40 & 3.37 & 4.00 & 5.60 & 6.47 & 0.13 & 0.23 & 6.10 & 4.33 \\
\hline & & & 100 & 90 & 60 & 70 & 100 & 100 & 60 & 30 & 100 & 100 & 0 & 0 \\
\hline & \multirow{2}{*}{ XL1-Blue MRF' } & \multirow{2}{*}{$\begin{array}{l}\text { Transf. } \\
\text { Rec. }\end{array}$} & 3.40 & 3.97 & 1.23 & 1.43 & 1.87 & 2.77 & 6.50 & 4.10 & 0.17 & 0.20 & 6.70 & 4.60 \\
\hline & & & 100 & 100 & 70 & 80 & 100 & 100 & 30 & 60 & 100 & 100 & 10 & 10 \\
\hline & $\begin{array}{l}\text { Transformation effic } \\
\text { Recombination effic } \\
\text { *100). }\end{array}$ & $\begin{array}{l}y \text { (Trans } \\
\text { y (Rec.) }\end{array}$ & ) is meas & d by PC & numbe & of colo & nserted & units on & the $E$. & ey agar & containir & g Kanam & $\operatorname{cin}(x 1)$ & $\begin{array}{l}\text { E). } \\
\text { ted) }\end{array}$ \\
\hline
\end{tabular}

1. Pre-transformed with both vectors, then a linear insert cassette.

2. Pre-transformed with both vectors containing an integrated insert cassette.

3. Pre-transformed with pBS-derived, then pACYC-derived vector (linear insertion cassette).

4. Pre-transformed with $\mathrm{pBS}$-derived vector containing an integrated insertion cassette, then $\mathrm{pACYC}$-derived vector.

5. Pre-transformed with $\mathrm{pACYC}$-derived vector, then $\mathrm{pBS}$-derived plus a linear insert.

6. Pre-transformed with $\mathrm{pACYC}$-derived vector, then $\mathrm{pBS}$-derived plus integrated insert. 


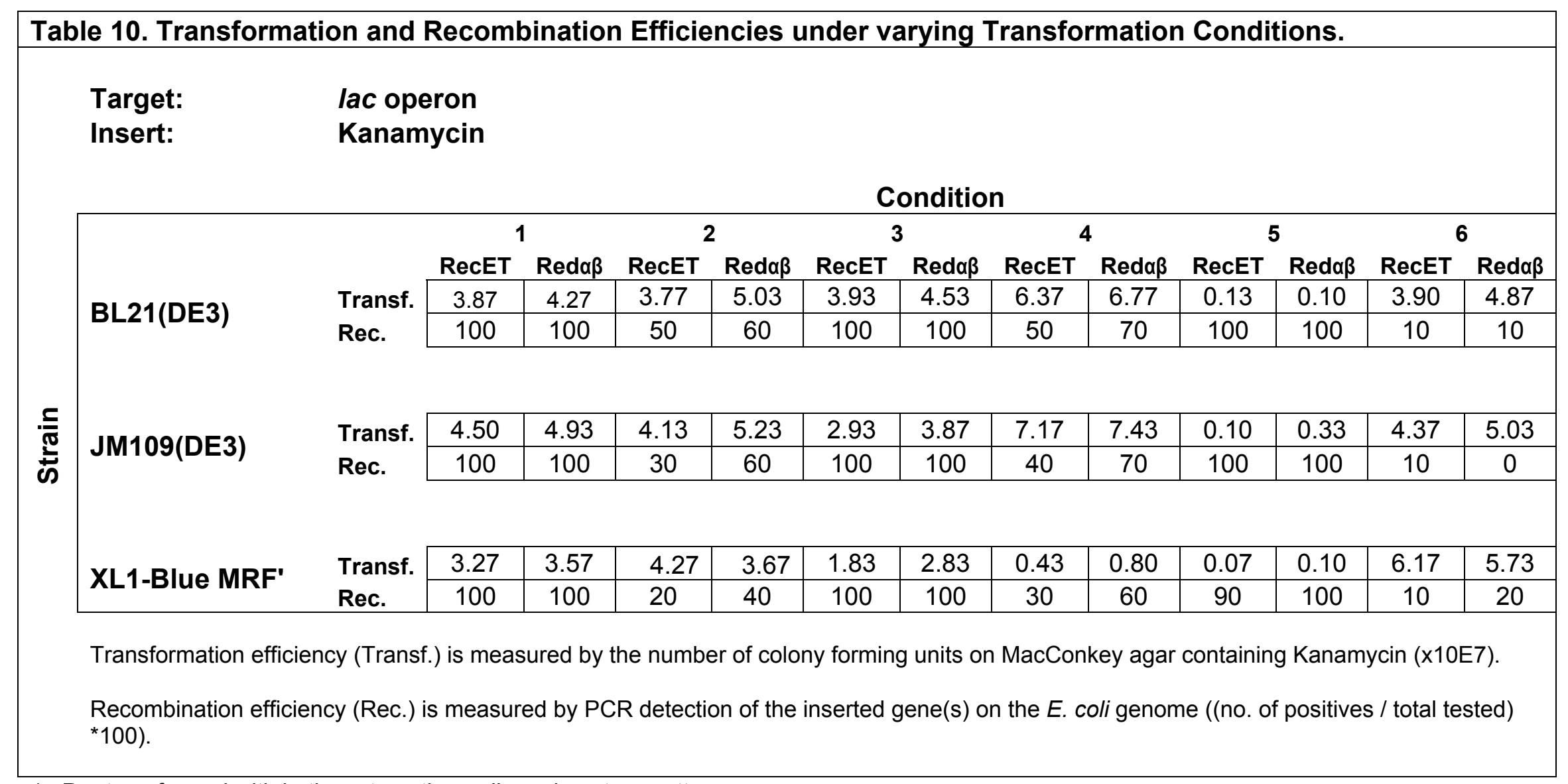

1. Pre-transformed with both vectors, then a linear insert cassette.

2. Pre-transformed with both vectors containing an integrated insert cassette.

3. Pre-transformed with $\mathrm{pBS}$-derived, then $\mathrm{PACYC}$-derived vector (linear insertion cassette).

4. Pre-transformed with $\mathrm{pBS}$-derived vector containing an integrated insertion cassette, then pACYC-derived vector.

5. Pre-transformed with $\mathrm{pACYC}$-derived vector, then $\mathrm{pBS}$-derived plus a linear insert.

6. Pre-transformed with $\mathrm{pACYC}$-derived vector, then $\mathrm{pBS}$-derived plus integrated insert. 


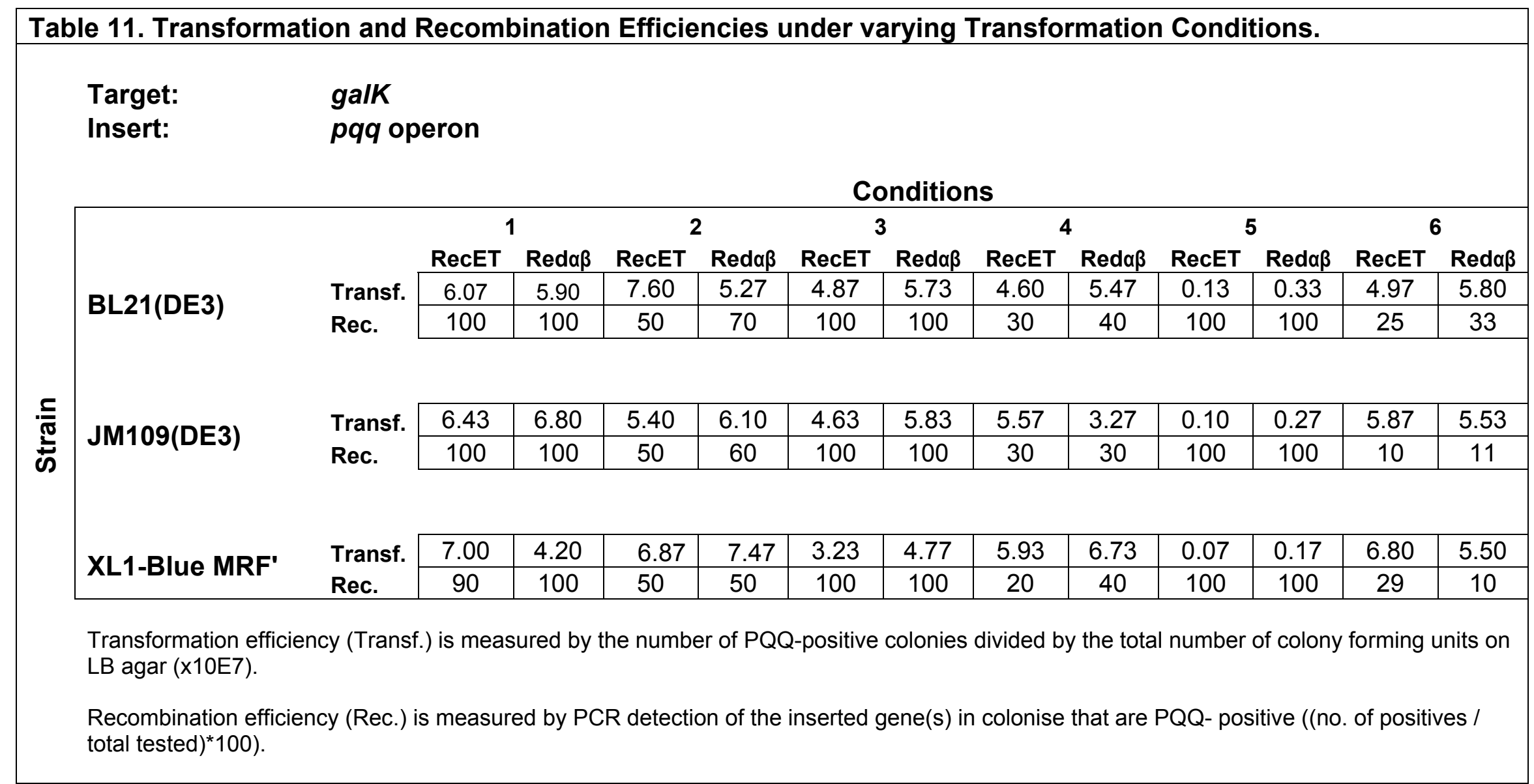

1. Pre-transformed with both vectors, then a linear insert cassette.

2. Pre-transformed with both vectors containing an integrated insert cassette.

3. Pre-transformed with pBS-derived, then pACYC-derived vector (linear insertion cassette).

4. Pre-transformed with $\mathrm{pBS}$-derived vector containing an integrated insertion cassette, then $\mathrm{pACYC}$-derived vector.

5. Pre-transformed with $p A C Y C$-derived vector, then $p B S$-derived plus a linear insert.

6. Pre-transformed with $\mathrm{pACYC}$-derived vector, then $\mathrm{pBS}$-derived plus integrated insert. 


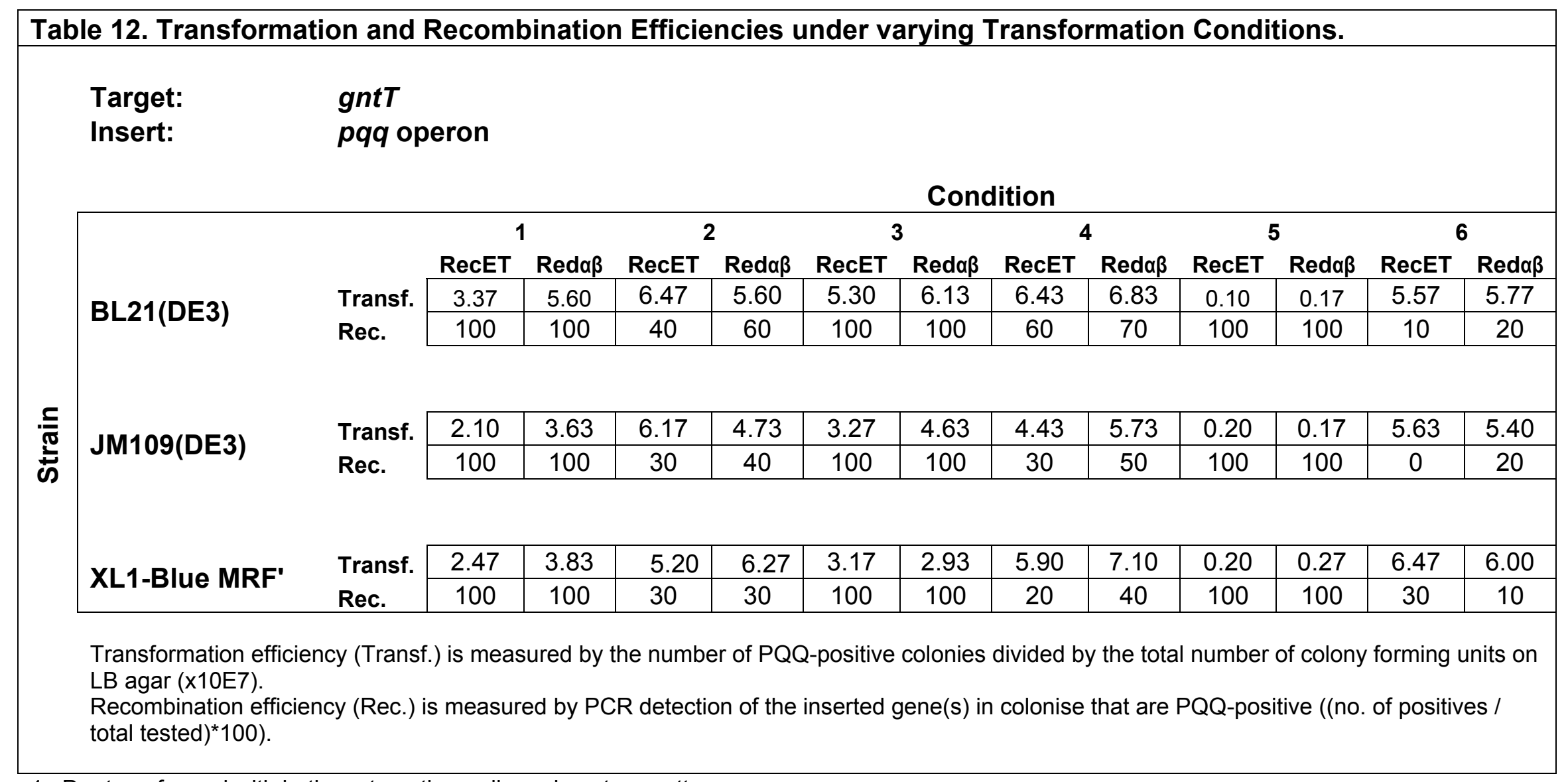

1. Pre-transformed with both vectors, then a linear insert cassette.

2. Pre-transformed with both vectors containing an integrated insert cassette.

3. Pre-transformed with pBS-derived, then pACYC-derived vector (linear insertion cassette).

4. Pre-transformed with $\mathrm{pBS}$-derived vector containing an integrated insertion cassette, then $\mathrm{pACYC}$-derived vector.

5. Pre-transformed with $\mathrm{pACYC}$-derived vector, then $\mathrm{pBS}$-derived plus a linear insert.

6. Pre-transformed with $\mathrm{pACYC}$-derived vector, then $\mathrm{pBS}$-derived plus integrated insert. 


\begin{tabular}{|c|c|c|c|c|c|c|c|c|c|c|c|c|c|c|}
\hline \multirow{10}{*}{ 竞 } & \multirow{5}{*}{$\begin{array}{l}\text { Target: } \\
\text { Insert: } \\
\\
\text { BL21(DE3) }\end{array}$} & \multicolumn{13}{|c|}{$\begin{array}{l}\text { lac operon } \\
\text { pqq operon }\end{array}$} \\
\hline & & & \multicolumn{2}{|c|}{1} & \multicolumn{2}{|c|}{2} & \multicolumn{2}{|c|}{3} & \multicolumn{2}{|c|}{4} & \multicolumn{2}{|c|}{5} & \multicolumn{2}{|c|}{6} \\
\hline & & & RecET & Reda $\beta$ & RecET & Reda $\beta$ & RecET & Reda $\beta$ & RecET & Reda $\beta$ & RecET & Reda $\beta$ & RecET & Reda $\beta$ \\
\hline & & Transf. & 4.23 & 6.70 & 7.17 & 5.23 & 1.27 & 1.67 & 5.30 & 5.53 & 0.47 & 0.60 & 3.37 & 4.60 \\
\hline & & Rec. & 100 & 100 & 30 & 30 & 100 & 100 & 30 & 40 & 100 & 100 & 0 & 10 \\
\hline & \multirow{3}{*}{ JM109(DE3) } & \multirow{2}{*}{$\begin{array}{l}\text { Transf. } \\
\text { Rec. }\end{array}$} & 2.77 & 7.07 & 4.57 & 6.43 & 1.20 & 2.83 & 6.93 & 6.10 & 0.33 & 0.43 & 5.60 & 4.00 \\
\hline & & & 100 & 100 & 40 & 30 & 100 & 100 & 20 & 60 & 100 & 100 & 0 & 30 \\
\hline & & & & & & & & & & & & & & \\
\hline & \multirow{2}{*}{ XL1-Blue MRF' } & \multirow{2}{*}{$\begin{array}{l}\text { Transf. } \\
\text { Rec. }\end{array}$} & 3.20 & 6.07 & 7.20 & 6.80 & 0.97 & 2.77 & 7.43 & 6.80 & 0.20 & 0.23 & 6.00 & 6.87 \\
\hline & & & 100 & 100 & 20 & 20 & 100 & 100 & 30 & 30 & 100 & 100 & 20 & 20 \\
\hline
\end{tabular}

1. Pre-transformed with both vectors, then a linear insert cassette.

2. Pre-transformed with both vectors containing an integrated insert cassette.

3. Pre-transformed with $\mathrm{pBS}$-derived, then $\mathrm{pACYC}$-derived vector (linear insertion cassette).

4. Pre-transformed with $\mathrm{pBS}$-derived vector containing an integrated insertion cassette, then $\mathrm{pACYC}$-derived vector.

5. Pre-transformed with $\mathrm{pACYC}$-derived vector, then $\mathrm{pBS}$-derived plus a linear insert.

6. Pre-transformed with $\mathrm{PACYC}$-derived vector, then $\mathrm{pBS}$-derived plus integrated insert. 


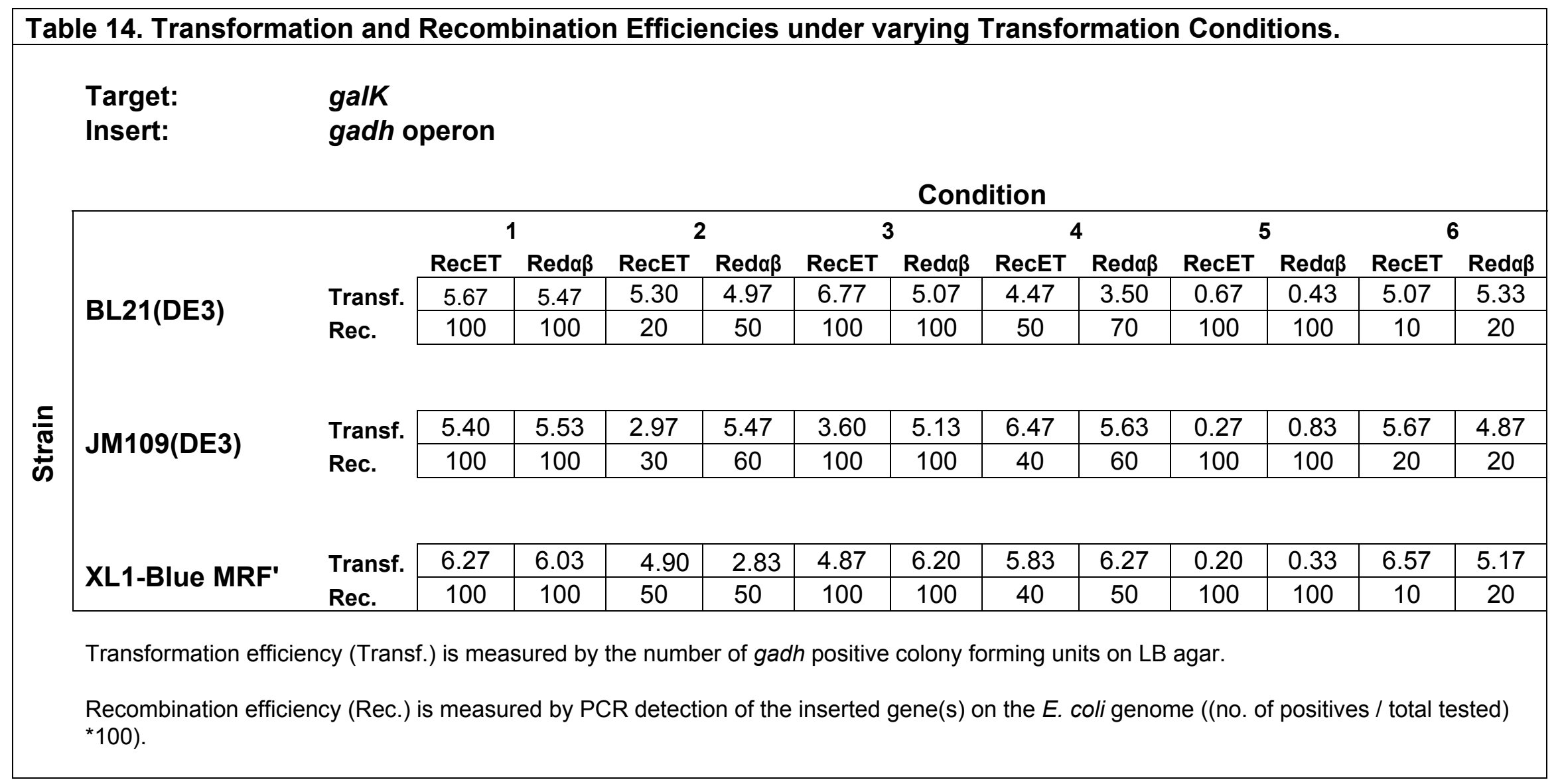

1. Pre-transformed with both vectors, then a linear insert cassette.

2. Pre-transformed with both vectors containing an integrated insert cassette.

3. Pre-transformed with pBS-derived, then PACYC-derived vector (linear insertion cassette).

4. Pre-transformed with $\mathrm{pBS}$-derived vector containing an integrated insertion cassette, then $\mathrm{PACYC}$-derived vector.

5. Pre-transformed with $\mathrm{pACYC}$-derived vector, then $\mathrm{pBS}$-derived plus a linear insert.

6. Pre-transformed with $\mathrm{pACYC}$-derived vector, then pBS-derived plus integrated insert. 


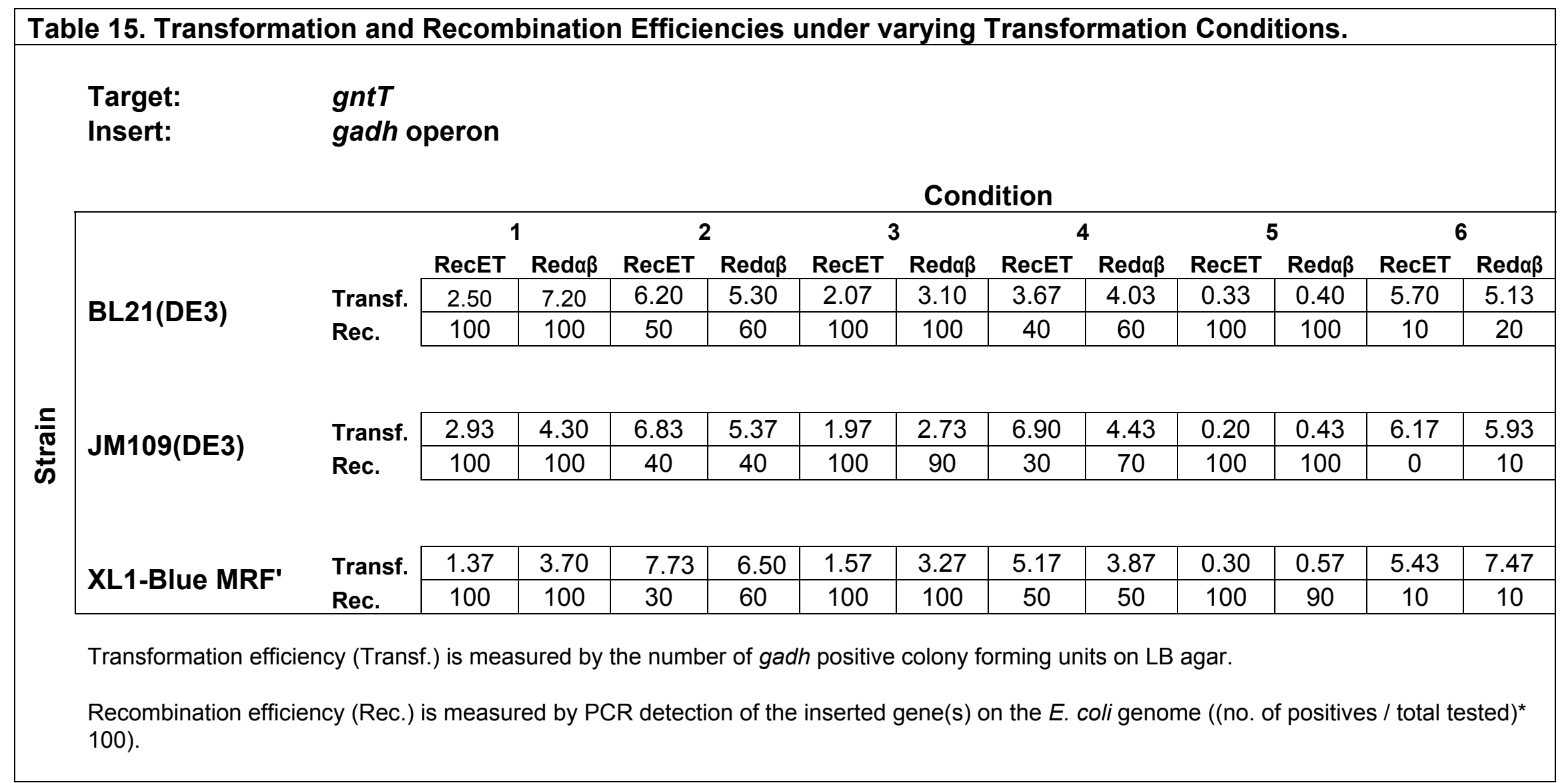

1. Pre-transformed with both vectors, then a linear insert cassette.

2. Pre-transformed with both vectors containing an integrated insert cassette.

3. Pre-transformed with pBS-derived, then PACYC-derived vector (linear insertion cassette).

4. Pre-transformed with $\mathrm{pBS}$-derived vector containing an integrated insertion cassette, then $\mathrm{PACYC}$-derived vector.

5. Pre-transformed with $\mathrm{pACYC}$-derived vector, then $\mathrm{pBS}$-derived plus a linear insert.

6. Pre-transformed with $\mathrm{pACYC}$-derived vector, then pBS-derived plus integrated insert. 


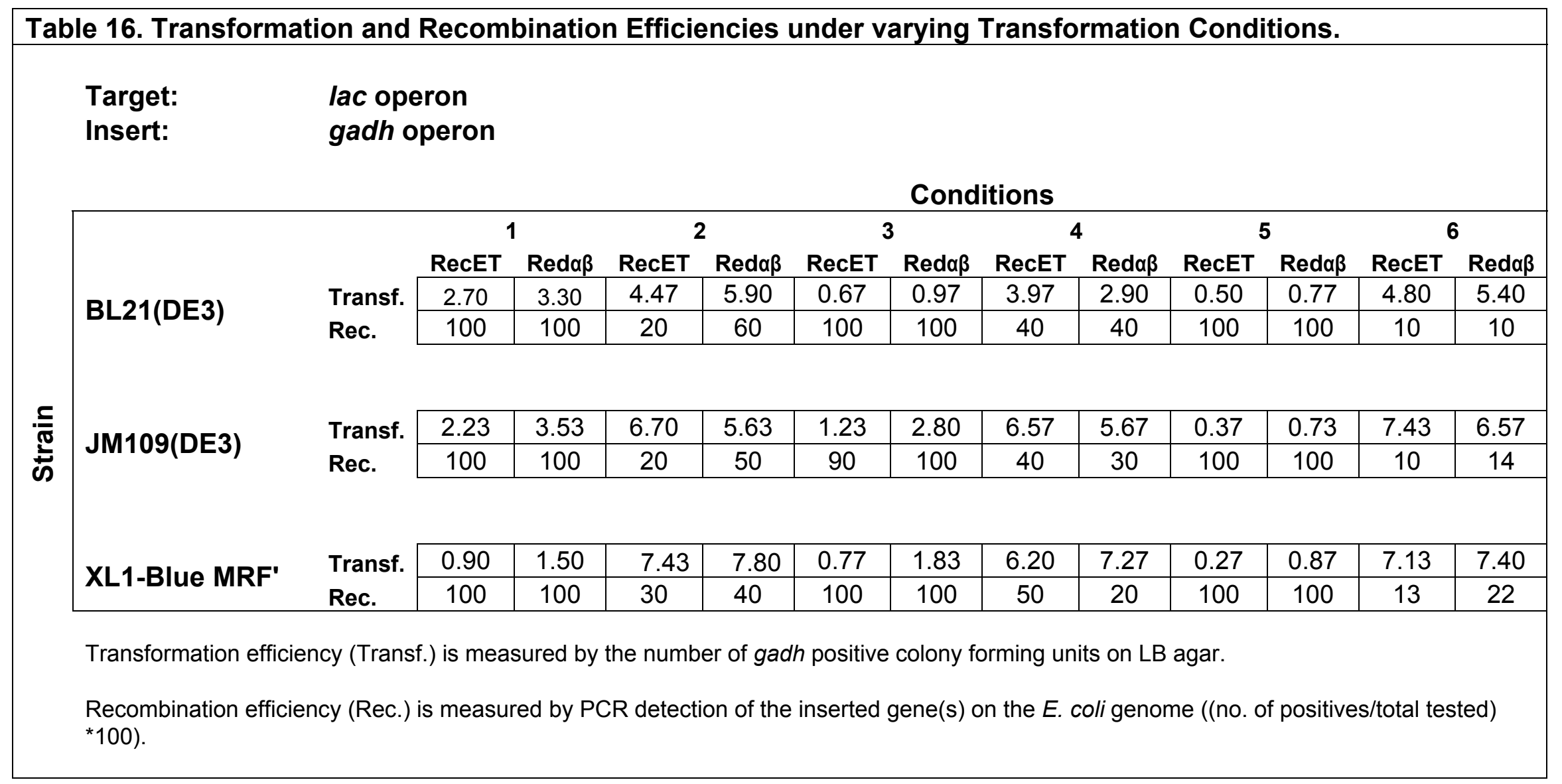

1. Pre-transformed with both vectors, then a linear insert cassette.

2. Pre-transformed with both vectors containing an integrated insert cassette.

3. Pre-transformed with pBS-derived, then PACYC-derived vector (linear insertion cassette).

4. Pre-transformed with $\mathrm{pBS}$-derived vector containing an integrated insertion cassette, then $\mathrm{PACYC}$-derived vector.

5. Pre-transformed with $\mathrm{pACYC}$-derived vector, then $\mathrm{pBS}$-derived plus a linear insert.

6. Pre-transformed with $\mathrm{pACYC}$-derived vector, then pBS-derived plus integrated insert. 


\section{Appendix E: Experimental Protocols.}

\section{A. Plasmid DNA Isolation (1)}

The following protocol was taken from Sigma's GenElute ${ }^{T M}$ Plasmid Miniprep Kit and was one of two methods used in the isolation of plasmid DNA.

1. Transfer $300 \mu \mathrm{l}(1 \mathrm{ml}$ if low-copy) of recombinant $E$. coli to a microfuge tube and pellet cells at $\geq 12,000 \times g$ for 1 minute. Discard the supernatant.

2. Lyse the resuspended cells by adding $200 \mu \mathrm{l}$ of the Lysis Solution. Immediately mix the contents by gentle inversion (6-8 times) until the mixture becomes clear and viscous. Do not allow the lysis reaction to exceed 5 minutes.

3. Precipitate the cell debris by adding $350 \mu \mathrm{l}$ of the Neutralization/Binding Solution. Gently invert the tube 4-6 times. Pellet the cell debris by centrifuging at $\geq 12,000 \times g$ or maximum speed for 10 minutes.

4. Insert a GenElute Miniprep Binding Column (with a blue o-ring) into a provided microfuge tube. Add $500 \mu \mathrm{l}$ of the Column Preparation Solution to each miniprep column and centrifuge at $12,000 \times g$ for 30 seconds to 1 minute. Discard the flow through liquid.

5. Transfer the cleared lysate from step 3 to the column prepared in step 4 and centrifuge at $\geq 12,000 \times g$ for 30 seconds to 1 minute. Discard the flow-through liquid.

6. Add $500 \mu \mathrm{l}$ of the Optional Wash Solution to the column. Centrifuge at $\geq 12,000 \times g$ for 30 seconds to 1 minute. Discard the flow-through liquid.

7. Add $750 \mu \mathrm{l}$ of the diluted Wash Solution to the column. Centrifuge at $\geq 12,000$ 
$\mathrm{x} g$ for 30 seconds to 1 minute. Discard the flow-through liquid and centrifuge again at maximum speed for 1 to 2 minutes without any additional Wash Solution to remove excess ethanol.

8. Transfer the column to a fresh collection tube. Add $75 \mu \mathrm{l}$ of nuclease-free water to the column. Centrifuge at $\geq 12,000 \times g$ for 1 minute. The DNA is now present in the eluate and is ready for immediate use or storage at $-20^{\circ} \mathrm{C}$. 


\section{B. Plasmid DNA Isolation (2)}

The following protocol was taken from Zymo Research's Zyppy Plasmid Miniprep Kit and was one of two methods used in the isolation of plasmid DNA.

1. Pellet $700 \mu \mathrm{l}$ of overnight culture (1.5 $\mathrm{ml}$ if low-copy) in a $1.5 \mathrm{ml}$ microfuge tube by spinning at full speed for $15-20$ seconds.

2. Discard supernatant as much as possible.

3. Add $200 \mu \mathrm{L}$ of buffer P1 and resuspend pellet completely.

4. Add $200 \mu \mathrm{L}$ of buffer $\mathrm{P} 2$ and mix by inverting and swirling the microfuge tube for 4 - 6 times.

5. Add $400 \mu \mathrm{L}$ of buffer P3 and mix thoroughly, but gently. Do not hard vortex.

6. Spin for 3 minutes.

7. Load the supernatant to the Zymo-spin III column.

8. Spin the Zymo-spin column with the collection tube for 30 seconds.

9. Discard the flow-through in the collection tube.

10. Add $600 \mu \mathrm{L}$ of Wash Buffer onto the column with the collection tube and spin for 30 seconds.

11. Add $40 \mu \mathrm{L}$ of nuclease-free water to the column and place the column onto a $1.5 \mathrm{ml}$ microfuge tube, spin for $10-15$ seconds to elute the plasmid. 


\section{Isolation of Genomic DNA}

The following protocol was adapted from Sigma's GenElute ${ }^{T M}$ Bacterial Genomic DNA Kit which was used to isolate all genomic DNA.

1. Pellet $750 \mu \mathrm{l}$ of an overnight bacterial broth culture by centrifuging for 2 minutes at $12,000-16,000 \times g$. Remove the culture medium completely and discard.

2. Resuspend the pellet thoroughly in $180 \mu \mathrm{l}$ of Lysis Solution T.

3. Add $20 \mu \mathrm{l}$ of the Proteinase $\mathrm{K}$ solution to the sample. Mix and incubate for 60 minutes at $55^{\circ} \mathrm{C}$.

4. Add $200 \mu \mathrm{l}$ of Lysis Solution C, vortex thoroughly (about 15 seconds), and incubate at $55^{\circ} \mathrm{C}$ for 30 minutes.

5. Add $500 \mu \mathrm{l}$ of the Column Preparation Solution to each pre-assembled GenElute Miniprep Binding Column seated in a $2 \mathrm{ml}$ collection tube. Centrifuge at $12,000 \times g$ for 1 minute. Discard the flow-through liquid.

6. Add $200 \mu \mathrm{l}$ of ethanol (95-100\%) to the lysate and mix thoroughly by vortexing for $5-10$ seconds. A homogeneous mixture is essential.

7. Transfer the entire contents of the tube into the binding column. Use a wide bore pipette tip to reduce shearing the DNA when transferring the contents into the column. Centrifuge at $\geq 6500 \times g$ for 1 minute. Discard the collection tube containing the flow-through liquid and place the column in a new $2 \mathrm{ml}$ collection tube.

8. Add $500 \mu \mathrm{l}$ of Wash Solution $\mathrm{O}$ to the column and centrifuge for 1 minute at $\geq 6,500 \times \mathrm{g}$. Discard the collection tube containing the flow-through liquid and 
place the column in a new $2 \mathrm{ml}$ collection tube.

9. Prior to first use, prepare the Wash Solution by diluting the Wash Solution Concentrate with ethanol as described under Preparation Instructions. Add $500 \mu \mathrm{l}$ of Wash Solution to the column and centrifuge for 3 minutes at maximum speed $(12,000-16,000 \times g)$ to dry the column. The column must be free of ethanol before eluting the DNA. Centrifuge the column for an additional 1 minute at maximum speed if residual ethanol is seen. Finally, discard the collection tube containing the flow-through liquid and place the column in a new $2 \mathrm{ml}$ collection tube.

10. Pipette $200 \mu \mathrm{l}$ of the nuclease-free directly onto the center of the column; centrifuge for 1 minute at $\geq 6,500 \times g$ to elute the DNA. To increase the elution efficiency, incubate for 5 minutes at room temperature after adding the nuclease-free water, then centrifuge. Repeat with an additional $200 \mu \mathrm{l}$ of nuclease-free water. 


\section{DNA clean up from enzymatic reactions}

Enzymatically-manipulated DNA was cleaned using the DNA Clean and Concentrator Kit from Zymo Research.

1. Add 2 volumes of DNA Binding Buffer to each volume of DNA sample.

2. Load sample into a Mini-Spin Column and place column into a $2 \mathrm{ml}$ collection tube.

3. Centrifuge at $\geq 10,000 \mathrm{~g}$ for $5-10$ seconds. Discard the flow-through.

4. Add $200 \mu \mathrm{l}$ of Wash Buffer to the column. Spin at $\geq 10,000 \mathrm{~g}$ for $5-10$ seconds. Add an additional $200 \mu \mathrm{l}$ of Wash Buffer. Spin at $\geq 10,000 \mathrm{~g}$ for 30 seconds.

5. Add $35 \mu \mathrm{l}$ of nuclease-free water directly to the column matrix. Place column into a $1.5 \mathrm{ml}$ tube. Spin 60 seconds at $\geq 10,000 \mathrm{~g}$ to elute DNA. 


\section{E. DNA Extraction from agarose}

All DNA fragments were isolated using Zymoclean Gel DNA Recovery Kit from Zymo research.

1. Excise the DNA fragment from the agarose gel with a razor blade and transfer to a $1.5 \mathrm{ml}$ tube.

2. Add 3 volumes of Agarose Dissolving Buffer to each volume of agarose gel.

3. Incubate at $55^{\circ} \mathrm{C}$ for $5-10$ minutes to dissolve gel completely.

4. Load the melted agarose solution into a Zymo-Spin Column and place column into a $2 \mathrm{ml}$ collection tube.

5. Centrifuge at $\geq 10,000 \mathrm{~g}$ for $5-10$ seconds. Discard the flow-through.

6. Add $200 \mu \mathrm{l}$ of Wash Buffer to the column. Spin at $\geq 10,000 \mathrm{~g}$ for $5-10$ seconds. Add another $200 \mu \mathrm{l}$ of Wash Buffer. Spin at $\geq 10,000 \mathrm{~g}$ for 30 seconds.

7. Add $6-8 \mu \mathrm{l}$ of nuclease-free water directly to the column matrix. Place column into a $1.5 \mathrm{ml}$ tube. Spin 60 seconds at $\geq 10,000 \mathrm{~g}$ to elute DNA. 


\section{F. Isolating the GADH operon from Pseudomonas aeruginosa}

1. Partially Kpn I digest to PAO1 genomic DNA. Use the serial dilution method and incubate at $37^{\circ} \mathrm{C}$ for 15 minutes.

2. Separate the Kpn I fragments on a $1 \%$ TAE-agarose gel, 2 hours at 65 volts.

3. Isolate the 5 to 6 kilobase fragments.

4. Ligate the PAO1 fragments to Kpn I, SAP-treated pBluescript.

5. Transform E. coli (XL1-Blue MRF', DH5a or TOP 10F'). Plate on LB or SOB plates that contain $100 \mu \mathrm{g} / \mathrm{ml}$ ampicillin and $50 \mathrm{mM}$ sodium gluconate.

6. Screen by soaking filter paper with the gluconate dehydrogenase assay solution and placing the filter over the colonies. Transfer colonies that undergo an immediate color change to $3 \mathrm{ml}$ SOB media containing $100 \mu \mathrm{g} / \mathrm{ml}$ ampicillin and $50 \mathrm{mM}$ sodium gluconate. Incubate at $37^{\circ} \mathrm{C}$ overnight with shaking at $\sim 250 \mathrm{rpm}$.

7. Pellet cells and resuspend in $50 \mathrm{mM}$ Tris- $\mathrm{HCl}, \mathrm{pH} 7.5$ containing $250 \mathrm{mM}$ sodium gluconate. Centrifuge the tubes at $7500 \times \mathrm{g}$ for 5 minutes at room temperature.

8. Decant and resuspend in $3 \mathrm{ml}$ of the same buffer and repeat the centrifugation. Decant and resuspend in $3 \mathrm{ml} 50 \mathrm{mM}$ Tris- $\mathrm{HCl}, \mathrm{pH} 7.5$ containing $250 \mathrm{mM}$ sodium gluconate.

9. To the resuspended cells add $100 \mu \mathrm{l}$ of DCIP and $50 \mu \mathrm{l}$ of PMS. Positive cells will undergo a color change from blue to yellow within 2 minutes. 
10. Transfer $2 \mathrm{ml}$ of the positive cell solutions to $15 \mathrm{ml}$ of liquid media containing $100 \mu \mathrm{g} / \mathrm{ml}$ ampicillin and $50 \mathrm{mM}$ sodium gluconate. Incubate at $37^{\circ} \mathrm{C}$ for 3 hours while shaking at $\sim 250 \mathrm{rpm}$.

11. Isolate plasmids from each positive cell flask, $\mathrm{Kpn} \mathrm{I} \mathrm{digest} \mathrm{and} \mathrm{repeat}$ electrophoresis. Isolate the 4700 base pair band and ligate to Kpn I-digested, SAP-treated pBluescript.

12. Transform E. coli and assay for GADH activity. Isolate the positives and reexamine the plasmids on a $1.0 \%$ gel. Repeat steps $6-12$ until extraneous bands are no longer present. 


\section{G. Isolating the $P Q Q$ operon from Klebsiella pneumoniae}

1. Completely digest K. pneumoniae genomic DNA with Xba I and Kpn I.

2. Separate DNA fragments using 1.0\% TAE-agarose, 2 hours at 65 volts.

3. Excise and extract DNA in the 8-9 kilobase range.

4. Ligate Kpn I/Xba I fragments to Kpn I/Xba I, SAP-treated pBluescript.

5. Transform E. coli (XL1-Blue MRF', DH5a or TOP 10F') and plate on LB + SGal. Incubate overnight at $37^{\circ} \mathrm{C}$.

6. Transfer all white colonies to $2 \mathrm{ml} \mathrm{SOB}$ media containing X-gal and IPTG.

7. Isolate plasmid DNA from all positive tubes and digest with $\mathrm{Kpn} I / X b a I$.

8. Electrophorese using 1.0\% TAE-agarose, 2 hours at 65 volts and excise band(s) corresponding to 8.3 kilobases.

9. Repeat steps 4-8 until all extraneous bands are removed.

10. Xho I-digest the 8.3 kilobase fragment and electrophorese using 1.0\% TAEagarose, 1.25 hours at 65 volts. The presence of 4.0 and 4.3 kilobase bands indicates the presence of the PQQ operon.

11. Transform E. coli JM1109 (pts) with all potential PQQ-containing plasmids and plate on minimal media containing glucose.

12. Any colonies that form will possess the pqq operon.

13. Confirm by electrophoresis. 


\section{H. Induction of the Targeted Recombination Vectors}

Listed by experimental condition (see Tables 2-13).

1. Experimental conditions where a linear targeting cassette is employed.

a. Pre-transform with $\mathrm{pBS}$ and $\mathrm{pACYC}$-derived vectors (Use $r e c E / T$ or exo/bet).

b. Plate on LB-agar $75 \mu \mathrm{g} / \mathrm{ml}$ Ampicillin and $30 \mu \mathrm{g} / \mathrm{ml}$ Chloramphenicol and incubate overnight at $37^{\circ} \mathrm{C}$.

c. Select several colonies and prepare as competent cells.

d. Transform using $0.3 \mu \mathrm{g}$ of linear targeting cassette.

i. Incubate for 60 min in SOB media, plus arabinose.

e. Plate on appropriate agar media.

f. Screen for phenotype.

2. Experimental conditions where an integrated targeting cassette is employed.

a. Pre-transform with $\mathrm{pACYC}$ and $\mathrm{pBS}$-derived vectors (integrated targeting cassette).

i. Incubate for $60 \mathrm{~min}$ in $\mathrm{SOB}$ media, plus arabinose.

b. Plate on appropriate agar media.

c. Screen for phenotype. 


\section{PCR-Detection of inserted DNA Fragments}

All PCR reactions were carried out at $50 \mu \mathrm{l}$ using either Hot Master Mix (Eppendorf) or REDTaq Readymix Plus (Sigma Aldrich) under standard conditions as described by the manufacturer. Conditions were optimized for each target in each $E$. coli strain for each insert. 


\section{J. Gluconate Dehydrogenase Assay}

1. Centrifuge $1 \mathrm{ml}$ of bacteria grown overnight at $37^{\circ} \mathrm{C}$ in complete media containing $20 \mathrm{mM}$ gluconate, $15,000 \mathrm{x} \mathrm{g}$, room temperature, 1 minute.

2. Resuspend in $1 \mathrm{ml}$ Tris- $\mathrm{HCl}, 20 \mathrm{mM}$ gluconate, $\mathrm{pH} 7.6$

3. Repeat centrifuge.

4. Resuspend in $1 \mathrm{ml} \mathrm{Tris-HCl,} \mathrm{pH}$ 7.6.

5. Add assay solution minus substrate (gluconate or glucose) ${ }^{*}$ and transfer to cuvette. Place in UV/Visible spectrometer at wavelength $=600 \mathrm{~nm}$.

6. Add substrate (total volume equal to $3 \mathrm{ml}$ ).

7. Incubate 1 minute.

8. Record reading.

Assay Solution:

$\begin{array}{ll}\text { Component } & \text { Final Volume }\end{array}$

PMS $\quad 0.1 \mathrm{mM}$

Substrate* $^{*} \quad 33.33 \mathrm{mM}$

Bring to a final volume of $3 \mathrm{ml}$ using $20 \mathrm{mM}$ Tris- $\mathrm{HCl}, \mathrm{pH} 7.6$

*Use gluconate for gluconate dehydrogenase and glucose for gluconate dehydrogenase plus pyrroloquinoline quinone. 


\section{K. Preparing Competent E. coli}

Taken from Inoue, H., H. Nojima, and H. Okayama. (1990) High efficiency transformation of Escherichia coli with plasmids. Gene 96:23-28.

1. Inoculate from an overnight grown in LB.

2. Grow in $250 \mathrm{ml} \mathrm{SOB}$ at $18 \mathrm{C}$ until $\mathrm{OD}_{600}=0.6$.

3. On ice for 10 minutes.

4. Spin at $2500 \times \mathrm{g}(5000 \mathrm{rpm}$ in a Sorvall GSA) for $10 \mathrm{~min}$. at $4 \mathrm{C}$.

5. Resuspend cells gently in $80 \mathrm{ml}$ of ice cold TB

6. Incubate on ice for 10 minutes.

7. Spin at $2500 \times \mathrm{g}(5000 \mathrm{rpm}$ in a Sorvall GSA, $5500 \mathrm{rpm}$ in a Sorvall SS-34) for $10 \mathrm{~min}$. at $4 \mathrm{C}$.

8. Resuspend cells gently in $20 \mathrm{ml}$ of ice cold TB.

9. Add DMSO to a final concentration of $7 \%$.

10. Place on ice for 10 minutes.

11. Aliquot into 1-2 $\mathrm{ml}$ and freeze in liquid nitrogen.

12. Store in liquid nitrogen.

Transformation Buffer $=55 \mathrm{mM} \mathrm{MnCl}_{2}, 15 \mathrm{mM} \mathrm{CaCl}_{2}, 250 \mathrm{mM} \mathrm{KCl}$. Adjust $\mathrm{pH}$ to 6.7 with $5 \mathrm{~N} \mathrm{KOH}$ prior to adding the $\mathrm{MnCl}_{2}$. 


\section{Transformation of E. coli}

1. Add $0.3 \mu \mathrm{g}$ of DNA (volume no greater than $20 \mu \mathrm{l}$ ) to $50 \mu \mathrm{l}$ of frozen, competent cells.

2. Incubate on ice for 30 minutes.

3. Heat shock at $42^{\circ} \mathrm{C}$ for the appropriate amount of time for the particular strain of bacteria.

4. Add $200 \mu \mathrm{l}$ of SOB media containing $100 \mu \mathrm{M}$ arabinose and incubate at $37^{\circ} \mathrm{C}$ for 45 minutes.

5. Transfer to agar plate with appropriate antibiotic.

6. Incubate overnight at $37^{\circ} \mathrm{C}$. 